\title{
Outcrop Lithostratigraphy and Petrophysics of the Middle Devonian Marcellus Shale in West Virginia and Adjacent States
}

\author{
Margaret E. Walker-Milani \\ West Virginia University
}

Follow this and additional works at: https://researchrepository.wvu.edu/etd

\footnotetext{
Recommended Citation

Walker-Milani, Margaret E., "Outcrop Lithostratigraphy and Petrophysics of the Middle Devonian Marcellus Shale in West Virginia and Adjacent States" (2011). Graduate Theses, Dissertations, and Problem Reports. 3327.

https://researchrepository.wvu.edu/etd/3327

This Thesis is protected by copyright and/or related rights. It has been brought to you by the The Research Repository @ WVU with permission from the rights-holder(s). You are free to use this Thesis in any way that is permitted by the copyright and related rights legislation that applies to your use. For other uses you must obtain permission from the rights-holder(s) directly, unless additional rights are indicated by a Creative Commons license in the record and/ or on the work itself. This Thesis has been accepted for inclusion in WVU Graduate Theses, Dissertations, and Problem Reports collection by an authorized administrator of The Research Repository @ WVU. For more information, please contact researchrepository@mail.wvu.edu.
} 
Outcrop Lithostratigraphy and Petrophysics of the Middle Devonian Marcellus Shale in West Virginia and Adjacent States

\author{
Margaret E. Walker-Milani
}

\title{
THESIS
}

submitted to the

College of Arts and Sciences

at West Virginia University

in partial fulfillment of the requirements

for the degree of

Master of Science

in Geology

Richard Smosna, Ph.D., Chair

Timothy Carr, Ph.D.

John Renton, Ph.D.

Kathy Bruner, Ph.D.

Department of Geology and Geography

Morgantown, West Virginia

2011 


\begin{abstract}
Outcrop Lithostratigraphy and Petrophysics of the Middle Devonian Marcellus Shale in West Virginia and Adjacent States

Margaret E. Walker-Milani
\end{abstract}

A stratigraphic study of 15 partial outcrops of the Marcellus Shale in West Virginia, Pennsylvania, and Maryland has identified six distinct lithofacies. These include grey calcareous shale (Facies 1), limestone (Facies 2), black calcareous shale (Facies 3), black non-calcareous shale (Facies 4), grey non-calcareous shale (Facies 5) and K-bentonite (Facies 6). Packages of these facies have been organized into six vertically stacked units (A-F). Deposition of the facies resulted from the rise and fall of relative sea level, which in turn shifted the location of the thermocline and affected the amount of terrigenous sediment distributed from the eastern source. Facies 1 and 2 were deposited above the thermocline and just below wave base. Facies 3 and 5 were deposited both above and below the thermocline depending on seasonal mixing and storm events. Facies 4 was deposited under the thermocline in the deepest water ( 60 meters). Facies 1 and 5 accumulated in response to increased sediment influx, whereas Facies 2, 3 and 4 accumulated at times of low sediment supply. A decrease in sediment supply corresponded to a rise in relative sea level that allowed for the storage of terrigenous sediment far landward and the deposition of carbonate and organic-rich sediment on the foreland ramp. The intimate stratigraphic relationship among the shale and limestone facies over time and space indicates a dynamic and complex shallow-water environment for the deposition of the Marcellus Shale, as opposed to the traditional deep-water, sediment starved and statically-anoxic model.

A spectral gamma-ray type log constructed for the Marcellus Shale in outcrop (Units AF) shows a good correlation with the formation in the nearby subsurface. Moreover, the outcrop units can be identified in terms of the subsurface nomenclature: Units A-C correspond to the Union Springs Formation; Unit D, the Cherry Valley Member; and Units E-F, the Oatka Creek Formation. Correlations indicate that the Marcellus becomes increasingly enriched in black shale (Facies 4) westward, resulting in an increased thickness of organic-rich condensed section. On the other hand, limestone and calcareous shale become less abundant westward into the basin due to the reduced sediment supply and greater water depth. 


\section{TABLE OF CONTENTS}

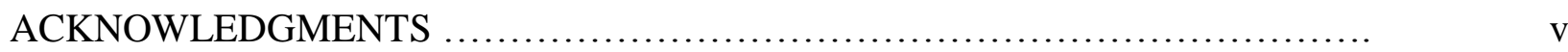

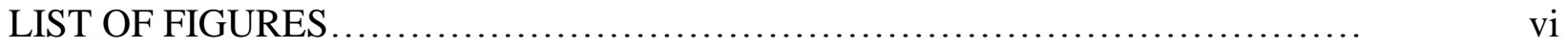

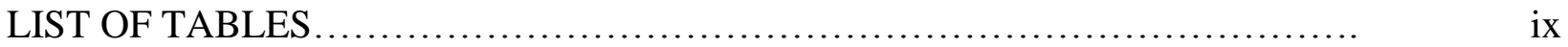

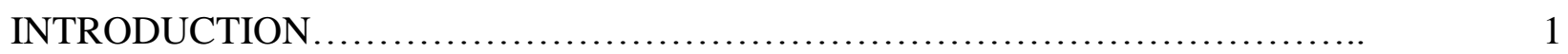

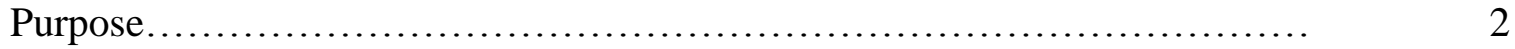

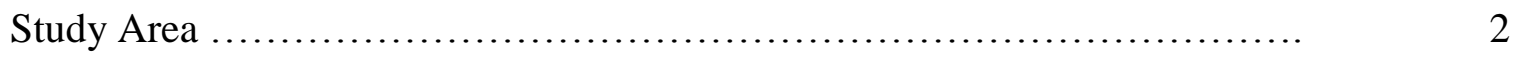

Methods.......................................................... $\quad 5$

GEOLOGIC SETTING ............................................ 10

Regional Overview............................................... $\quad 10$

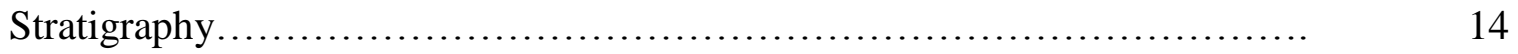

PREVIOUS STUDIES OF BLACK SHALES $\ldots \ldots \ldots \ldots \ldots \ldots \ldots \ldots \ldots \ldots \ldots \ldots \ldots \ldots$

FACIES ANALYSIS .................................................. 21

Facies Descriptions............................................ $\quad 25$

Facies Interpretations........................................... 39

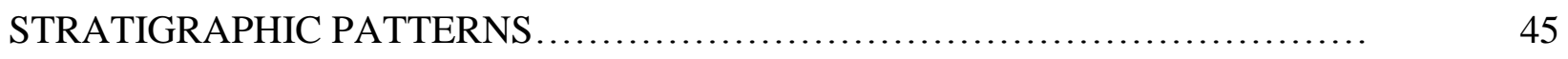

GAMMA-RAY CORRELATIONS ....................................... 64

CONCLUSIONS ......................................................... 74

REFERENCES ....................................................... 77

APPENDIX-OUTCROP DESCRIPTIONS.................................. 83

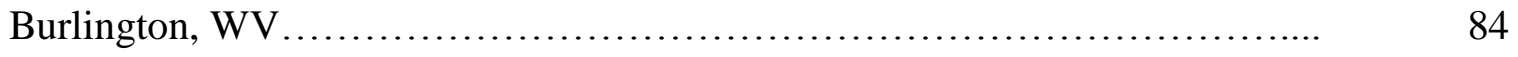

Springfield, WV ............................................... 88

Greenspring, WV ............................................... 90

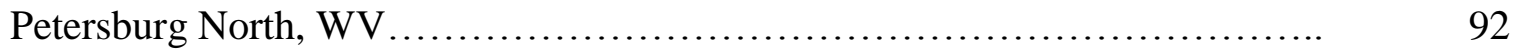


Tyrone, PA...................................................... 95

Whip Gap, WV ............................................... 97

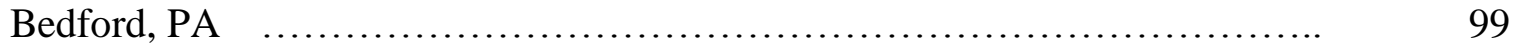

Hiser, WV ........................................................ 102

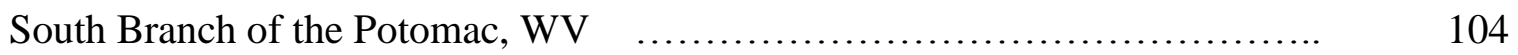

Oak Flat, WV ................................................... 106

Berkeley Springs, WV ......................................... 109

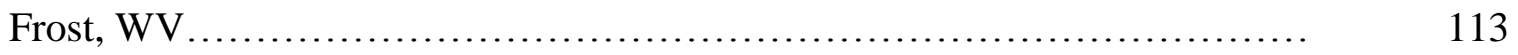

McCoole, MD ..................................................... 116

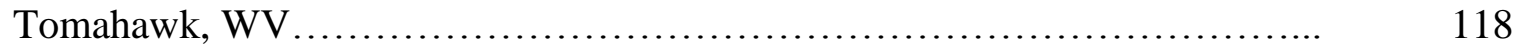

Petersburg West, WV .............................................. $\quad 120$ 


\section{ACKNOWLEDGMENTS}

First and foremost, I would like to express my gratitude to my advisor, Dr. Richard Smosna for his superior guidance, dedication and enthusiasm. Thank you for your humor and constructive criticism, as well as your faith in me to tackle this awesome project. I would also like to thank my committee members Dr. Tim Carr, Dr. Kathy Bruner, and Dr. John Renton for their contributions to this project.

This project would not have been possible without funding from the URS Corporation and the Department of Energy, as well as additional funds provided by Enerplus Corporation through Dr. Carr and Gus Gustason. X-ray diffraction and thermogravimetric analyses were performed by Dr. Mohindar Seehrah, Vivek Singh, and Mohita Yalamanchi. Subsurface well log data was provided by Marathon Oil Corporation.

Special thanks to Katharine Lee Avary and Dr. Jaime Toro for their time and helpful advice on this project. I would also like to recognize and thank my amazing friends and fellow graduate students for their support, camaraderie, and entertainment.

I am ever so grateful to my mom and dad for being my biggest cheerleaders; your support and love is paramount.

Last, but certainly not least, I would like to thank my field partner Kyle Littlefield. Thank you for your patience, kindness, and hard work. I could not have done this without you. 


\section{LIST OF FIGURES}

FIGURE

PAGE

1. Map of study area with outcrop and well locations.

2. Stratification and parting scheme used for description of shale lithofacies

3. Descriptive terms for lamina continuity, shape, and geometry

4. Laminae and bed thickness scheme

5. An example of a Sedlog ${ }^{\circledR}$ outcrop stratigraphic column for the Marcellus Shale at Burlington, WV

6. Paleogeography of Old Red Sandstone continent (Laurussia) during Devonian time

7. Middle Devonian paleogeographic reconstruction (385 Ma)

8. Regional facies model for the Acadian clastic wedge in the Appalachian Basin

9. Appalachian Basin regional stratigraphy

10. Marcellus stratigraphy in New York

11. XRD and TGA sample locations at Springfield and Burlington outcrops

12. XRD and TGA sample locations at Whip Gap and Greenspring outcrop

13. XRD and TGA sample location at Petersburg North outcrop

14. Outcrop photographs of Facies 1, grey calcareous shale.

15. Outcrop photographs of Facies 2, limestone. 
16. Outcrop photographs of Facies 3, black calcareous shale.

17. Outcrop photographs of Facies 4, black non-calcareous shale.

18. Outcrop photographs of Facies 5, grey non-calcareous shale.

19. Outcrop photographs of Facies 6, Tioga K-bentonite

20. Generalized Marcellus Shale facies model depicting periods of low clastic sediment influx.

21. Generalized Marcellus Shale facies model depicting periods of increased clastic sediment influx.

22. TGA total organic carbon analysis plotted against clay content from XRD analysis.....

23. Graph illustrating the average quartz percentage for Facies 1, 3, 4 and 5 ....

24. Composite stratigraphic column and type log for Marcellus Shale in West Virginia.....

25. Burlington, WV stratigraphic column and spectral gamma-ray curve.

26. Springfield, WV stratigraphic column and spectral gamma-ray curve

27. Greenspring, WV stratigraphic column and spectral gamma-ray curve....

28. Petersburg North, WV stratigraphic column and spectral gamma-ray curve

29. Tyrone, PA stratigraphic column and spectral gamma-ray curve.

30. Whip Gap, WV stratigraphic column and spectral gamma-ray curve

31. Bedford, PA stratigraphic column and spectral gamma-ray curve.... 
32. Hiser, WV stratigraphic column....

33. South Branch, WV stratigraphic column and spectral gamma-ray curve.

34. Oak Flat, WV stratigraphic column and spectral gamma-ray curve.

35. Berkeley Springs, WV stratigraphic column and spectral gamma-ray curve

36. Frost, WV stratigraphic column.

37. McCoole, MD stratigraphic column and spectral gamma-ray curve

38. Tomahawk, WV stratigraphic column and spectral gamma-ray curve.................

39. Petersburg West, WV stratigraphic column and spectral gamma-ray curve

40. Outcrop type log (units A-F) correlated with three subsurface wells.

41. Units (A-F) of the Marcellus Shale type log correlated with two adjacent wells in Grant County, West Virginia 


\section{LIST OF TABLES}

TABLE

PAGE

1. Names and locations (latitude and longitude) of studied Marcellus Shale outcrops........ 4

2. Luster and color of rock when powdered based on field characteristics of lithofacies..... 6

3. X-ray diffraction and TOC data (weight percent).............................. 21

4. Sedimentary characteristics of Facies 1, grey calcareous shale..................... 26

5. Sedimentary characteristics of Facies 2, limestone............................... 28

6. Sedimentary characteristics of Facies 3, black calcareous shale..................... 30

7. Sedimentary characteristics of Facies 4, black non-calcareous shale................... 33

8. Sedimentary characteristics of Facies 5, grey non-calcareous shale................... 35

9. Sedimentary characteristics of Facies 6, K-bentonite........................... 37 


\section{INTRODUCTION}

The Marcellus Shale of the Appalachian Basin has traditionally been regarded as the petroleum source rock for conventional Upper Devonian and Lower Mississippian reservoirs. Although the Marcellus has a history of gas production dating back to 1821, the recent rejuvenation of Marcellus exploration began in 2004 when Range Resources introduced two crucial drilling and treatment technologies: horizontal wells and slickwater fracture stimulation. Their initial reports announced remarkable success with these techniques in Pennsylvania, kicking off a new unconventional shale gas play in the Appalachian Basin. The core area of this play - where the formation exceeds $50 \mathrm{ft}$. thick, is thermally mature, and is generally understood to have the best gas potential—includes Pennsylvania, West Virginia and New York, a staggering 50,000 sq. mi.

To date, most sedimentary studies have focused on the subsurface near the Marcellus core area (Roen, 1984; Boswell, 1996; Harper, 1999; Milici and Swezey, 2006; Ettensohn, 2008; Wrightstone, 2009; Boyce, 2010) and on outcrops in New York and Pennsylvania (Engelder 2008; Lash, 2009). Very few detailed investigations have addressed the outcrops of West Virginia, though preliminary work suggests that the Marcellus shale in West Virginia has a significantly different character than that to the north and west (Woodward, 1943; Dennison, 1960).

The primary goal of this thesis is to describe and interpret the sedimentological and stratigraphic nature of the Marcellus Shale in the outcrop belt of West Virginia and adjacent states of Pennsylvania and Maryland. A secondary goal is to create a type log from outcrop 
spectral gamma-ray data and correlate it to nearby well logs, so that these interpretations may be extended into the subsurface of the Appalachian Basin.

\section{Purpose}

The purpose of this thesis is to better characterize the Marcellus Shale in terms of its sedimentological, stratigraphic and petrophysical properties within the outcrop belt of West Virginia and adjacent areas in Pennsylvanian and Maryland. Another purpose is to identify and describe the facies within the Marcellus and interpret them in terms of water depth, water chemistry, terrigenous input, organic content, and their temporal and spatial distribution. The spectral gamma-ray scintillometer was used to create an outcrop type log. The outcrop type log is used to correlate gamma-ray profiles to nearby well logs. The intent is to add further insight concerning the factors that control black shale deposition.

\section{Study Area}

The study area (Fig. 1) consists of portions of West Virginia, Pennsylvania, and Maryland. It includes the majority of the eastern outcrop belt of West Virginia and includes one outcrop from western Maryland and two outcrops in south-central Pennsylvania (Table 1). The subsurface spectral gamma-ray well logs used for correlation are located in Randolph County (well \#1), Preston County (well \#2), and Grant County (well \#4; well \#5) in West Virginia and Somerset County (well \#3) in Pennsylvania (Fig. 1). 


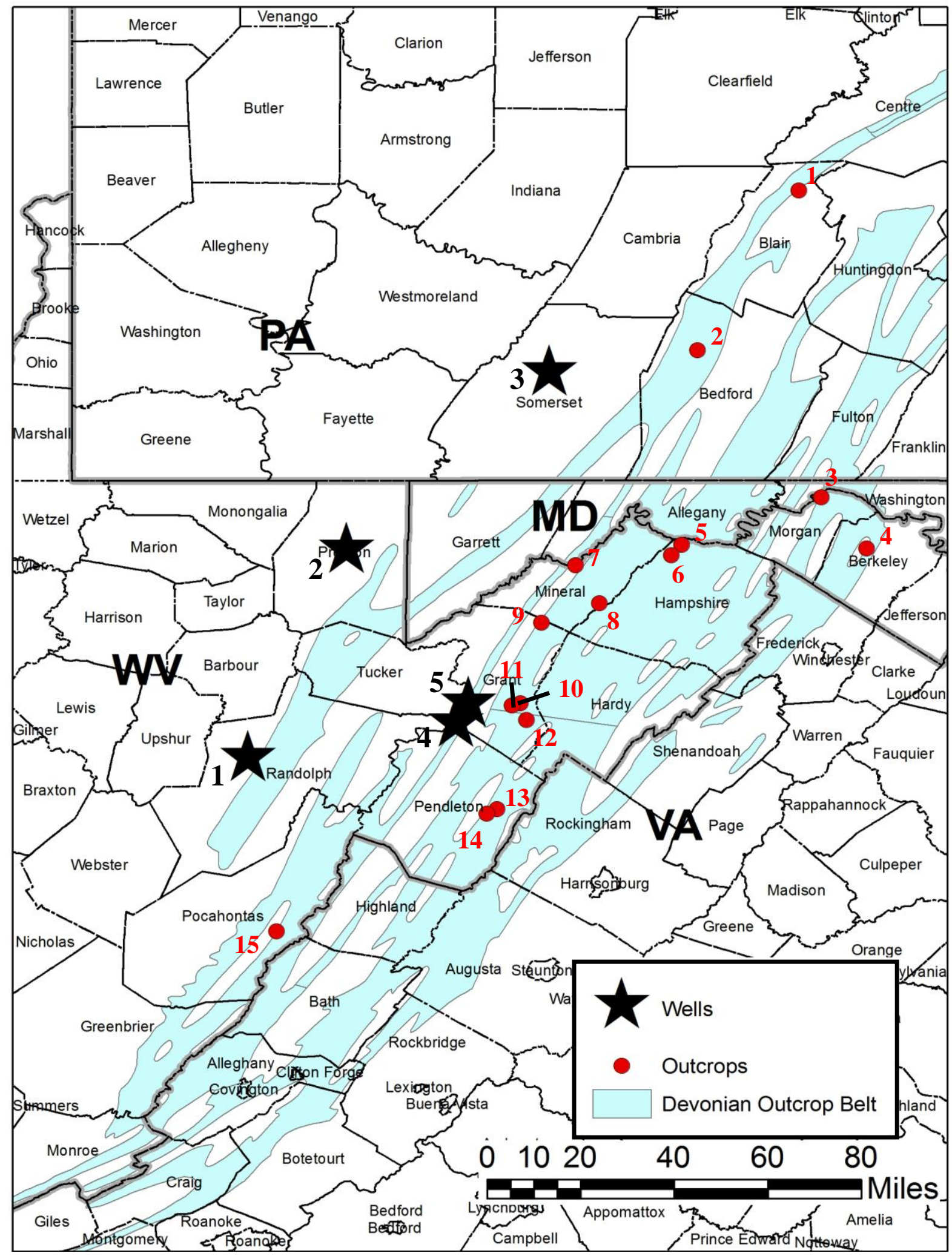

Figure 1. Map of study area with outcrop and well locations. Well data was donated by petroleum companies, locations are approximate due to constraints on proprietary data. 


\begin{tabular}{|c|l|c|c|}
\hline Number & Outcrop & Latitude & Longitude \\
\hline 1 & Tyrone, PA & 40.648802 & -78.269722 \\
\hline 2 & Bedford, PA & 40.138302 & -78.583749 \\
\hline 3 & Berkeley Springs, WV & 39.669142 & -78.200169 \\
\hline 4 & Tomahawk, WV & 39.506425 & -78.060651 \\
\hline 5 & Greenspring, WV & 39.517384 & -78.632605 \\
\hline 6 & Springfield, WV & 39.483756 & -78.664749 \\
\hline 7 & McCoole, MD & 39.451803 & -78.960822 \\
\hline 8 & Burlington, WV & 39.330279 & -78.887382 \\
\hline 9 & Whip Gap, WV & 39.269075 & -79.066308 \\
\hline 10 & North Petersburg, WV & 39.011781 & -79.131689 \\
\hline 11 & West Petersburg, WV & 39.003594 & -79.156687 \\
\hline 12 & Hiser, WV & 38.95794 & -79.112806 \\
\hline 13 & South Branch of the Potomac, WV & 38.674019 & -79.203486 \\
\hline 14 & Oak Flat, WV & 38.658471 & -79.23475 \\
\hline 15 & Frost, WV & 38.2833 & -79.885224 \\
\hline
\end{tabular}

Table 1. Names and locations (latitude and longitude) of studied Marcellus Shale outcrops. See corresponding outcrop number on study area map (Fig. 1). 


\section{Methods}

Fifteen partial Marcellus Shale outcrops in West Virginia, Pennsylvania and Maryland (Table 1; Fig.1) were measured and described in detail. Descriptions of lithofacies are based on field observations (see appendix) and include: rock type, color (fresh and weathered), grain size, visible minerals, parting thickness and geometry, bedding or parting surface, sedimentary structures, nodules, fossil content, color of shale when powdered and luster of shale streak. Parting thickness was based on Potter's (Potter et al., 1980) scheme for shale in outcrop (Fig. 2). Parting

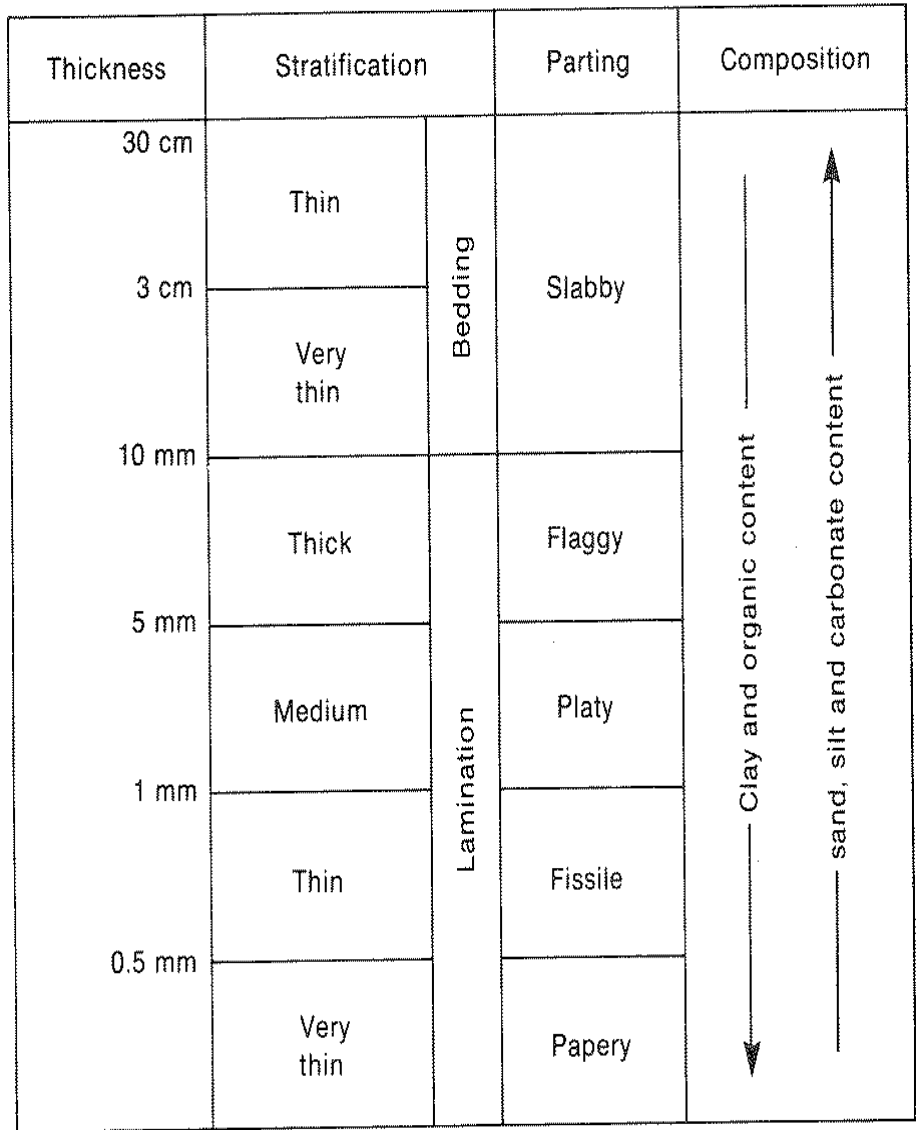

Figure 2. Stratification and parting scheme used for description of shale lithofacies (Potter et al.,1980). geometry was based on descriptive terms of Campbell (1967) (Fig. 3). The shale texture was determined by the luster and the color of the powder when the shale is scratched (Lazar et al., 2010) (Table 2). Bedding thickness for limestone and bentonite was classified using the scheme of Campbell (1967) (Fig. 4). Lithologic data were entered into SedLog® to create stratigraphic columns for each outcrop (Fig. 5). Columns were correlated and then combined into a composite section for the Marcellus Shale for the study area. 


\begin{tabular}{|c|l|l|l|}
\hline \multicolumn{1}{|c|}{ Rock type $=>$} & Siltstone & Siliceous Mudone & \\
\hline Attributes & & & \\
\hline $\begin{array}{c}\text { Grain Size: } \\
\text { Median }\end{array}$ & $>2 / 3$ silt & Clay $>2 / 3$ & $2 / 3>$ clay $>1 / 3$ \\
Range & $.0625-.004 \mathrm{~mm}$ & Silt to Clay & $.0625-.004 \mathrm{~mm}$ \\
\hline Color: Powder & White, Light & Brown, Dark & $\begin{array}{l}\text { Intermediate, Light to } \\
\text { Dark }\end{array}$ \\
\hline Luster: Scratch & Dull & & $\begin{array}{l}\text { Mid-lustrous, Dull to } \\
\text { Waxy }\end{array}$ \\
\hline
\end{tabular}

Table 2. Luster and color of rock when powdered based on field characteristics of lithofacies modified after (Lazar et al., 2010).
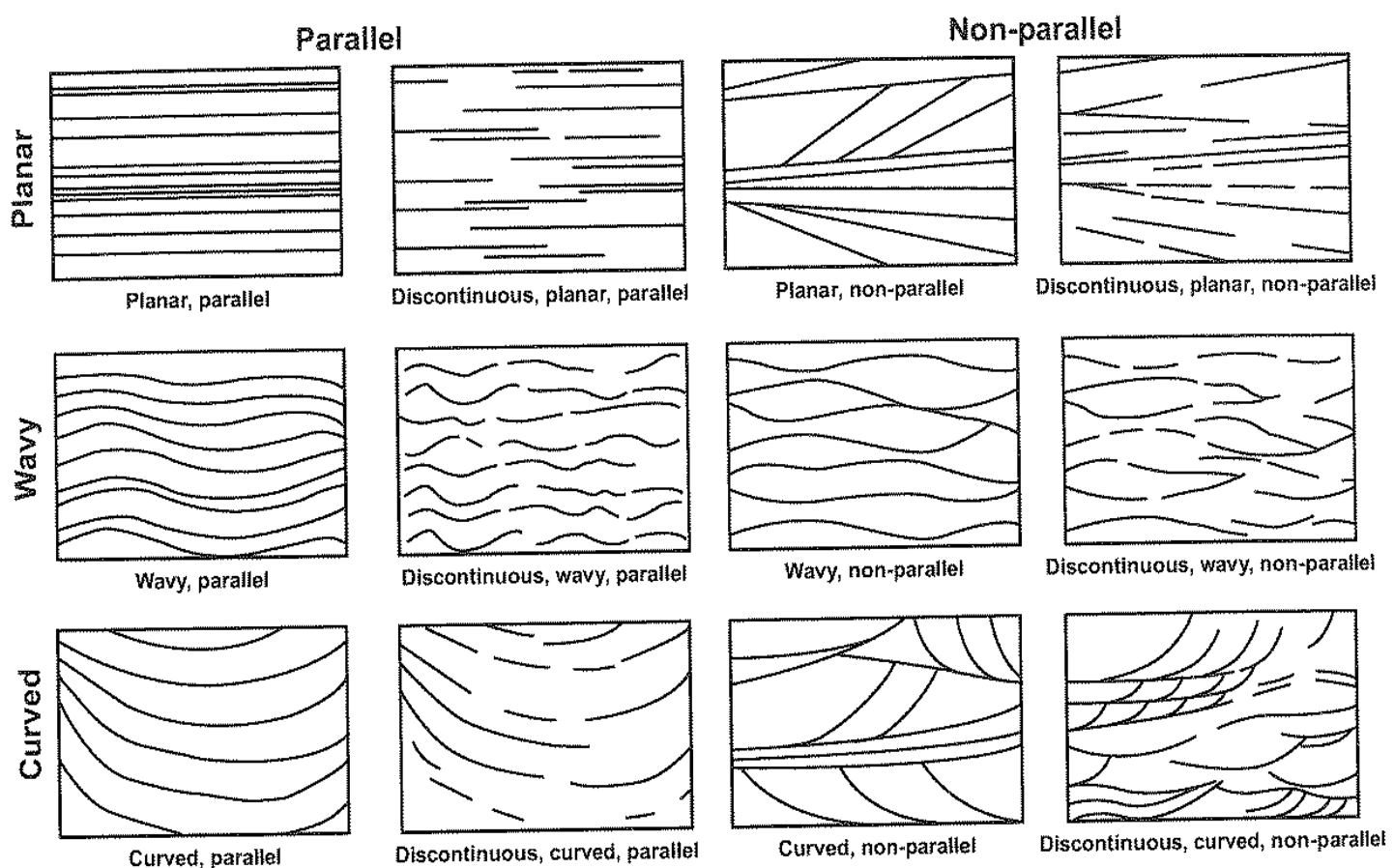

Figure 3. Descriptive terms for lamina continuity, shape and geometry (Lazar et al., 2010; modified after Campbell, 1967). 
A spectral gamma-ray

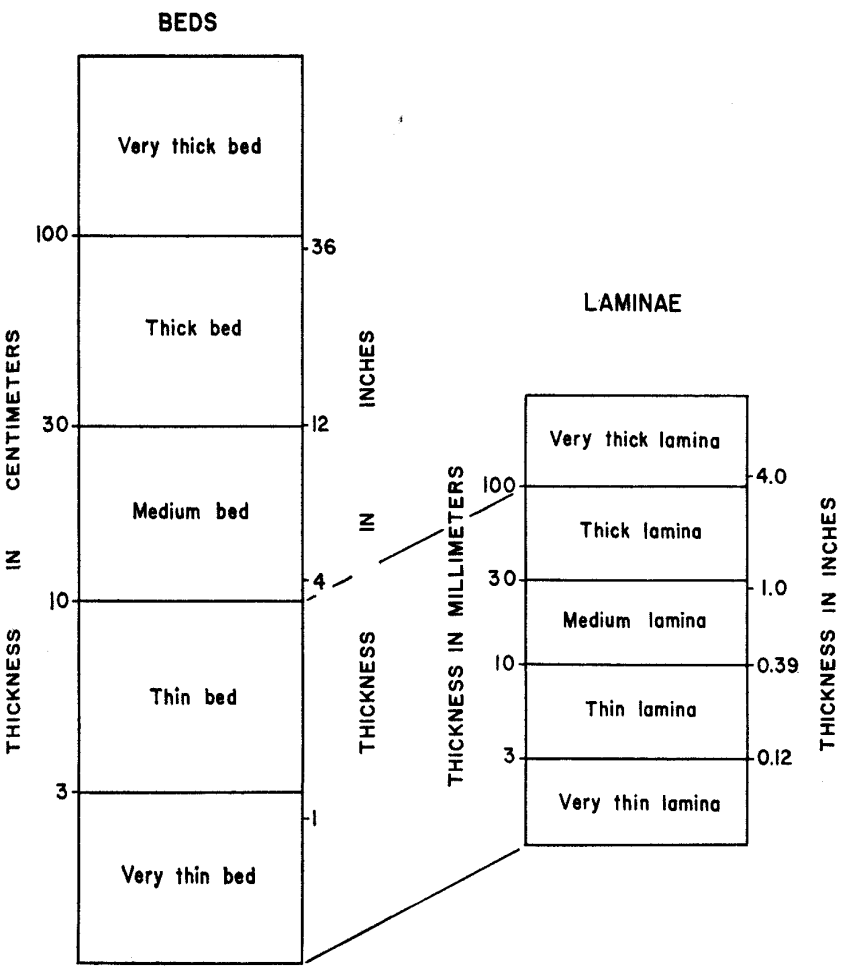

column, reduced uranium $\left(\mathrm{U}^{+4}\right)$ is

Figure 4. Laminae and bed thickness scheme relatively immobile and is thus (adapted from Ingram, 1953; after Campbell, 1967). deposited along with organic material under anoxic conditions (Nielsen et al., 1987). Increased uranium concentrations are, therefore, typically associated with enriched total organic carbon (Swanson, 1960; Schmoker, 1981). Thorium concentrations in the Marcellus Shale are believed to be linked to clay concentrations, most notably illite (Boyce, 2010). Gamma-ray data were collected at 1.0 foot intervals along the outcrop. Effort was made to clear each outcrop of weathered material and, where possible, to place the detector at a consistent position against the outcrop to insure a constant rock volume was sampled for each reading (Lazar et al., 2010). The spectral gamma-ray data were downloaded to RS-Analyst ${ }^{\circledR}$ and imported into Microsoft Excel@ and Petra® to create spectral gamma-ray profiles (Fig. 5). Conversions of gamma-ray data from parts per million (ppm) to standard American Petroleum Institute (API) units were based on (Korsbech, 2002). 


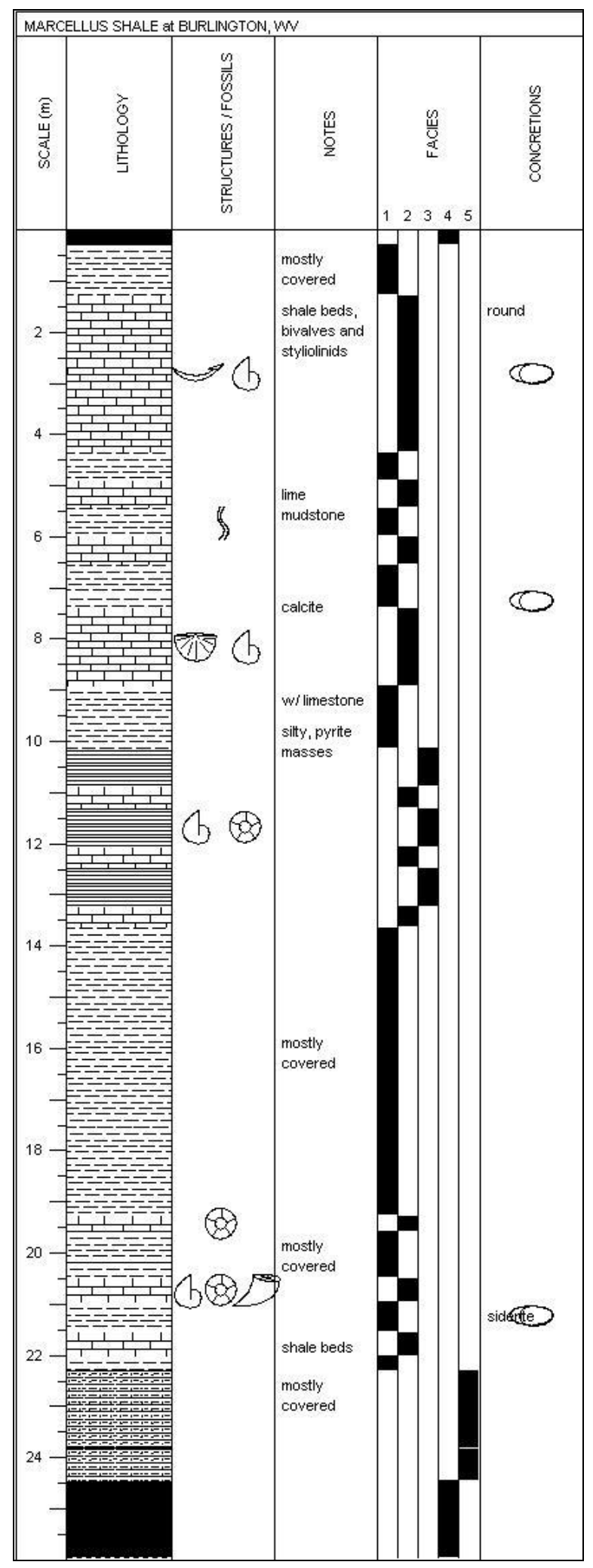

Figure 5. An example of a Sedlog® outcrop stratigraphic column for the Marcellus Shale at Burlington, WV. 
A gamma-ray type log was compiled from spectral gamma-ray outcrop profiles and used to correlate the Marcellus Shale into the subsurface.

Representative rock samples from several outcrops were collected and analyzed by X-ray diffraction (XRD) and thermogravimetric analyses (TGA) to determine the bulk shale mineralogy and total organic carbon (TOC) of each sample.

Field descriptions, stratigraphic columns, XRD and TOC analysis, and spectral gammaray outcrop data provided the basis for identification of lithofacies and interpretation of depositional environments (Fig. 11-13). 


\section{GEOLOGIC SETTING}

\section{Regional Overview}

The Middle Devonian marks the arrival of the Acadian orogen and its first influence as a clastic source in the Appalachian region (Ettensohn and Barron, 1981; Faill, 1985). The Acadian orogeny resulted from the collision between the Avalonia terrane and Laurentia to form the Laurussian continent (Fig. 6) (Faill, 1997; Ettensohn, 1987). Tectonic loading stemming from this orogenic event as well as the eustatic Eifelian-Givetian sea level rise created a shallow epicontinental sea in the foreland basin adjacent to the Acadian mountains (Werne et al., 2002).

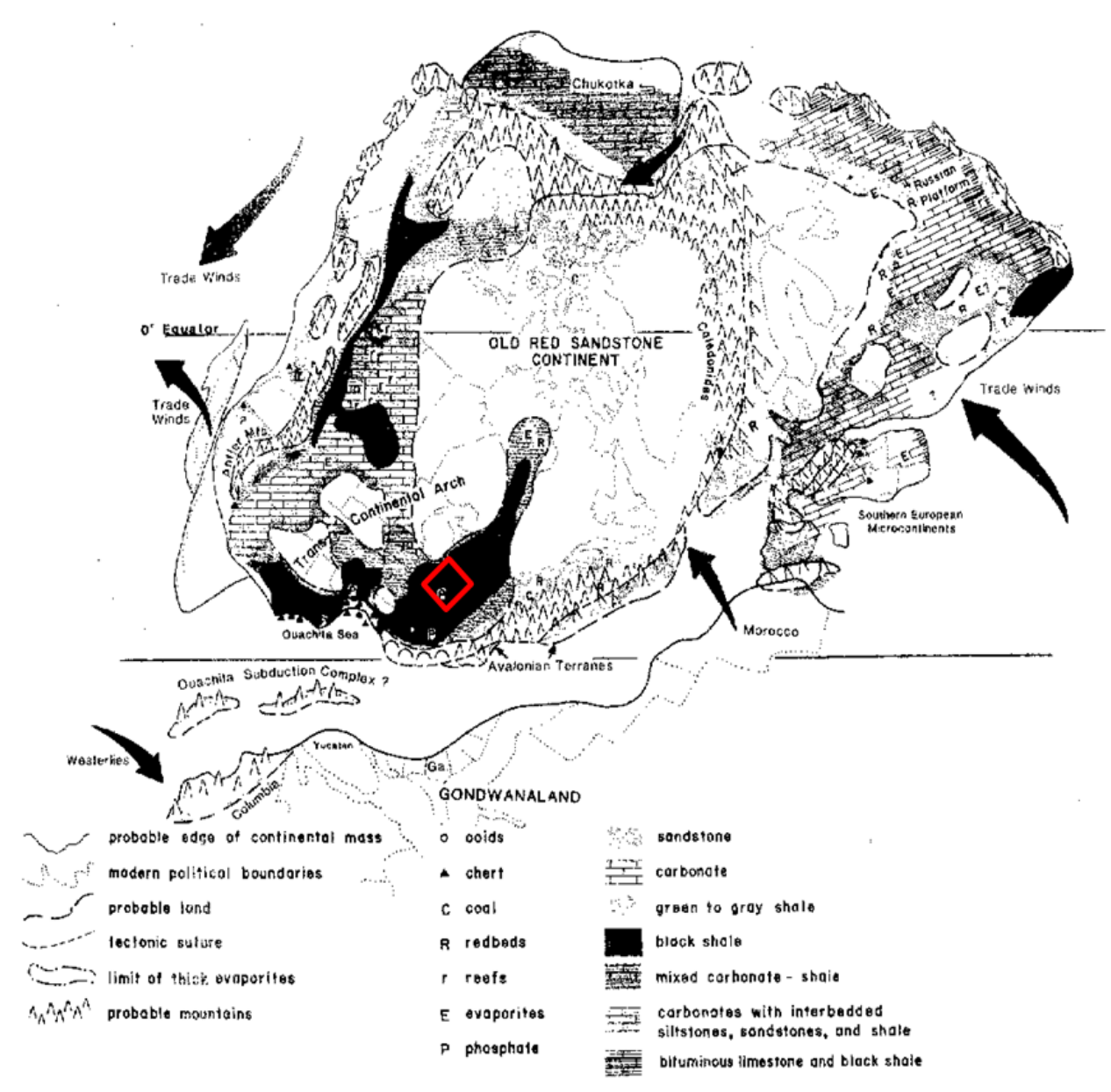

Figure 6. Paleogeography of Old Red Sandstone Continent (Laurussia) during Devonian time modified from Ettensohn (1998). The study area is outlined in red. 
The central Appalachian foreland basin is an asymmetrical, northeast-trending trough bounded on the south and east by the Acadian highlands, on the west by the Cincinnati arch, and on the north by the Old Red Sandstone continent (Ettensohn and Barron, 1981; Gao et al., 2000). This geometry resulted in restricted marine circulation within the Appalachian Basin during Middle Devonian time. A paleogeographic reconstruction of the Middle Devonian (Fig. 7) depicts present-day West Virginia, Pennsylvania and parts of New York, Virginia, Maryland and Ohio as a nearly-enclosed epicontinental sea (Woodrow, 1985; Blakey, 2011).

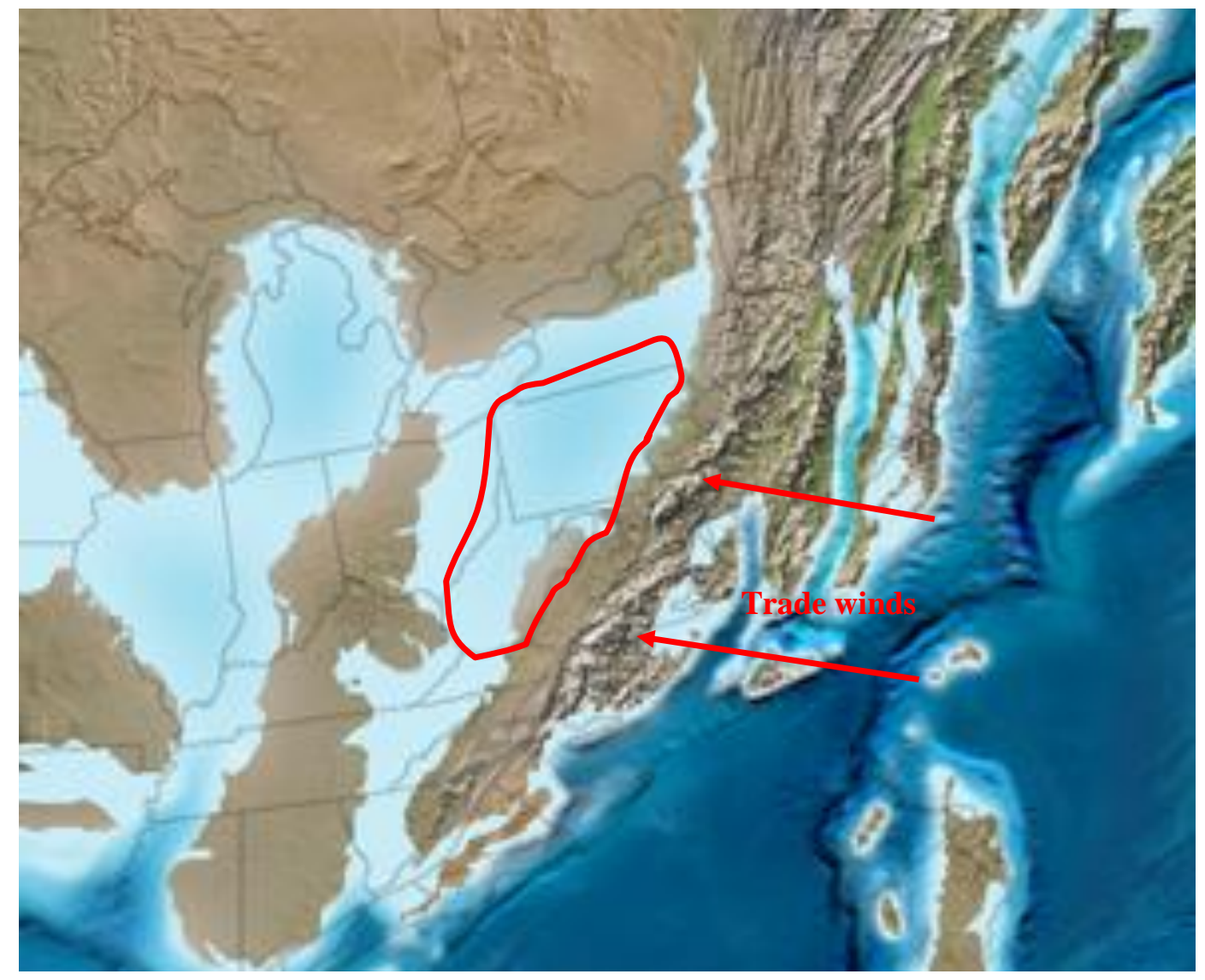

Figure 7. Middle Devonian paleogeographic reconstruction (385 Ma). Appalachian Basin indicated modified after Blakey (2011). 
During Devonian time, the central Appalachian Basin was situated near the equator. Exact placement of the equator during this time is still debated, but most agree that Laurussia was an equatorial landmass located approximately 15-30 degrees south (Heckel and Witzke, 1979; Ziegler et al., 1979; Ettensohn and Baron, 1981). The central Appalachian Basin was located in the humid equatorial belt and subject to the easterly trade winds (Ettensohn and Baron, 1981). The Acadian highlands may have blocked the easterly trade winds carrying moisture from the adjacent ocean (Fig. 7), creating a rainshadow effect on the western side of the highlands (Ettensohn and Baron, 1981; Woodrow, 1985). The resulting paleoclimate experienced during the early part of the middle Devonian (Eifelian) may have been arid to semi-arid with the occurrence of large seasonal storms (Woodrow, 1985; Werne et al., 2002). Along with the influence of basin geometry and paleoclimate, other large-scale factors influencing the sedimentation of black shale in the Appalachian Basin were: active tectonism, subsidence and eustatic sea level rise.

The Acadian clastic wedge consists of two deltaic complexes including the Middle to Upper Devonian Catskill delta and the Late Devonian to Early Mississippian Price-Rockwell delta (Ettensohn, 1985; Boswell, 1996). The Catskill delta reaches its maximum thickness of 12,000 feet in eastern Pennsylvania and thins westward across the basin to nearly 400 feet (De Witt et al., 1975; Milici and Swezey, 2006). The Catskill delta complex is dominated by prograding sediments shed into the basin from the Acadian mountains to the east (Fig. 8). These sediments are grouped into five time-transgressive magnafacies (Harper, 1999). Facies I consists of "dark gray to black, somewhat calcareous, pyritic, sparsely fossiliferous mud" (Harper, 1999). This facies is interpreted as basinal muds deposited under anoxic conditions. Within the clastic wedge, seven transgressive black shale units (Facies I) were deposited extensively across the 
basin and interfinger with coarser, lighter sediments (Facies II-V). These seven black shale tongues of the Catskill delta include the Marcellus (lowermost), Harrell, Geneseo, Middlesex, Rhinestreet, Huron and the Lower Mississippian Sunbury Shale (Dennison, 1985; De Witt et al., 1993; Harper, 1999; Milici and Swezey, 2006).

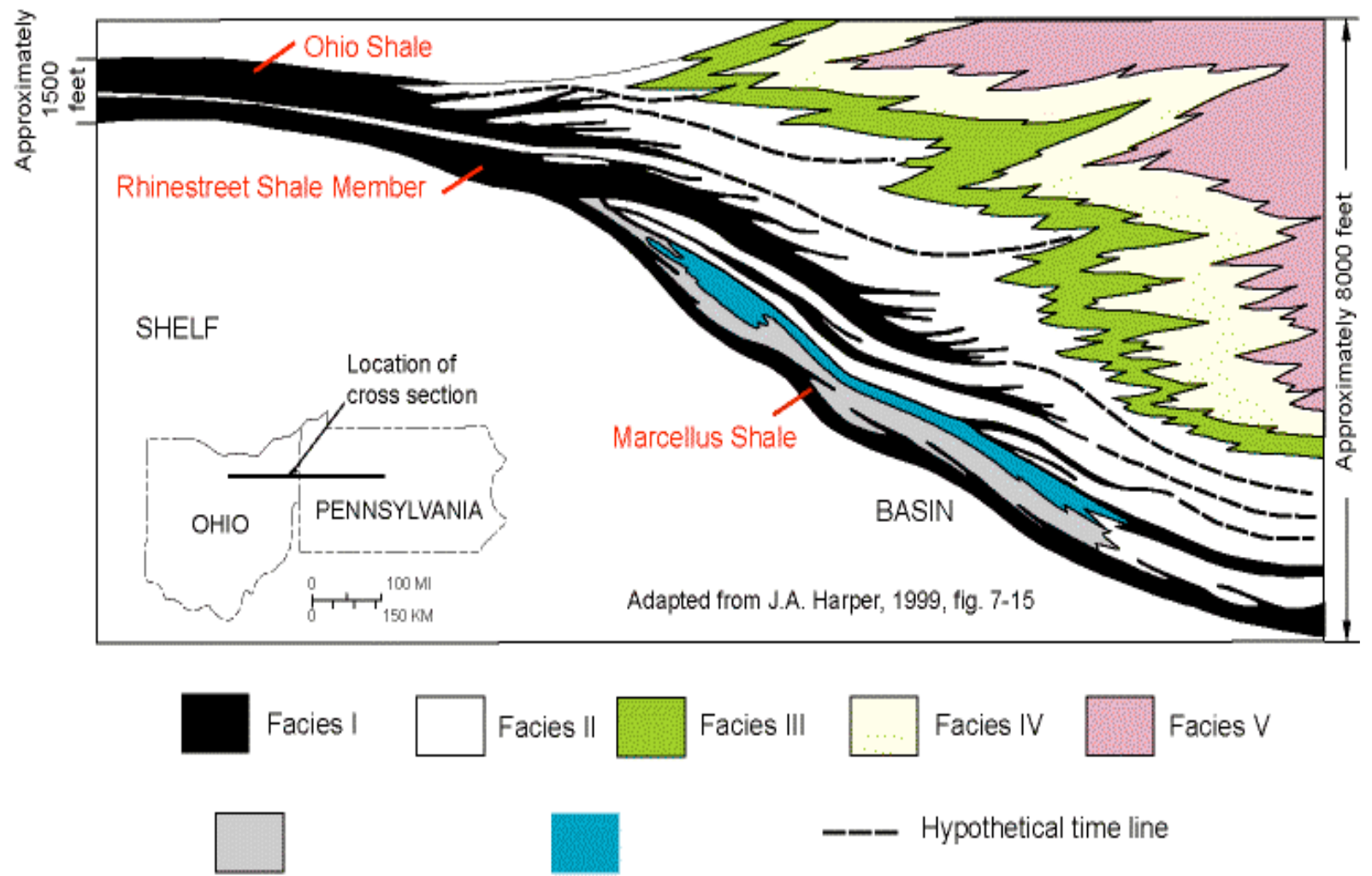

Undifferentiated upper Tully Limestone Middle Devonian rocks

Figure 8. Regional facies model for the Acadian clastic wedge in the Appalachian Basin. Facies I: dark colored, organic-rich, basinal shales. Facies II: interbedded subfissile shales, fine-to coarse-grained, very thinly bedded siltstones and rare fine-grained sandstones. Facies III: marine clastic rocks that vary extensively in color and texture (fossiliferous). Facies IV: Interbedded multicolored mudrocks, shales, thin to thickbedded siltstones, sandstones and conglomerates. Facies V: Red, green, or gray, non marine detrital rocks from Harper (1999). 


\section{Stratigraphy}

Comprised of the older Marcellus Shale and the younger Mahantango Formation, the Middle Devonian Hamilton Group was deposited in the Appalachian Basin in Pennsylvania, West Virginia, and parts of Maryland, New York, Virginia, and Ohio (Willard, 1935;

Woodward, 1943) (Fig. 7). The Hamilton Group, deposited roughly $385 \mathrm{Ma}$, belongs to the Eifelian and Givetian stages of the Middle Devonian (Fig. 9).

The Hamilton Group increases in thickness and complexity from southwest to the northeast (Harper, 2008). It ranges in thickness from approximately 50 feet in western West Virginia to roughly 1700 feet in southwestern Pennsylvania (Woodward, 1943). Throughout the Appalachian Basin, the Marcellus Shale ranges from thickness of zero feet in Ohio, to roughly 800 feet in eastern reaches of the basin (Harper, 1999). Woodward (1943) suggests a maximum thickness of roughly 250-300 feet in the eastern panhandle of West Virginia, however, these thickness values are overestimated due to faulting and deformation. Regional mapping suggests a maximum thickness of 200 feet in West Virginia (Wrightstone, 2009; VanMeter, 2011, personal communication). 


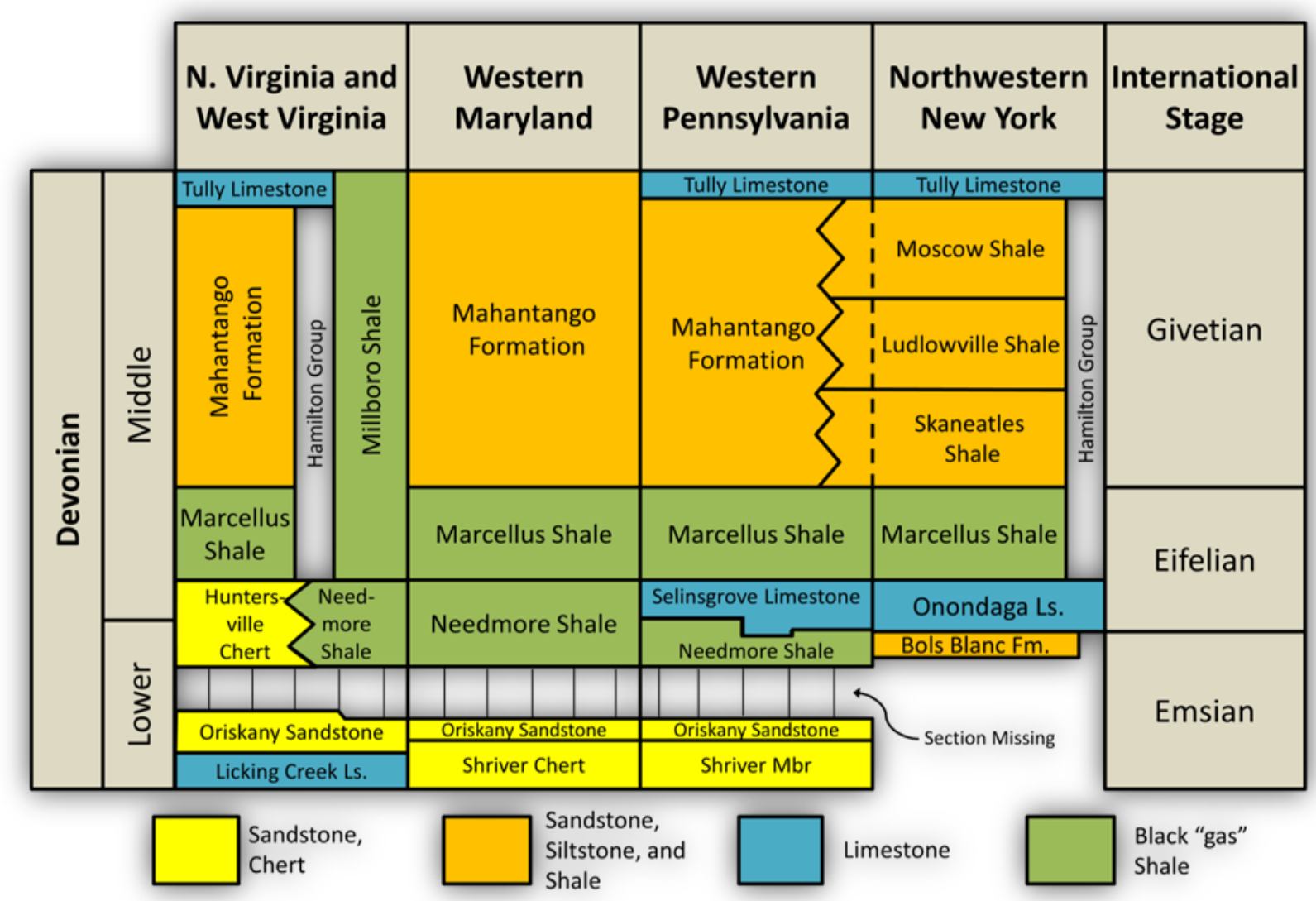

Figure 9. Appalachian Basin regional stratigraphy modified from Milici and Swezey (2006).

As a whole, the Marcellus Shale is frequently described as homogenous carbonaceous black shale, containing locally-abundant pyrite, carbonate concretions, and very few fossils (Ettensohn and Baron, 1981; Harper, 1999). The Marcellus Shale of West Virginia has previously been described as black fissile carbonaceous shale that weathers grey. Several beds of calcareous shale and black limestone, and one or more zones of concretions (varying in composition, abundance and character) have also been recognized (Woodward, 1943; Dennison, 1960). The Marcellus shale has been reported to maintain this same character from east-central Pennsylvania to as far south as Bluefield, Virginia (Woodward, 1943). 
The Marcellus Shale of western New York has been elevated to subgroup status and contains two distinct formations, the Union Springs and the Oatka Creek (Ver Straeten, 2007). The Union Springs is a highly organic, calcareous mudstone containing skeletal lags (Sageman et al., 2003). The overlying Oatka Creek Formation consists of several members including the Cherry Valley, Hurley and Berne members (Fig. 10) (Engelder and Lash, 2011). Directly overlying the Oatka Creek Formation in western New York are the dark shales and fossiliferous limestone beds of the Hurley Member (Engelder and Lash, 2011). The Cherry Valley Member of western New York is a bedded to nodular limestone that contains thin to thick black shale interbeds (Ver Straeten, 2007). The Cherry Valley Limestone, also called the Purcell Member, is recognized as calcareous shale in southern Pennsylvania and nodular limestone and shale in West Virginia and Virginia (Ver Straeten, 2007). The overlying Berne Member is a dark grey to black shale (Engelder and Lash, 2011).

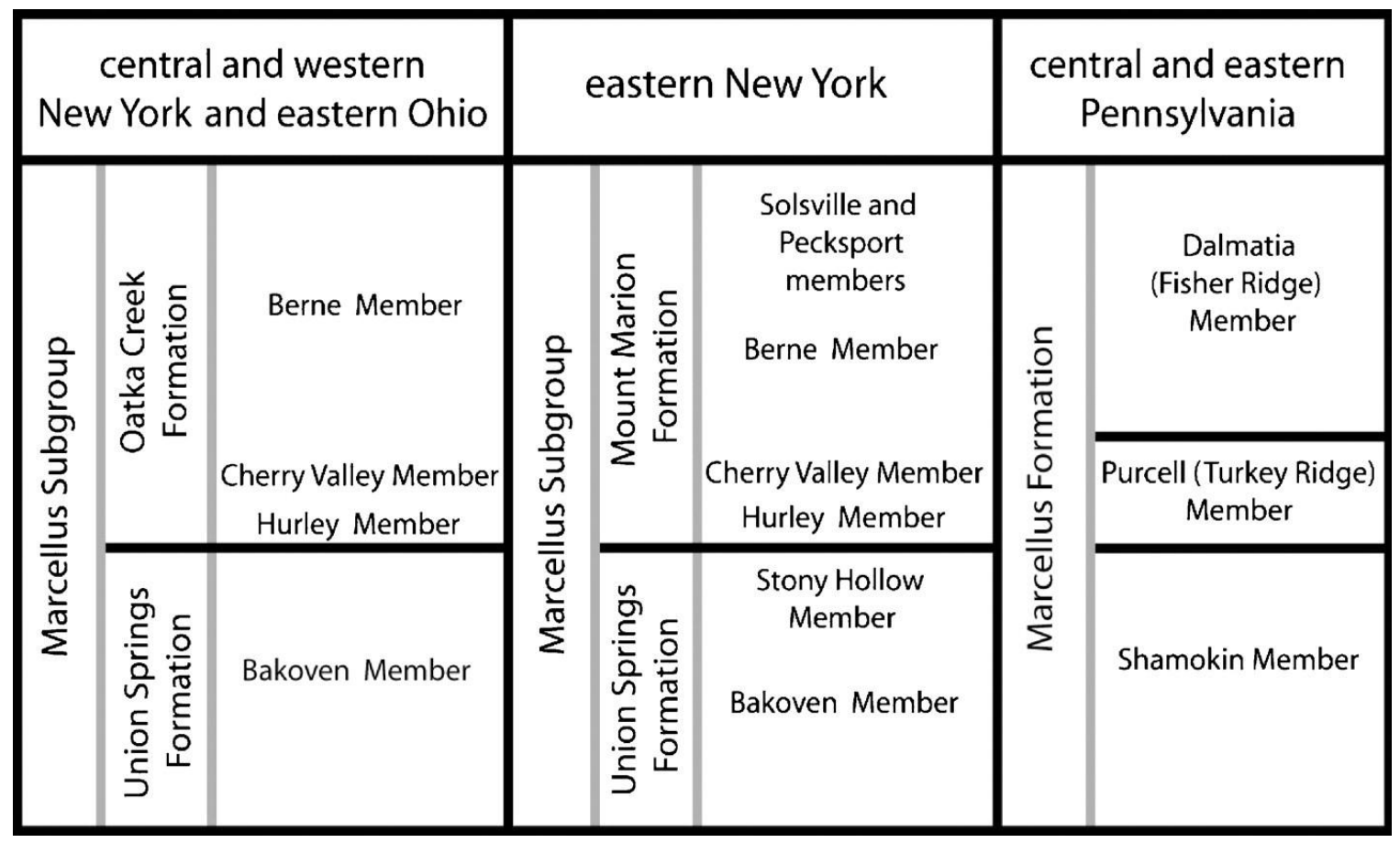

Figure 10. Marcellus stratigraphy in New York modified from Engelder and Lash (2011). 
Throughout most of the Appalachian Basin, the Marcellus Shale lies conformably upon Lower Devonian strata including the Onondaga Limestone, Huntersville Chert, and the Needmore Shale. These three facies interfinger laterally with one another and represent a western carbonate facies, a central basin siliceous facies, and an eastern clastic facies, respectively (Dennison, 1960; Basan et al., 1980; Sherrard and Heald, 1984).

The Tioga K-bentonite was deposited as seven distinct units across the basin during Onondaga through Marcellus time. The Tioga ash zones consist of micaceous tuff layers (middle coarse zone) and yellow to grey-brown, laminated, micaceous shale, and are thought to have originated from a volcano near Fredericksburg, Virginia (Dennison and Textoris, 1977; Harper, 1999; Ver Straeten, 2004).

Nearing the end of the Middle Devonian, coarse clastic sediments of the Mahantango Formation were shed into the basin. The Mahantango Formation, a large deltaic wedge, lies conformably above the Marcellus throughout the basin, and to the east it consists of grey to dark grey-black shale, siltstone, limestone and fine-grained sandstone (Ettensohn and Baron, 1981; Ver Straeten, 2007; Harper, 2008). 


\section{PREVIOUS STUDIES OF BLACK SHALE}

Two fundamental schools of thought attempt to explain the organic richness observed in black shale. The preservation school (Demaison and Moore, 1980; Ettensohn, 1981) requires the presence of a permanently-stratified water column (pycnocline). Under these conditions anoxic bottom waters can persist and allow for enhanced preservation of organic material in basin sediments. On the other hand, the production school (Pedersen and Calvert, 1990) argues that high concentrations of organic matter in black shale are a result of enhanced primary productivity in the surface water. Under enhanced productivity, the presence of anoxia is explained as a result of organic enrichment of bottom sediments rather than the cause.

Most depositional models for black shale combine both increased productivity and preservation of organic matter. These models for black shale deposition embrace multiple factors to explain productivity and preservation. They consider the effects of sediment rate, local tectonism, relative sea level, paleoclimate and biogeochemical cycling in the creation of black shale (Ettensohn and Barron, 1981; Werne et al., 2002; Sageman et al., 2003).

Ettensohn's (1985) depositional model called upon a deep-water environment for the deposition of black shale. His tectono-stratigraphic model emphasized active tectonism, which led to rapid subsidence and a deepening of the foreland basin. Oceanic upwelling of nutrientrich water resulted in high biologic productivity and subsequent accumulation of organic material in a deep-water basin below a permanent pycnocline. Sediment starvation due to the rain shadow effect from the Acadian mountains allowed for the preservation of the organic matter. The presence of a permanent pycnocline explains the preservation of organic matter, and implies a deep, stagnant basin for these circumstances to persist. Algeo and Schekler (1998) 
recognized the possible impact of Middle Devonian land plants on the deposition of black shale. The large increase in deep-rooted land plants in the Middle Devonian allowed for increased chemical weathering and nutrient runoff into the sea, as well as decreased erosion. These effects allowed for nutrients, but not clastic sediments, to enter the Appalachian Basin and create algal blooms. These factors resulted in the preservation of organic material in the basin (Algeo and Schekler, 1998).

Schwietering's $(1977,1981)$ depositional model favored the shallow to moderately-deep environment for the deposition of black shale. They proposed that black shale was deposited on the shallow epicontinental sea shelf along the western margin of the Appalachian Basin. Evidence for the deposition of black muds on a shallow shelf include: the westward thinning of the Hamilton group onto the paleo-shore of the Cincinnati Arch and the deposition of black shale as the first transgressive unit on top of an erosional unconformity. Both features indicate a shallow shelf rather than a deep basinal black shale deposit (Schwietering, 1977; Schwietering and Erwin, 1981). Sediment starvation of the western margin resulted from the basin center acting as a sediment trap for the clastic source to the east. This allowed black organic-rich sediment to accumulate on the shallow shelf. Streams entering the ocean from the stable western craton carried fresh water into the more saline sea water creating a stratified water column (halocline) on the shallow epicontinental sea shelf (Schweitering, 1977; Smith and Leone, 2010).

An alternative model relating to the deposition of the Marcellus Shale in New York envisions a shallow-water basin subjected to occasional storm activity that allowed for more oxygenated surface waters to mix with anoxic bottom waters (Sageman et al., 2003). Mixing led to seasonal oxic/anoxic oscillations, resulting in a seasonal thermocline rather than a permanent pycnolcine. Nutrient-rich bottom waters brought to the surface by mixing resulted in high levels 
of primary productivity in the surface water, thus increasing the potential delivery of organic matter to the sea floor. The seasonally anoxic basin, coupled with the effects of sediment starvation and relative sea level rise, resulted in the formation of the Oatka Creek Formation of the Marcellus Shale (Werne et al., 2002; Sageman et al., 2003).

Whereas many models associate the deposition of organic-rich black shale with the depth of the basin, facies and fauna changes within the Marcellus Shale may be due to factors independent of depth. These include changes in circulation, nutrient supply of the water column, sedimentation rates, and substrate stability (McCollum, 1988). Some authors speculated that water depth was not at all a critical factor in the deposition of black shale as long as there were high primary productivity and anoxic bottom waters (Provo, 1978; McCollum, 1988). 


\section{FACIES ANALYSIS}

A total of 15 partial Marcellus Shale outcrops were studied and six lithofacies were identified. The six lithofacies include: 1) grey calcareous shale; 2) limestone; 3) black calcareous shale; 4) black non-calcareous shale; 5) grey non-calcareous shale; and 6) K-bentonite. Samples from several outcrops (Fig. 11-13) were analyzed for quartz, illite, kaolinite, calcite and organic matter using X-ray diffraction and TGA analysis. Quartz ranges from 24-75\%, illite 12-47\%, kaolinite $0-12 \%$, calcite $0-47 \%$, and organic carbon $4-14.5 \%$ for the shale lithofacies (Table 3 ).

\begin{tabular}{|c|c|c|c|c|c|c|c|c|}
\hline Location & Sample No. & Facies & Quartz & Clay & Kaolinite & Calcite & Moisture & TOC \\
\hline Burlington & BU1-1 & 1 & 38.6 & 42.9 & 1.6 & 8.3 & 1 & 7.5 \\
\hline Burlington & BU2-1 & 1 & 35.3 & 39.3 & 1.4 & 15.7 & 1.3 & 7 \\
\hline Burlington & BU3-1 & 1 & 24.4 & 20.4 & 0.2 & 47.5 & 1 & 6.5 \\
\hline Springfield & S1-1 & 1 & 34 & 41.3 & 0.4 & 17.3 & 0.7 & 6.5 \\
\hline Burlington & BU1-3 & 3 & 44.2 & 41.8 & 0.1 & 6 & 1.5 & 6.5 \\
\hline Burlington & BU2-3 & 3 & 38.7 & 42 & 0.2 & 10.1 & 1.5 & 7.5 \\
\hline Burlington & BU3-3 & 3 & 37.8 & 39.1 & 0.1 & 14 & 1 & 8 \\
\hline Burlington & BU1-4 & 4 & 48.5 & 42 & - & - & 1.5 & 8 \\
\hline Petersburg N. & P1-4 & 4 & 42.9 & 48.6 & - & - & 1.5 & 7 \\
\hline Whip Gap & WG1-4 & 4 & 55.1 & 28.9 & - & - & 1.5 & 14.5 \\
\hline Whip Gap & WG2-4 & 4 & 52.9 & 38.6 & - & - & 1 & 7.5 \\
\hline Whip Gap & WG3-4 & 4 & 74.9 & 12.1 & - & - & 2 & 11 \\
\hline Burlington & BU1-5 & 5 & 52 & 42 & - & - & 1 & 5 \\
\hline Greenspring & GS1-5 & 5 & 43.2 & 40.5 & 11.6 & - & 0.7 & 4 \\
\hline Greenspring & GS2-5 & 5 & 42.5 & 47.3 & 5 & - & 0.7 & 4.5 \\
\hline Greenspring & GS3-5 & 5 & 47.6 & 43.4 & 2.5 & - & 1 & 5.5 \\
\hline
\end{tabular}

Table 3. X-ray diffraction and TOC data (weight percent). 

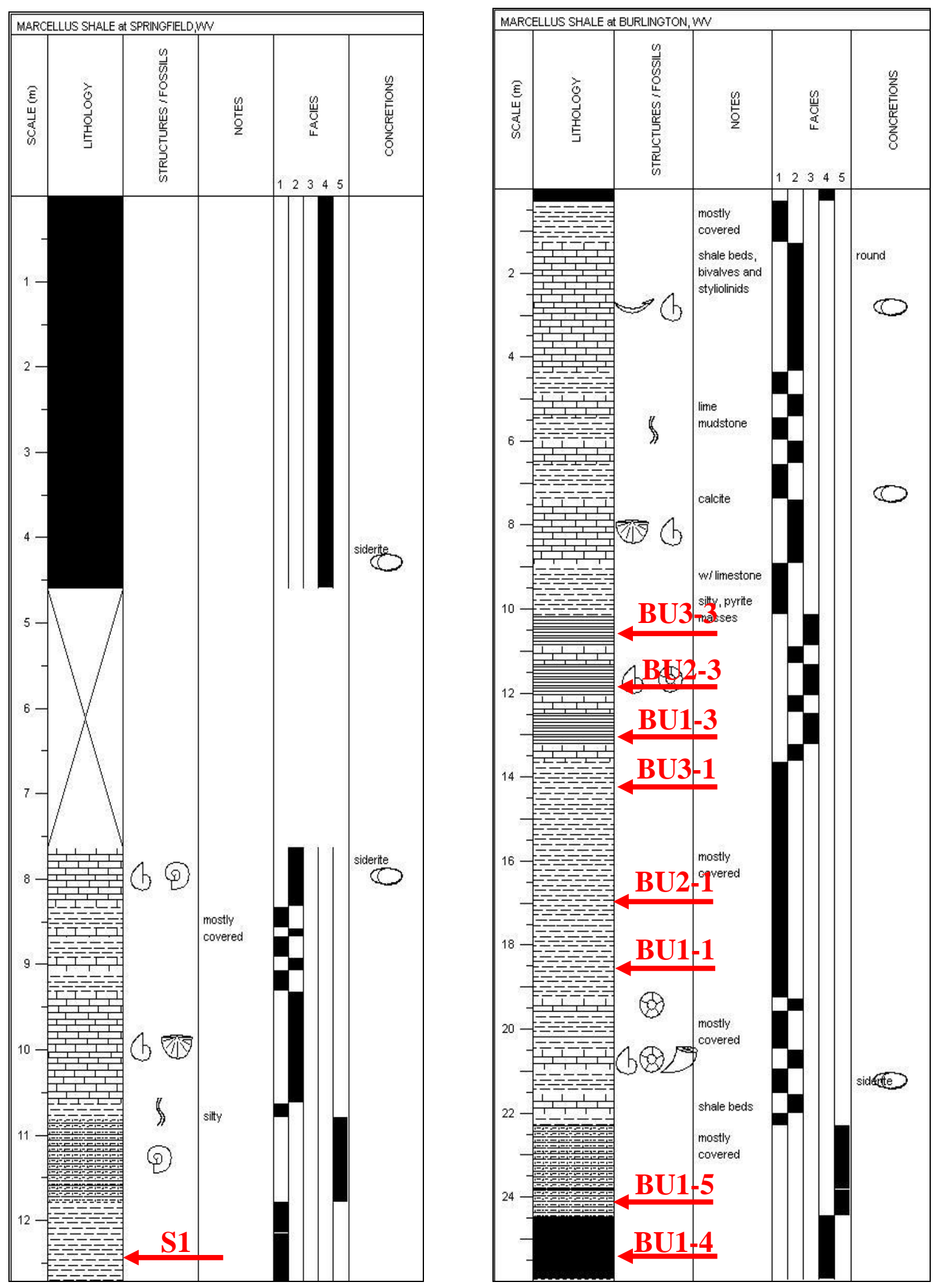

Figure 11. XRD and TGA sample locations at Springfield and Burlington outcrops are labeled and shown with red arrows. See table 3 for sample information. 

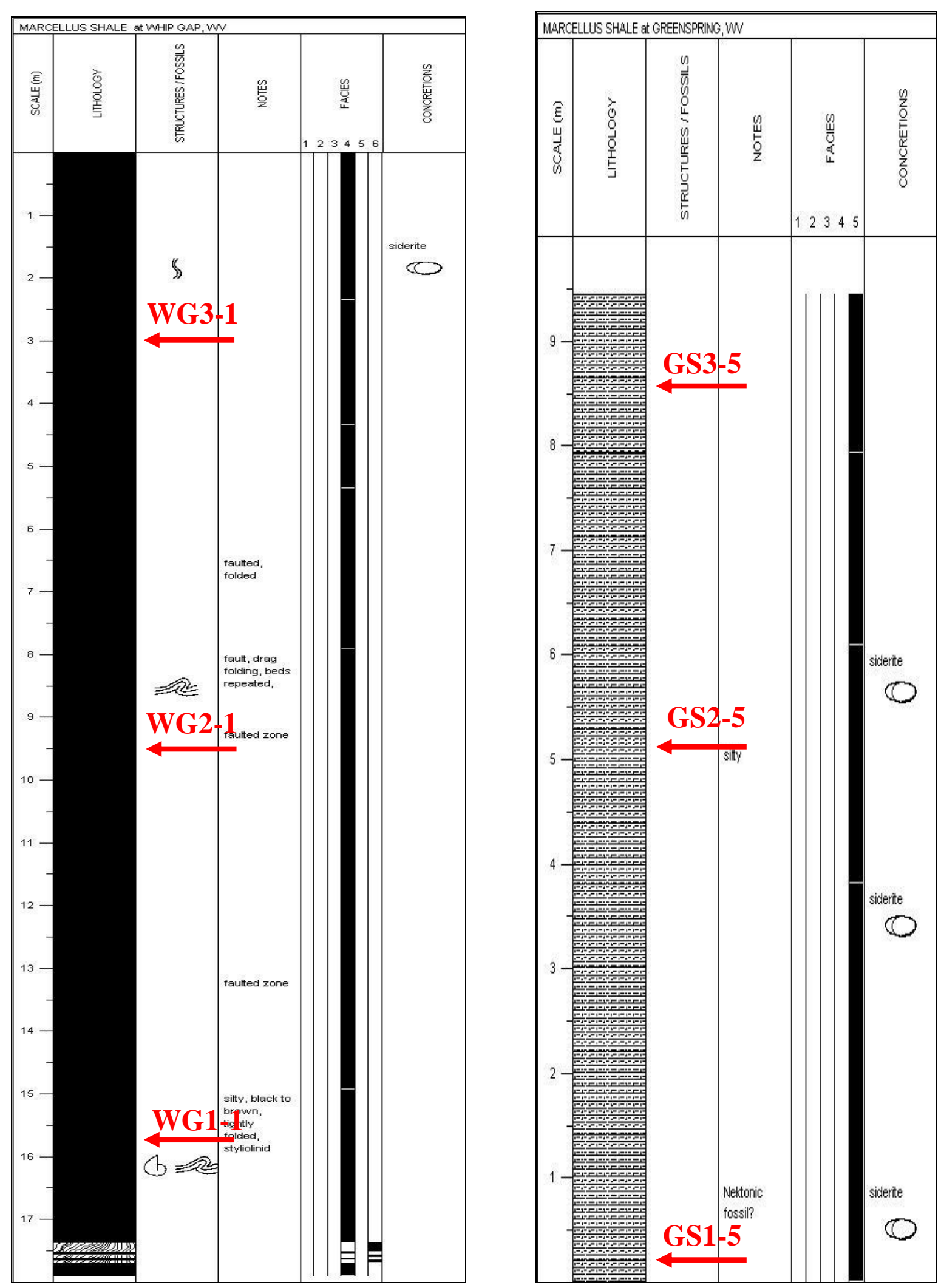

Figure 12. XRD and TGA sample locations at Whip Gap and Greenspring outcrops are labeled and shown with red arrows. See table 3 for sample information. 


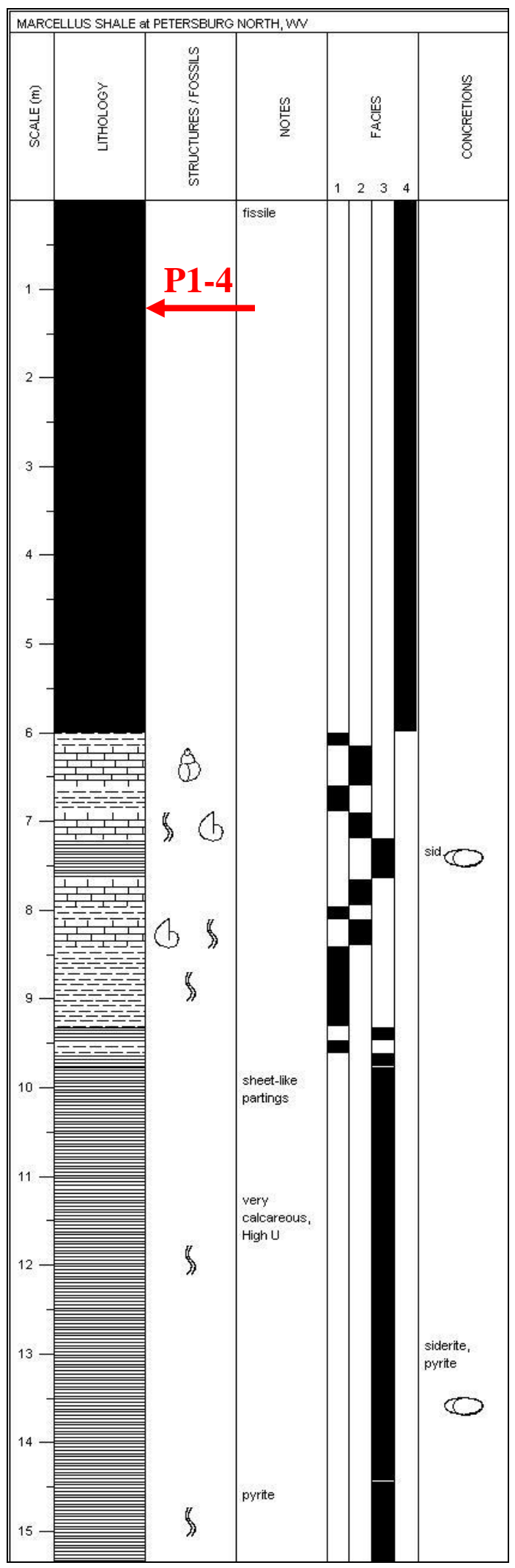

Figure 13. XRD and TGA sample location at Peterburg North outcrop is labeled and shown with a red arrow. See table 3 for sample information. 


\section{Facies Descriptions}

\section{Facies 1}

Facies 1 is grey calcareous shale, occasionally slightly calcareous (Table. 4). XRD analysis established a range of 8.3-47.5\% calcite, with the remaining constituents consisting of clastic sediment; clay, silt, and organic matter. The average TOC is $6.8 \%$ for representative samples of Facies 1. The shale weathers brown, white or maroon. Shale partings are usually platy and exhibit wavy and discontinuous geometry. Parting surfaces are often bumpy and irregular. Bioturbation is common including horizontal, vertical and unoriented burrows. Body fossils are occasional, but when present include articulate and linguloid brachiopods, crinoids, ostracods, and oxidized and/or replaced shell debris. Nodules of siderite and calcite, as well as masses of pyrite and incipient nodules, occur throughout the rock (Fig. 14). An incipient nodule is the initial or beginning stage of a nodule, not completely formed into a distinct mass, but markedly different from the surrounding shale. Incipient nodules typically exhibit an oxidation halo. The rock's texture varies from medium to coarse mudstone (silty mudstone) based on its scratch and luster (Table 4). 
Table 4. Sedimentary Characteristics of Facies 1, Grey Calcareous Shale

\begin{tabular}{cl}
\hline Color fresh & Medium-dark grey, brown \\
\hline Color weathered & Brown, white, maroon \\
\hline Grain size & Silt sized grains \\
\hline Parting thickness & Platy to flaggy, also papery to fissile where associated with Facies 2 \\
\hline Parting geometry & Mostly continuous, wavy, parallel \\
\hline Parting surface & Irregular, bumpy \\
\hline Nodules & Calcite, pyrite, siderite, incipient \\
\hline Body fossils & $\begin{array}{l}\text { Brachiopods (including linguloids), crinoids, ostracods, unidentified } \\
\text { shell debris, pyritized or replaced fossil debris }\end{array}$ \\
\hline Trace fossils & Common bioturbation, unoriented, vertical, and horizontal burrows \\
\hline Color when powdered & Light to intermediate, tan to medium brown \\
\hline Luster of streak & Intermediate \\
\hline
\end{tabular}



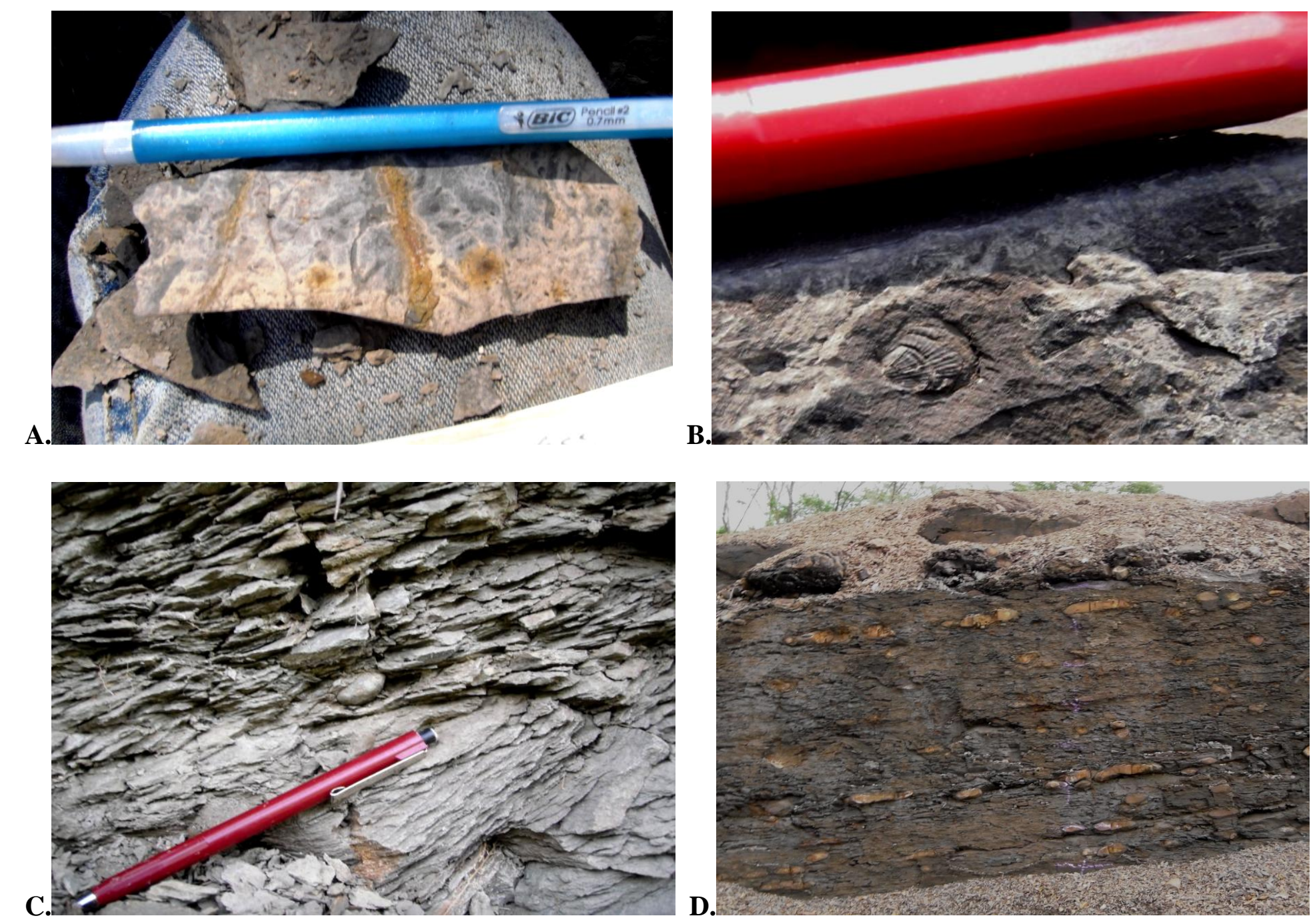

Figure 14. Outcrop photographs of Facies 1, grey calcareous shale. A. Oak flat outcrop: horizontal and vertical oxidized burrows on bedding plane (15-cm pencil for scale). B. Tyrone outcrop: Small fossil brachiopod imprint (15-cm pencil for scale). C. Burlington outcrop: platy to flaggy grey calcareous shale with small nodule (15-cm pencil for scale). D. Petersburg West outcrop: grey calcareous shale with bedded siderite nodules of various size and shape (section $\sim 9$ feet in height). 


\section{Facies 2}

Facies 2 is medium-grey to black limestone that weathers grey to brown (Table 5). The limestone beds are frequently micritic or argillaceous and are interbedded with both black and grey calcareous shale beds (Facies $1 \& 3$ ). Limestone beds are thinly-laminated to thicklybedded and exhibit tabular, lenticular (most common), or nodular geometry (Fig. 15). The nodular geometry is produced by soft sediment compaction between beds of shale. The fossil assemblage - consisting of crinoids, brachiopods, rugose corals, tabulate corals, bivalves, styliolinids, gastropods, and bactritid and goniatite cephalopods - exhibits a moderate to moderately-low diversity although the density can be high. The limestone frequently contains trace fossils (burrow, tracks and trails).

Table 5. Sedimentary Characteristics of Facies 2, Limestone.

\section{Color fresh $\quad$ Medium to dark grey, very dark grey, black}

Color weathered Light grey, grey, brown, red staining

Bedding thickness Very thinly to medium bedded, very thinly to thinly bedded, medium to thickly bedded, thinly laminated to thinly bedded

Bed geometry

Bedding surfaces

Nodules

Body fossils

\section{Beds thin or pinch out, lenticular, nodular or continuous beds}

Irregular, bumpy

\section{Calcareous concretions}

Crinoids, brachiopods, rugose and tabulate corals, bivalves, styliolinids, gastropods, bactritid and goniatite cephalopods 
A.
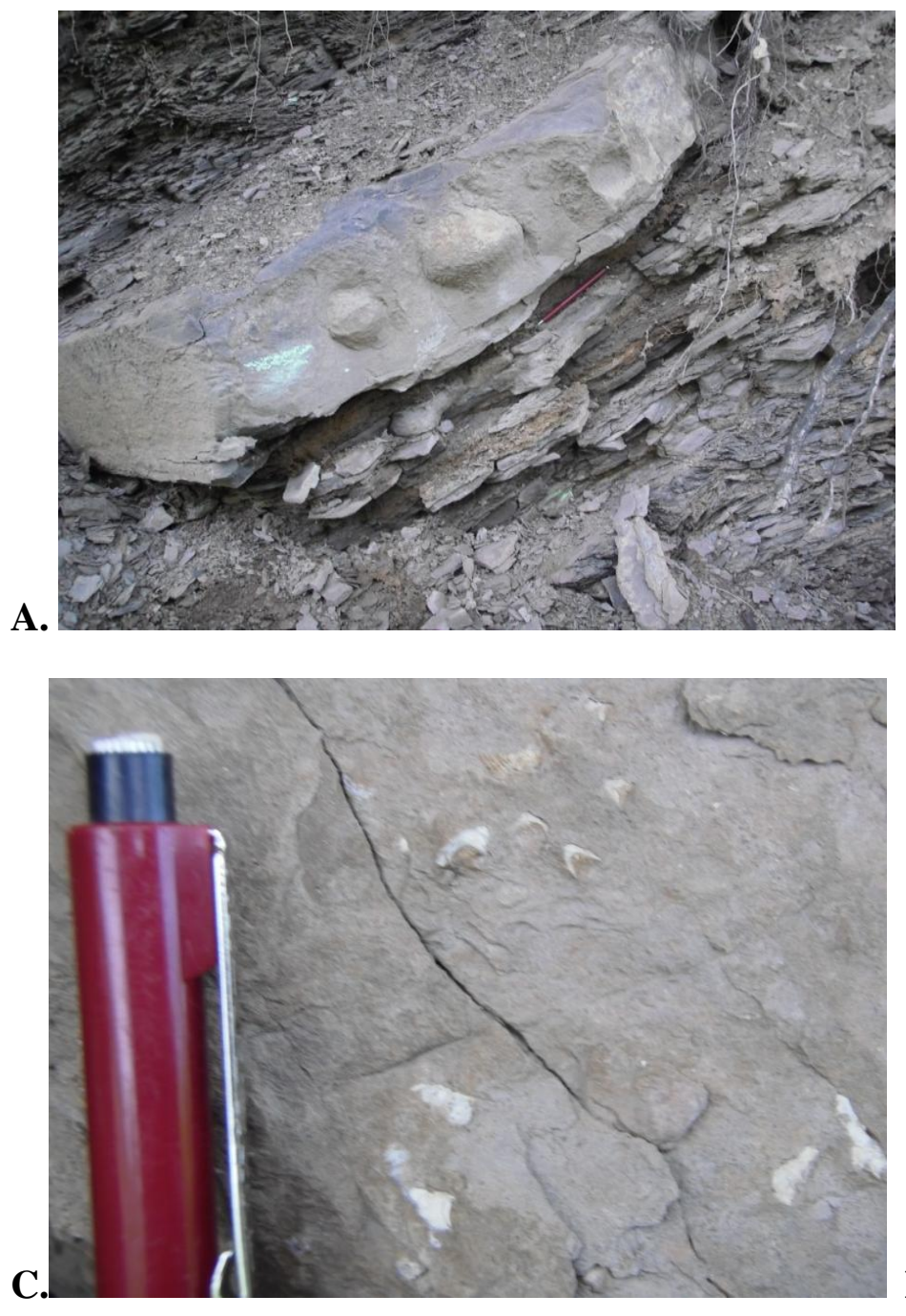
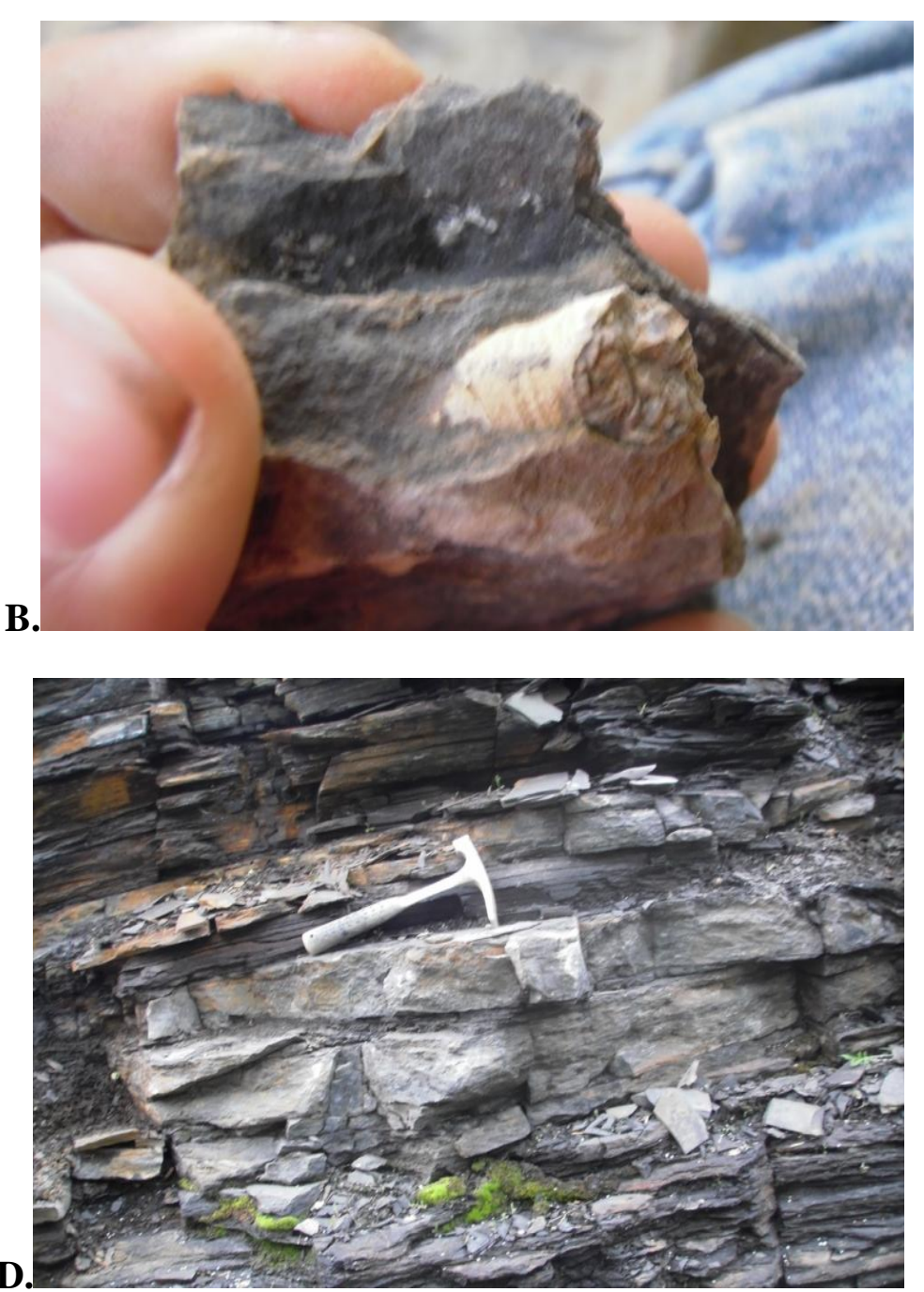

Figure 15. Outcrop photographs of Facies 2, limestone. A. Burlington outcrop: limestone bed ( $1 \mathrm{ft}$.) containing large calcareous concretions. B. Burlington outcrop: rugose coral. C. Burlington outcrop: brachiopod and crinoids stem debris on limestone bed (pencil for scale). D. Bedford outcrop: lenticular limestone beds (28-cm. hammer for scale). 


\section{Facies 3}

Facies 3 is black to dark-grey calcareous shale and is frequently interbedded with Facies 2 (Table 6). XRD and TGA analysis established a range of 6.0-17.3\% calcite and an average of $7.3 \%$ TOC. The quartz and clay content in Facies 3 is roughly $10 \%$ less than spatiallyequivalent rocks of Facies 5. Shale partings are commonly papery to fissile and platy. Partings are wavy and discontinuous; however, parting surfaces are commonly smooth and regular unless bioturbation is present (Fig. 16). Fossil debris of brachiopods and crinoids, surface traces, shallow burrows, and terrestrial plant debris are present, but rare. Siderite, calcite, and pyrite nodules do occur, but are rare. The rocks texture varies from a medium to fine-grained mudstone (Table 6).

\begin{tabular}{cl}
\hline Table 6. Sedimentary Characteristics of Facies 3, Black Calcareous Shale. \\
\hline Color fresh & Black to dark grey \\
\hline Color weathered & Orange, white, red, yellow \\
\hline Grain size & Clay to silt \\
\hline Parting thickness & Papery to fissile, platy \\
\hline Parting surface & Regular, irregularities associated with fossil debris \\
Nodules & Siderite, calcite and pyrite \\
Body fossils & Fossil debris, terrestrial plant debris \\
\hline Trace fossils & Surface traces, shallow burrows \\
\hline Color when powdered & Light to dark \\
\hline
\end{tabular}



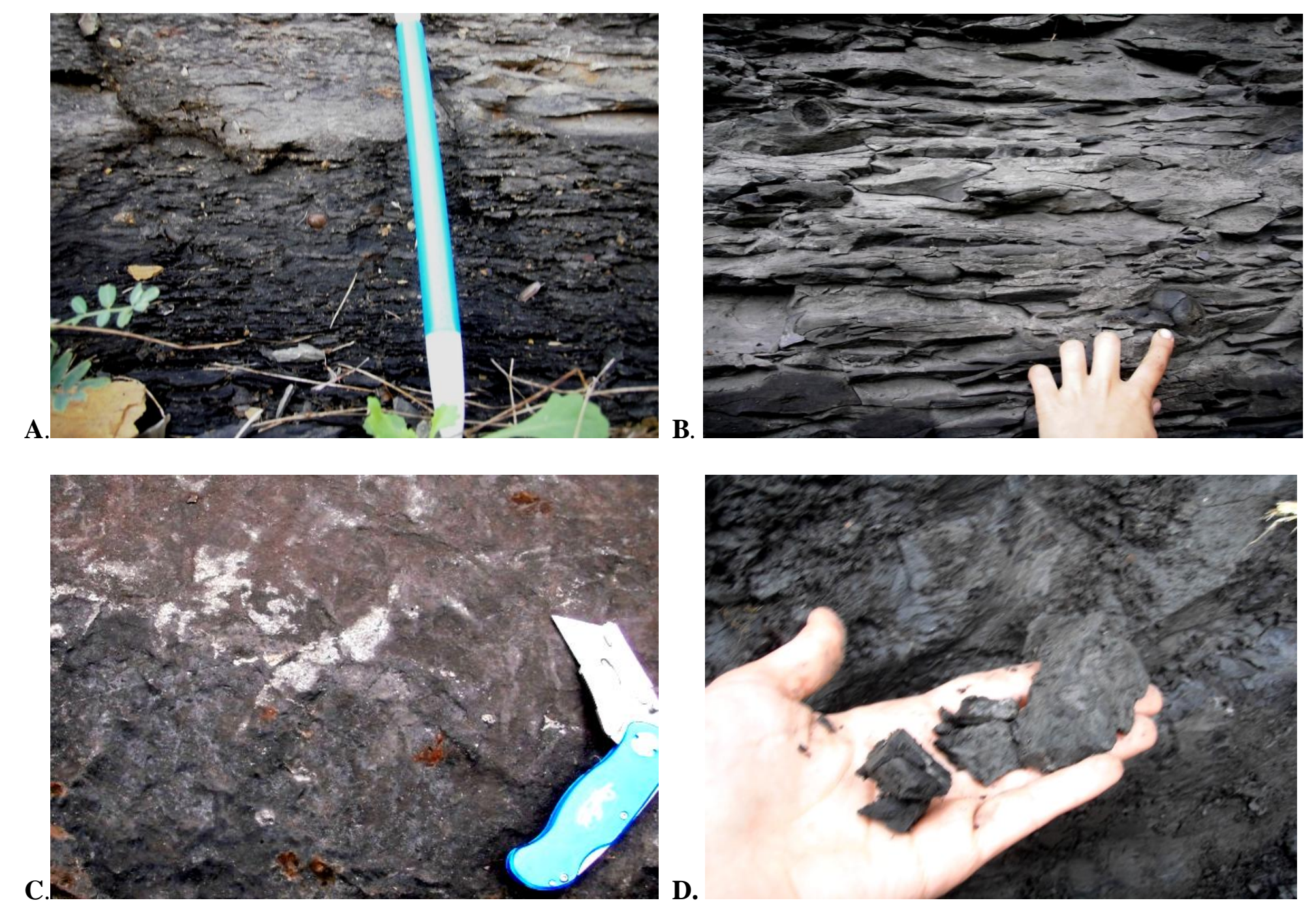

Figure 16. Outcrop photographs of Facies 3, black calcareous shale. A. Oakflat outcrop: calcareous black papery shale with small round siderite nodules (15-cm pencil for scale). B. Petersburg North outcrop: black calcareous shale with round calcareous nodules. C. Bedford outcrop: unoriented shallow burrows on bedding plane (12-cm knife for scale). D. Petersburg North outcrop: platy black calcareous shale with discontinuous partings. 


\section{Facies 4}

Facies 4 is black to dark-grey, occasionally chocolate-brown non-calcareous shale (Table 7). Orange and white weathering rinds are common. TGA analysis established an average of 9.6\% TOC for this facies. Similar to Facies 3, shale partings are typically papery to fissile and occasionally platy. In Facies 4, however, partings are most always parallel and continuous, and parting surfaces are smooth and regular (Fig. 17). Horizontal lamination is common and small pyrite lenses and laminae are present in fresh samples. The shale is typically brittle and breaks into regular sheets or fragments, though it may also weather papery or break into conchoidal fragments that lack distinctive partings. Nodules are common and diverse in size, shape and composition. These include round, oblong, and spherical nodules of pyrite, calcite, and nodules of undetermined composition. Incipient nodules with oxidation halos are also common. Rare fossils include styliolinids, goniatite ammonoids, and replaced fossil debris. Woodward (1943) identified the following genera in black shale of the Marcellus in West Virginia: Styliolina (zooplankton of uncertain affinity), Bactrites (cephalopod), Buchiola (bivalve), and the brachiopods Ambocoelia, Leiorhyncus, Lingula, Petrocrania, and Strophalosia. The texture of the rock is a claystone (Table 7). The shale is often extremely structurally-deformed: faulted, drag-folded, and slickensided. 
Table 7. Sedimentary Characteristics of Facies 4, Black Non-calcareous Shale.

Color fresh $\quad$ Black, black to dark grey, brown.

Color weathered $\quad$ Orange, white, yellow, maroon to red, brown to tan

Grain size Clay

Parting thickness Papery to fissile, platy, or destroyed by deformation

Parting geometry Continuous, parallel, discontinuous, chonchodial, soft and flaky

Parting surface $\quad$ Regular, flat, smooth, slightly irregular, wavy, ridges

Nodules Incipient, pyrite, calcite nodules, and concretions

Body fossils Styliolinids, goniatite ammonoids, rare replaced and undetermined fossil debris

Color when powdered Dark brown, medium brown, black

Luster of streak Waxy, very waxy, intermediate 

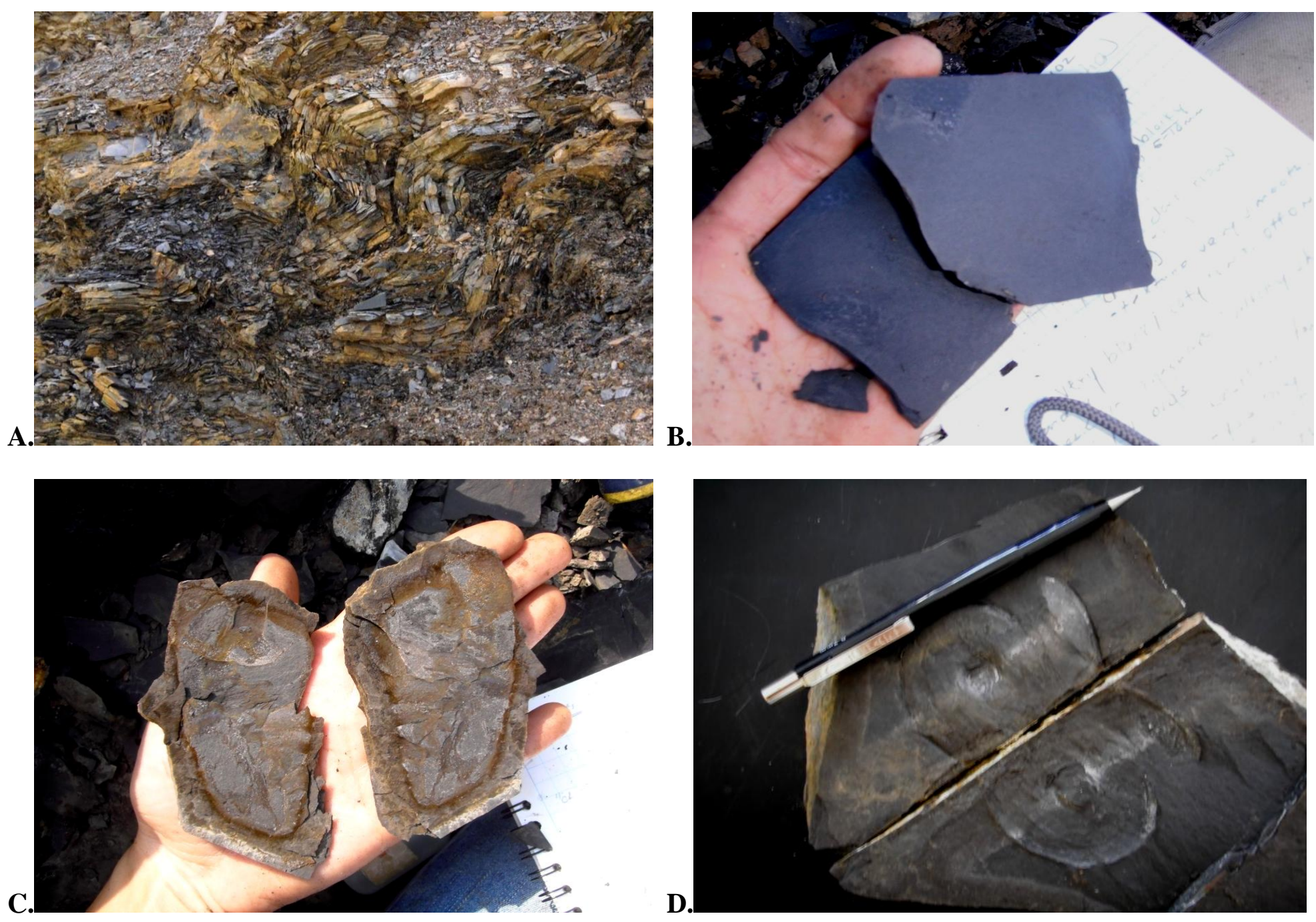

Figure 17. Outcrop photographs of Facies 4, black non-calcareous shale. A. Oakflat outcrop: highly deformed black shale with red and orange weathering (section 6-8 feet). B. Petersburg North outcrop: sooty, black, fissile shale with parallel continuous parting and regular parting surface. C. Tyrone outcrop: incipient nodule with red to orange weathering halo. D. Tyrone outcrop: goniatite ammonoid imprint in pyritic black shale (15-cm pencil for scale). 


\section{Facies 5}

Facies 5 is a dark to light-grey non-calcareous shale that weathers orange to red (Table 8). TGA analysis determined an average of $4.7 \%$ TOC for this facies. This shale is often silty and has platy and occasionally flaggy partings (Fig. 2). Parting geometry is typically discontinuous and parting surfaces are commonly irregular, bumpy, or wavy. Nodules are common and frequently aligned along bedding planes. Nodule composition includes siderite, calcite, pyrite, and undetermined minerals. Bioturbation is present, but rare. Body fossils are rare and include cephalopods and locally abundant brachiopods with low diversity. The rock's texture is a silty mudstone or siltstone (Table 8).

\begin{tabular}{|c|c|}
\hline Color fresh & Dark grey, medium grey, light grey \\
\hline Color weathered & Orange, red to maroon, white, tan to grey \\
\hline Grain size & Clay to silt \\
\hline Parting thickness & Platy $(1-5 \mathrm{~mm})$, platy to flaggy $(1-10 \mathrm{~mm})$, no distinctive partings \\
\hline Parting geometry & Discontinuous \\
\hline Parting surface & Slightly irregular, irregular, wavy, bumpy \\
\hline Nodules & $\begin{array}{l}\text { Siderite, calcite, pyrite and large calcareous concretions (often } \\
\text { concentrated along bedding planes) }\end{array}$ \\
\hline Body fossils & Small brachiopods, cephalopods, shell fragments \\
\hline Trace fossils & Bioturbation \\
\hline Color when powdered & Light, tan to brown \\
\hline Luster of streak & Dull, occasionally intermediate \\
\hline
\end{tabular}



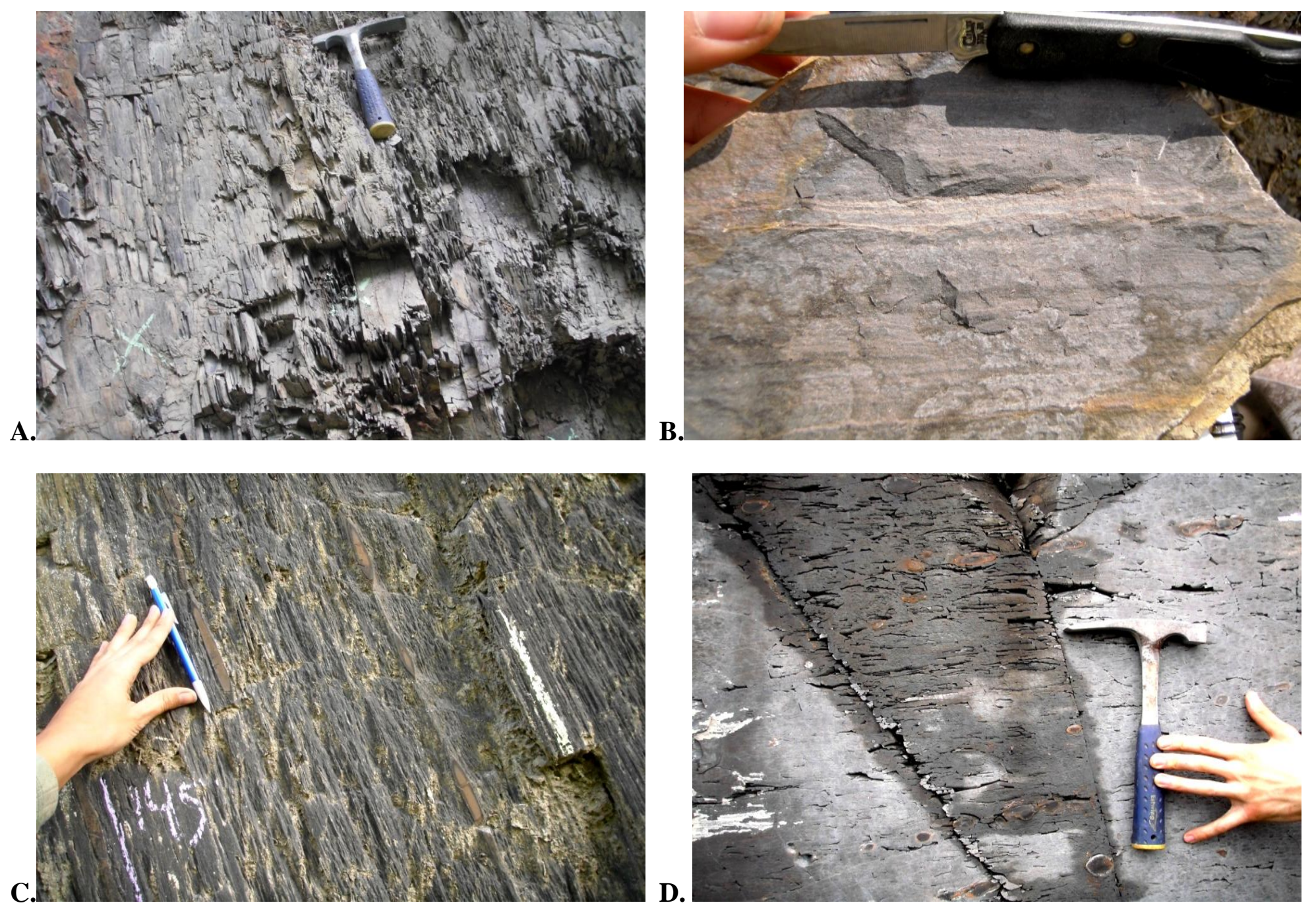

Figure 18. Outcrop photographs of Facies 5, grey non-calcareous shale. A. Greenspring outcrop: platy to flaggy grey shale (28-cm hammer for scale). B. Berkeley Springs outcrop: silty grey shale with wavy silt laminae (8-cm. knife for scale). C. Berkeley Springs outcrop: grey shale with flattened siderite nodules along bedding surface (15-cm pencil for scale). D. Petersburg West outcrop: grey shale that lacks distinctive partings and contains round siderite nodules (28-cm hammer for scale). 


\section{Facies 6}

Facies 6 is a $\mathrm{K}$ - bentonite (Table 9), an altered volcanic ash that is designated the Tioga Bentonite (Dennison and Textoris, 1970; Ver Straeten, 2007). These bentonites are tan to grey and typically weather to tan clay. Sand-sized mica flakes are common. Bentonite beds range from 3-15 cm in thickness and can be graded or reworked by burrowers. Outcrops in our study area contain between one and three K-bentonite beds over a stratigraphic interval of 2-5 meters at the base of the Marcellus.

Table 9. Sedimentary Characteristics of Facies 6, K-bentonite.

\begin{tabular}{cl}
\hline Color fresh & Tan, brown, light brown, light to dark grey \\
Color weathered & Tan, brown, and grey clay \\
Grain size & Clay to coarse sand \\
Visible Minerals & Mica, pyrite \\
Bed thickness & Very thin to medium bedded $(2.5-16 \mathrm{~cm})$ \\
\hline Sedimentary structures & Graded bedding, biogenically reworked \\
\hline
\end{tabular}



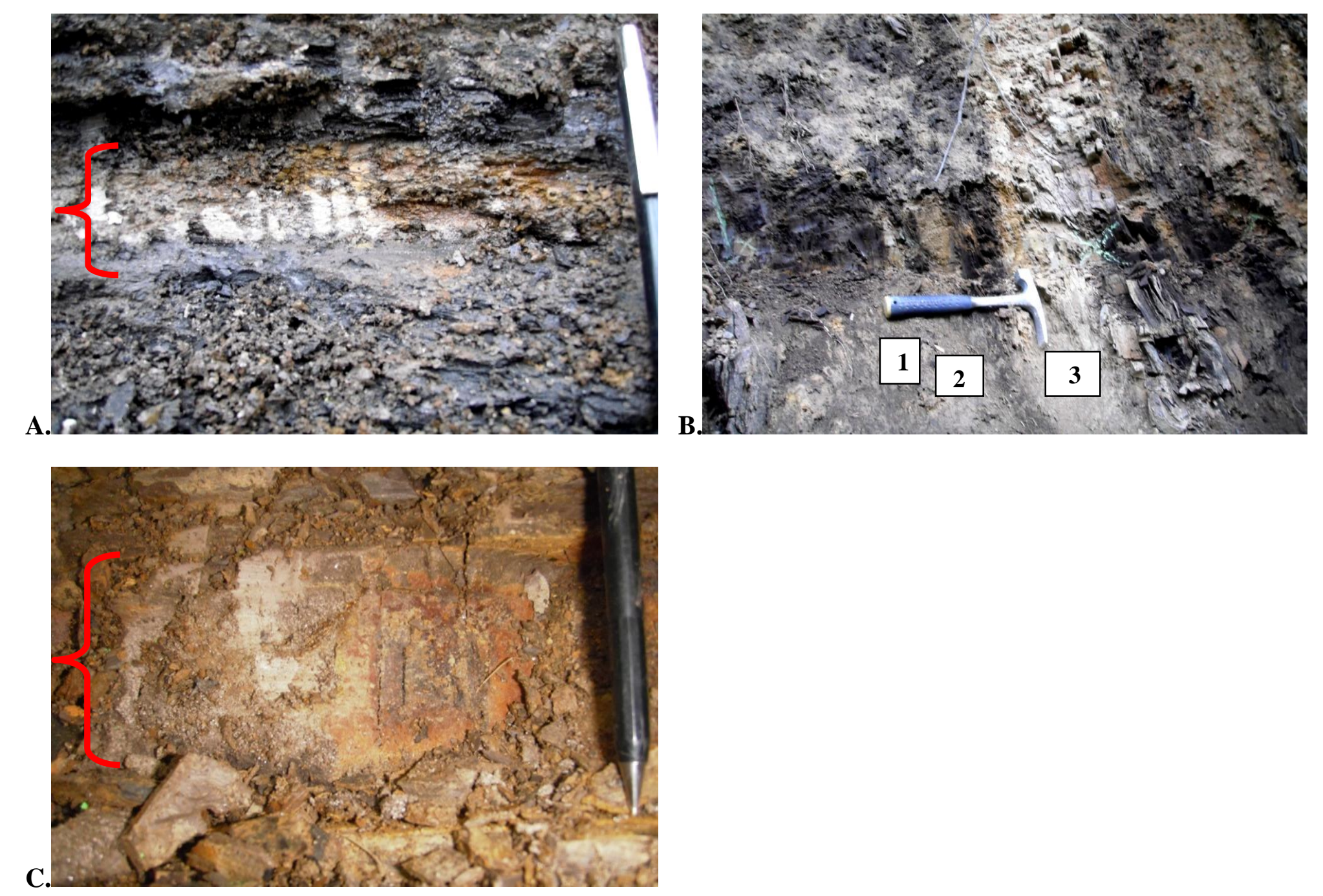

Figure 19. Outcrop photographs of Facies 6, Tioga K-bentonite. A. Bedford outcrop: grey to tan micaceous bentonite ( 2 inches). B. Whip gap outcrop: three vertical bentonite beds ranging from 1-6 inches interbedded with black papery shale. C. Tomahawk outcrop: brown to tan graded micaceous bentonite. 


\section{Facies Interpretations}

Facies 1 through 6 were deposited below wave base in a partially-enclosed epicontinental sea adjacent to the Appalachian highlands to the east. The epicontinental sea was relatively shallow and sediment input, water chemistry, and stratification were dynamic rather than stagnant. Sea level fluctuations, clastic influx, and shifts in the location of the thermocline resulted in the deposition of a number of facies including both calcareous and non-calcareous argillaceous mudstone, organic-rich facies, and limestone (Figs. 20; 21).

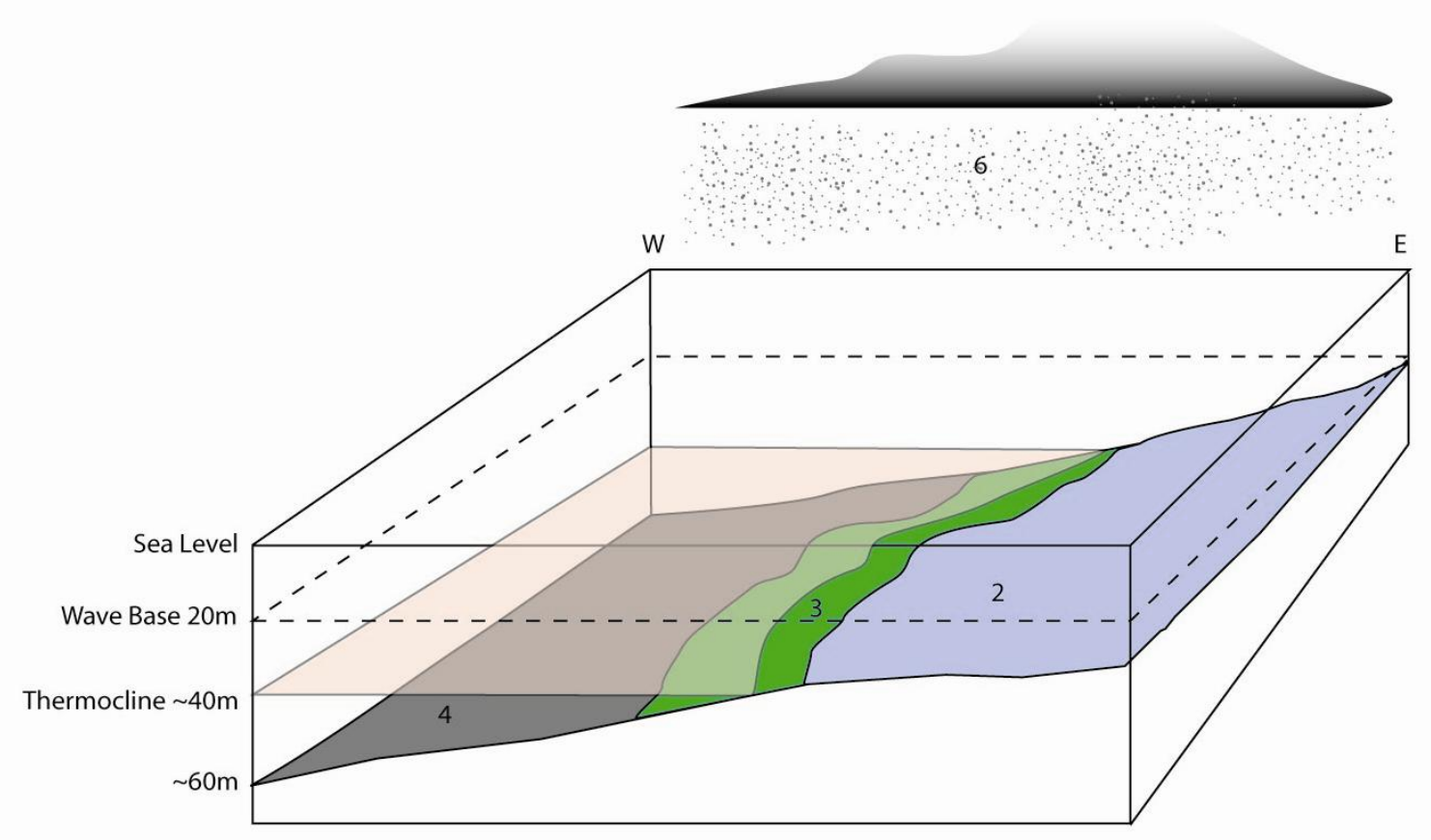

Figure 20. Generalized Marcellus Shale facies model depicting periods of low clastic sediment influx. The model includes Facies 2 (limestone), Facies 3 (black calcareous shale), Facies 4 (black non-calcareous shale) and Facies 6 (Tioga K-bentonite). 


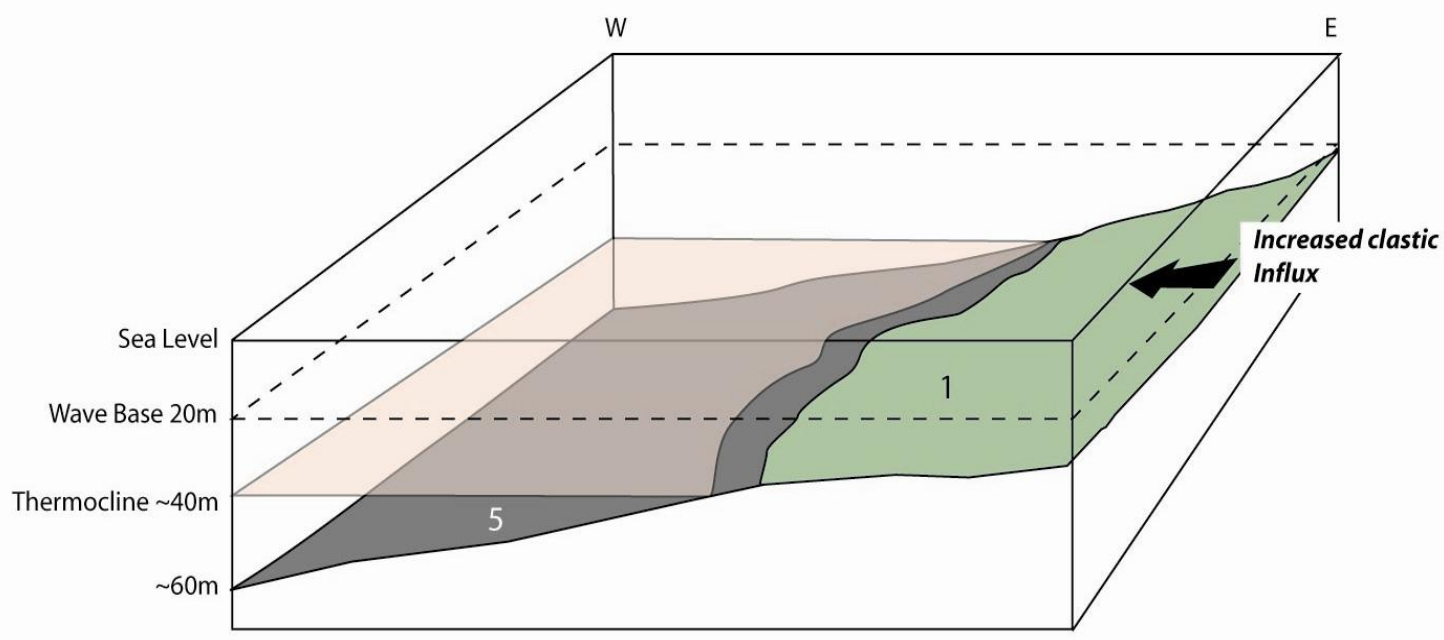

Figure 21. Generalized Marcellus Shale facies model depicting periods of increased clastic influx. The model includes the more proximal Facies 1 (grey calcareous shale) and more distal Facies 5 (grey non- calcareous shale).

The grey calcareous shale (Facies 1) was deposited on a low-energy ramp in relatively shallow water above the thermocline. Clastic sediment input was moderate, and the clastics mixed with biogenic lime sediment that formed in-situ on the seafloor. The assemblage of benthonic fauna, including brachiopods, crinoids, ostracods, and gastropods, indicates that bottom waters were oxygenated and the water salinity was normal marine. Common vertical and horizontal burrows show that the sediment was also oxic to suboxic.

The limestone (Facies 2) was deposited on a low-energy ramp during a time of low terrigenous sediment input. The presence of rugose and tabulate corals indicates that the limestone was deposited in relatively shallow water within the photic zone. The water salinity must have been normal marine throughout the water column to support the diverse faunal assemblage of corals, crinoids, brachiopods, bivalves, gastropods, and cephalopods as well as vertical and horizontal burrowers. Many limestone beds are lenticular and pinch out laterally into 
calcareous shale of Facies 1 and 3. This distribution suggests that the lime sediment mostly accumulated as pods on an otherwise muddy (shaley) seafloor.

The black calcareous shale (Facies 3) was deposited on the relatively shallow ramp near the depth of the thermocline ( 40 meters). The shallow, restricted nature of the epicontinental sea, high temperatures associated with the Devonian greenhouse climate, and overall low freshwater input likely resulted in a dynamic thermocline rather than a permanent halocline or pycnocline (Tyson and Pearson, 1991). The calcite in Facies 3 may have been formed in-situ or sourced from the adjacent lime mud environment. This black calcareous shale is typically interbedded with or grades laterally into Facies 2; therefore, it probably formed in an adjoining environment on the shallow ramp, although water was slightly deeper. Facies 3 was deposited typically below the thermocline, allowing for better preservation of accumulated organic matter.

The content of terrigenous sediment in Facies 3 indicates that clastic input from the eastern highlands was reduced. Diminished clastic sediment input allowed for organic matter to accumulate below the thermocline with minimal dilution. Although terrigenous clastic input was relatively low, concentrations of quartz in Facies 3 ranges from 37 to 44 percent. This quartz content may be a result of eolian or diagenetic processes (Schieber et al., 2000; Werne et al., 2002; Sageman et al., 2003). The thermocline persisted during the deposition of Facies 3; however, large storms and seasonal mixing occasionally disrupted the thermocline and allowed oxygen to temporarily mix in the water column. During these times, some benthic organisms and burrowers could survive.

Black non-calcareous shale (Facies 4) was deposited during a time of regional sea level rise. Facies 4 sediments accumulated below the thermocline where the bottom water and 
sediment were anoxic. Sea level rise caused flooding of the eastern landmass and subsequent storage of clastic sediment landward, resulting in the low clay content found in Facies 4. Low clastic sediment input allowed for the deposition of organic matter without dilution. This relationship is illustrated by the graph of clay content vs. total organic carbon derived from the XRD and TGA analyses (Fig. 22). Although terrigenous sediment input was low, Facies 4 has a significant amount of quartz (43-75\%) as illustrated by Fig. 23. Much of this quartz may have been sourced from wind-blown eolian silt (Werne et al., 2002; Sageman et al., 2003) or diagenetic processes (Schieber et al., 2000). Wind-blown nutrients may have been brought into the basin, creating algal blooms that resulted in a high accumulation of organic matter (Sageman et al., 2003; Wrightstone, 2010). In addition to lower terrigenous sediment input, increased primary productivity in the water column may have played a role in the increased total organic carbon in Facies 4 (Pederson and Calvert, 1990).

Although bottom waters were persistently anoxic, surface waters were oxic, which allowed for planktonic and nektonic organisms, such as styliolinids and goniatite ammonoids, to survive. Burrows and bioturbation are absent and bedding planes are smooth and continuous, indicating a depositional environment where infaunal organisms could not survive. 


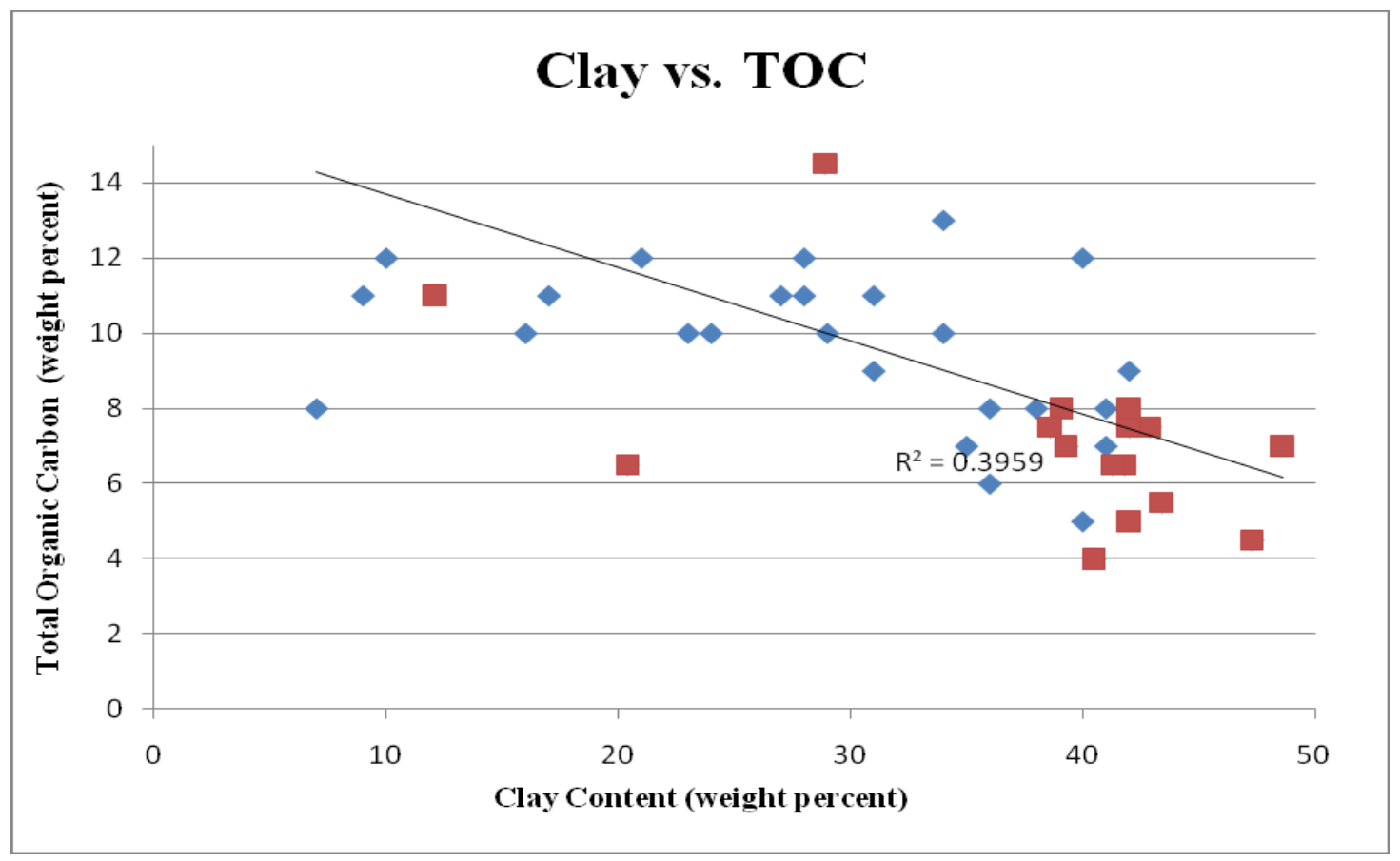

Figure 22. TGA total organic carbon analysis plotted against clay content from XRD analysis. This graph shows the outcrop data in red and subsurface data (Boyce, 2010) in blue.

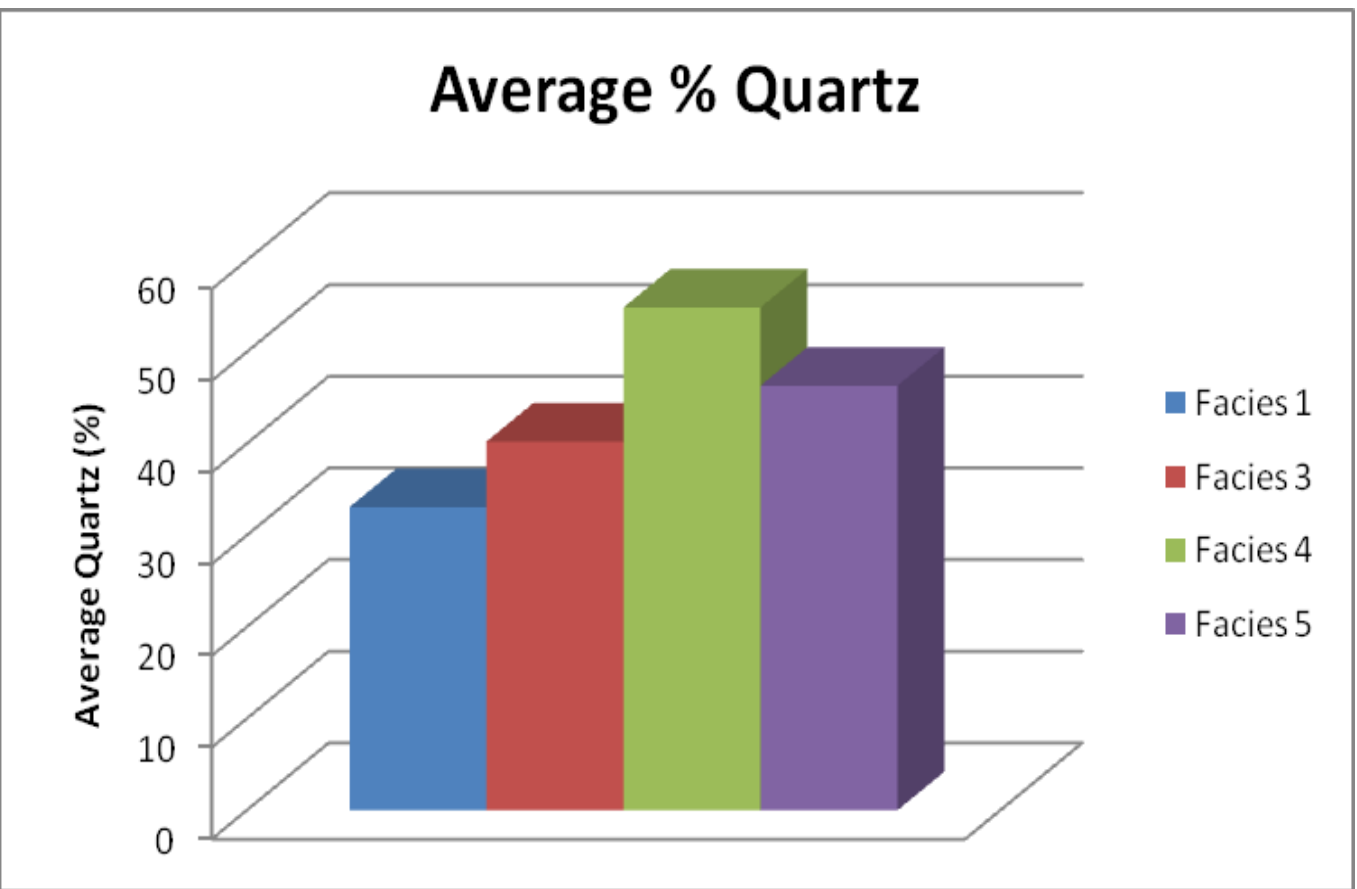

Figure 23. Graph illustrating the average quartz percentages for Facies 1, 3, 4 and 5. 
Grey non-calcareous shale (Facies 5) was deposited during times of increased terrigenous clastic input. Silt-sized quartz and mica are common. During increased sediment input, Facies 5 was deposited in place of Facies 3 and 4 both above and below the thermocline. However, the overall lack of bioturbation and low abundance of fauna indicates that Facies 5 was typically deposited below the thermocline. During times of seasonal mixing, burrowers and small brachiopods temporarily inhabited the sea floor.

Volcanic eruptions during the Early to Middle Devonian deposited Facies 6, Tioga Kbentonite, across the basin. In my study, as many as three K-bentonites are found in the Marcellus section enclosed in black shale (Facies 4) as well as black calcareous shale (Facies 3) and limestone (Facies 2). Although some bentonites may have been reworked by burrowers or seasonal storms, ashes generally settled through the water column during the deposition of black shale (Facies 4) without disruption, producing a gradded bed. The location of the source volcano is hypothesized to be in central Virginia (Dennison and Textoris, 1970; Ver Staeten, 2004). 


\section{STRATIGRAPHIC PATTERNS}

A composite graphic column (Fig. 24) was created based on correlations of 15 partial Marcellus Shale sections (Fig. 25-39) using key beds and combining the average thicknesses of the associated lithofacies. Each outcrop figure contains a vertical distribution of facies, fossil content, sedimentary features, concretions, and outcrop notes as well as a total gamma-ray curve, spectral gamma-ray curve (K, Th, U), and informal stratigraphic units. Six stratigraphic units (AF) are recognized within the Marcellus Shale.

\section{Unit A}

Unit A is the lowermost unit within the Marcellus Shale and has an average thickness of 5.5 meters. This is a transgressional unit overlying the Needmore Shale. Unit A consists of black calcareous shale of Facies 3, limestone of Facies 2, and beds of Facies 1, grey calcareous shale. Facies 6, the Tioga Bentonite, is also found within this unit. Interbedding of Facies 2 and 3 was caused by slight fluctuations of sea level, and the occasional occurrence of Facies 1 can be tied to increased sediment input during slight progradation of the shoreline. During deposition of Unit A the water increased to a depth between fair-weather wave base ( 20 meters) to near the position of the thermocline ( 40 meters) (Tyson and Pearon, 1991).

\section{Unit B}

Unit B has an average thickness of 7.0 meters. This unit consists entirely of Facies 4, non-calcareous black shale, plus several K-bentonite beds (Facies 6) and represents a continuing sea level rise from the underlying Unit A. During the deposition of Unit B water depth was on the order of 60 meters, where the bottom water was generally anoxic and near the maximum depth of seasonal mixing. Maximum effective anoxia on modern shelves occurs mostly in water 
less than 60 meters deep and the maximum depth of winter mixing in the semi-enclosed Black Sea is less than 60 meters (Tyson and Pearson, 1991; Kara et al., 2009).

\section{Unit C}

Unit C consists of grey non-calcareous shale (Facies 5) and black non-calcareous shale (Facies 4) and has an average thickness of 4.0 meters. The lower contact of Unit $\mathrm{C}$ is gradational: Facies 4 decreases while Facies 5 becomes more abundant. This change corresponds with a decrease in total gamma-ray values from Unit B up through Unit C, most notably in the concentration of uranium. These vertical changes suggest that a greater amount of detrital quartz silt and mica had entered the sea and diluted the organic material. The increased influx of clastics is tied to the progradation of the eastern shoreline into the foreland basin.

\section{Unit D}

Unit D typically contains interbedded rocks of grey calcareous shale (Facies 1) and very thin to thickly-bedded limestone (Facies 2). The average thickness of this unit is 8.0 meters, yet this unit can be as thin as 2.0 meters or as thick as 20 meters. Black calcareous shale (Facies 3 ) is also present but is minor. This unit was deposited during a time of regional sea level fall, when water depth shallowed to near wave base ( 20 meters) and only rarely exceeded the depth of the thermocline ( $\sim 40$ meters) during the deposition of Facies 3. Interbedding of Facies 1 and 2 represents fluctuations in sediment supply. The limestones of this unit are notably more argillaceous than the limestones of Unit A. This unit has a wide range of character over the study area. Some limestone and shale packages exhibit repeating coarsening-upward cycles, where calcareous shale passes vertically into thin argillaceous limestone and thicker fossiliferous limestone (Fig. 25). Other beds used for correlation of Unit D contain large calcite concretions or 
abundant brachiopods. Limestone and interbedded shale of this unit are most often fossiliferous and display a relatively diverse fossil assemblage, including well oxygenated, normal salinity, shallow-water fossils such as rugose corals and crinoids. The change from Unit D to Unit E is relatively abrupt from calcareous shales to non-calcareous black shale.

\section{Unit E}

Unit E, the upper black shale, has an average thickness of 6.4 meters. This unit is comprised of only Facies 4, non-calcareous black shale. This unit represents a relative rise in sea level to 60 meters, well below the thermocline and near the maximum depth of winter mixing of the water column. Low clay contents in Facies 4 is a result of storage of clastic sediment on the flooded eastern landmass.

\section{Unit F}

Unit $\mathrm{F}$ has an average thickness of 6.6 meters. This unit consists mostly of Facies 5, grey non-calcareous shale, and occasional interbeds of Facies 4. During deposition of this unit, progradation of the eastern shoreline produced an increase of clastics entering the basin. Interbedding between Facies 4 and 5 was likely caused by discontinuous progradation of the shoreline and intermittent supply of terrigenous silt. The contact with the overlying sandstone and silstone beds of the Mahantango Formation is sharp.

Units A and B were deposited during a regional sea level rise while Unit D was deposited during a regional fall in sea level. Unit $\mathrm{C}$ and Unit $\mathrm{F}$ were deposited during progradation of the eastern landmass which deposited clastic sediments into deeper water. After deposition of Unit F the advance of the Mahantango clastic wedge ended Marcellus shale deposition in the Appalachian Basin. 


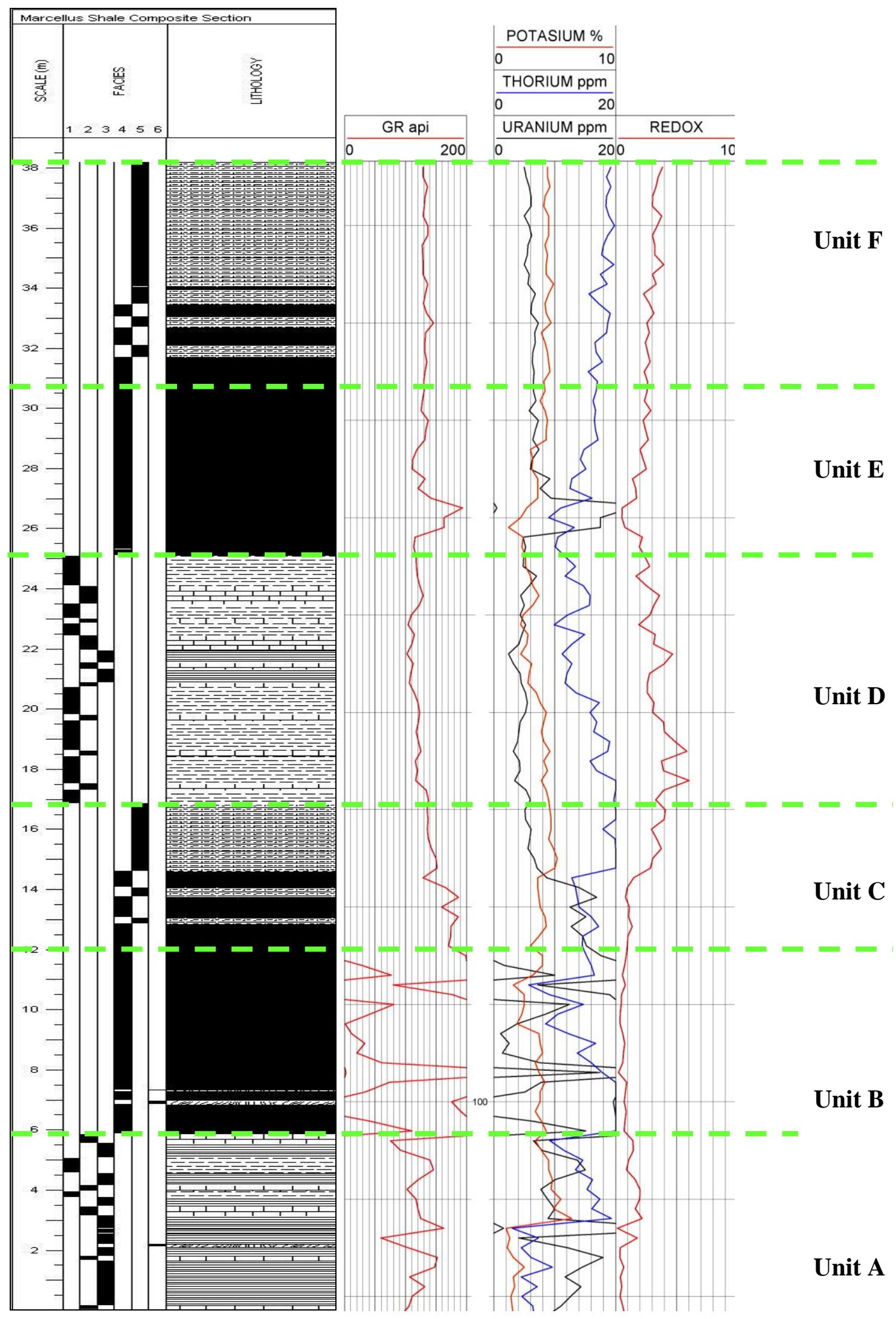

Figure 24. Composite stratigraphic column and type log for Marcellus Shale in West Virginia. 


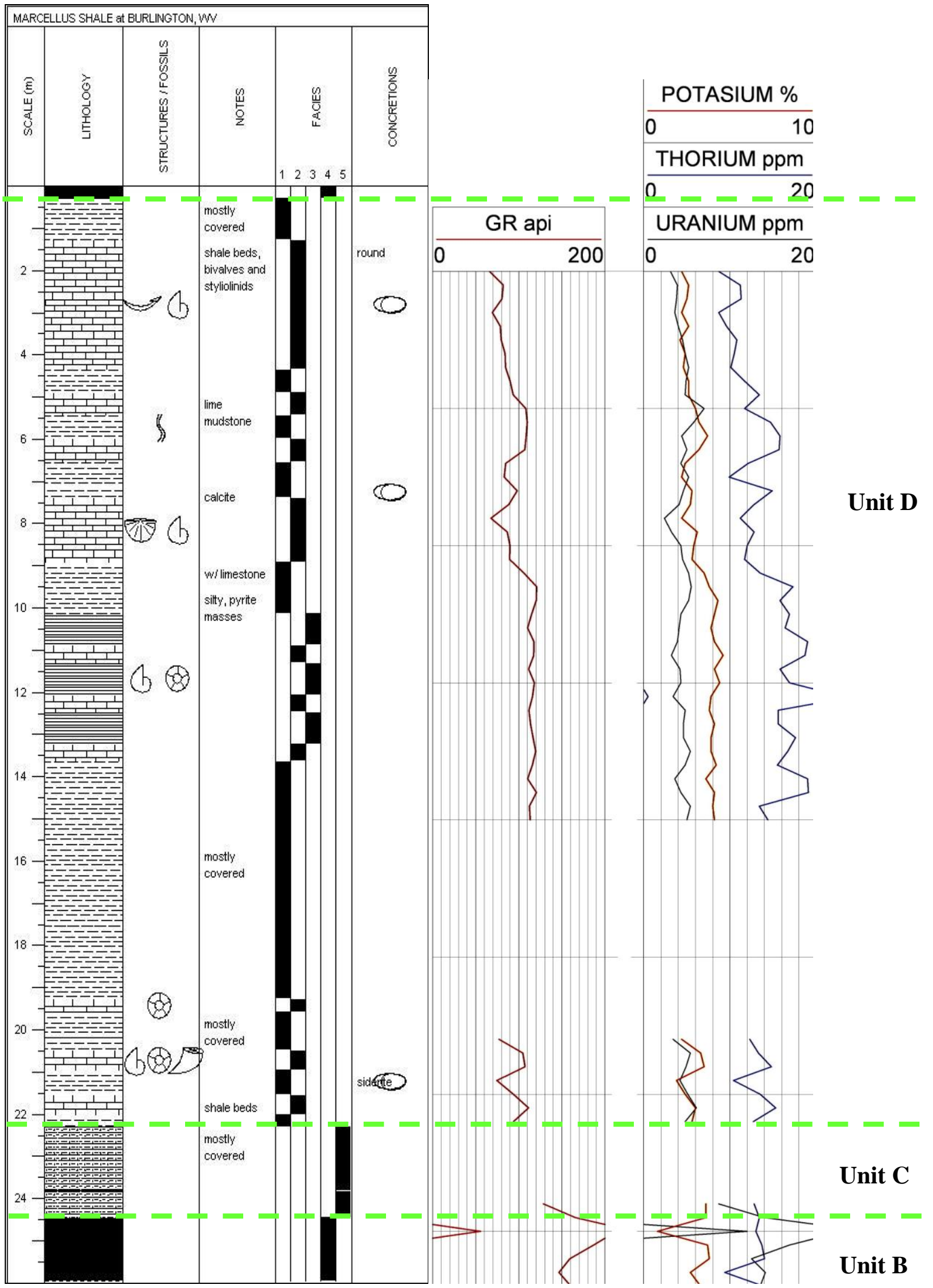

Figure 25. Burlington, WV stratigraphic column and spectral gamma-ray curve. 


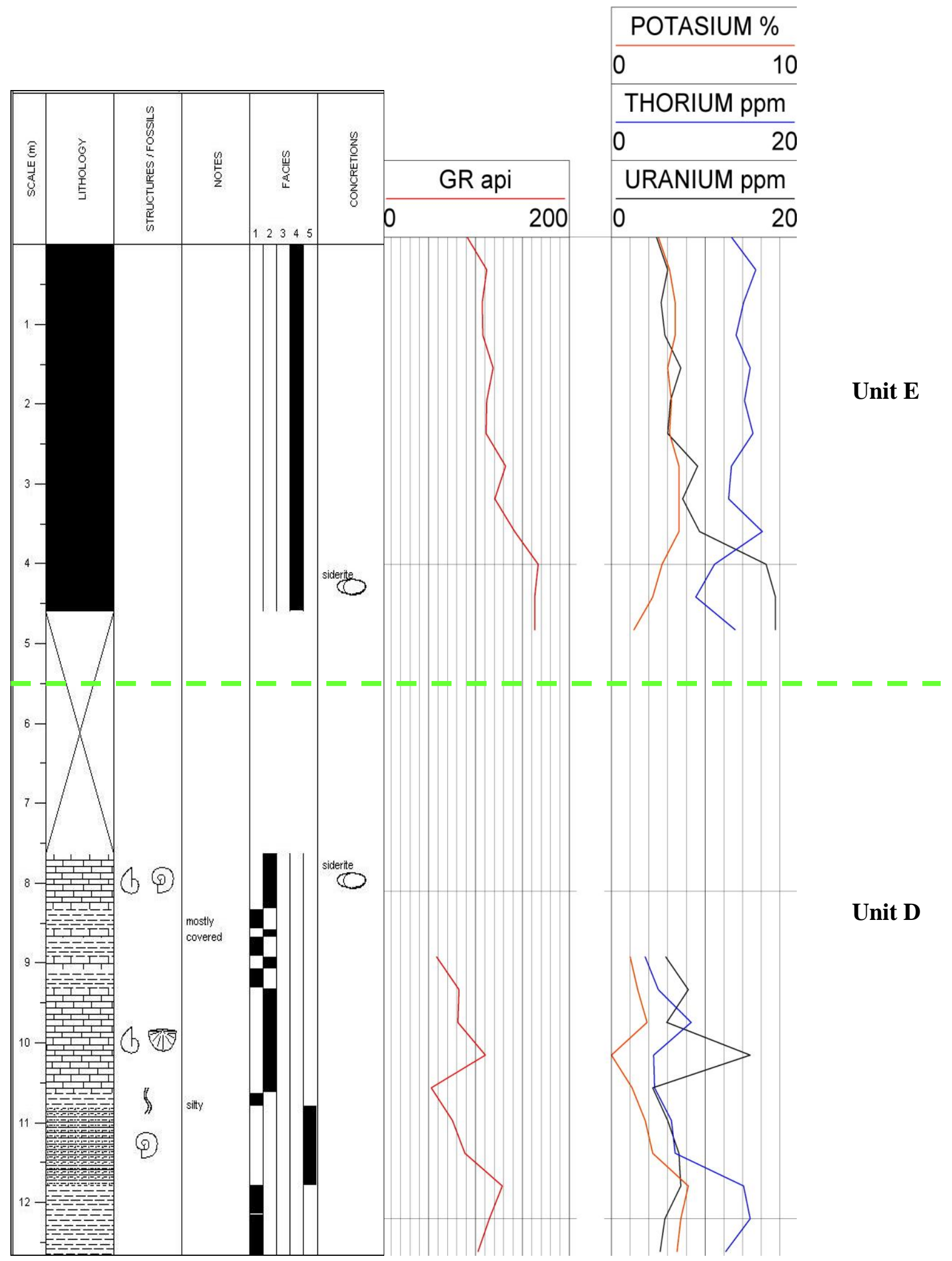

Figure 26. Springfield, WV stratigraphic column and spectral gamma-ray curve. 


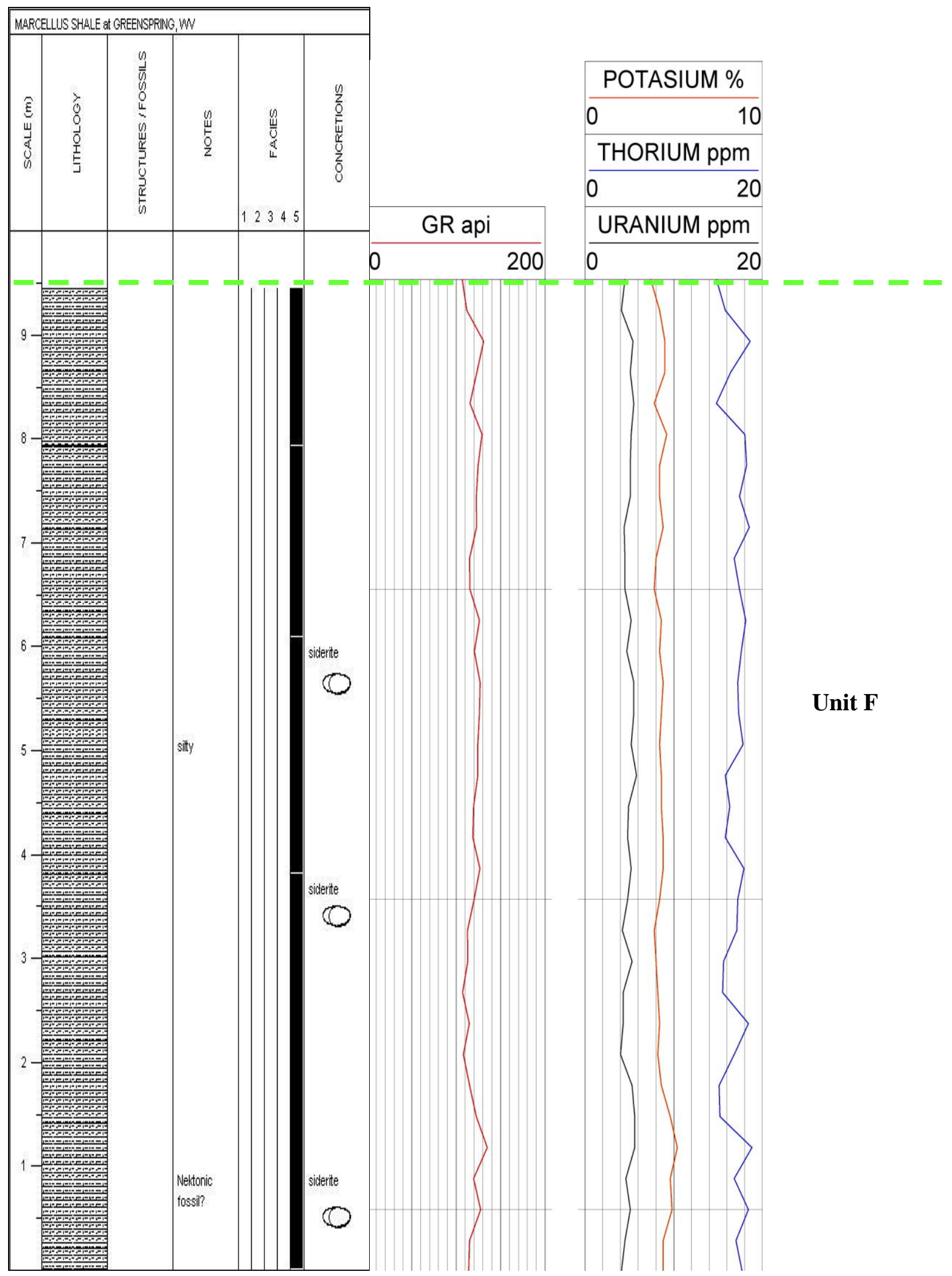

Figure 27. Greenspring, WV stratigraphic column and spectral gamma-ray curve. 


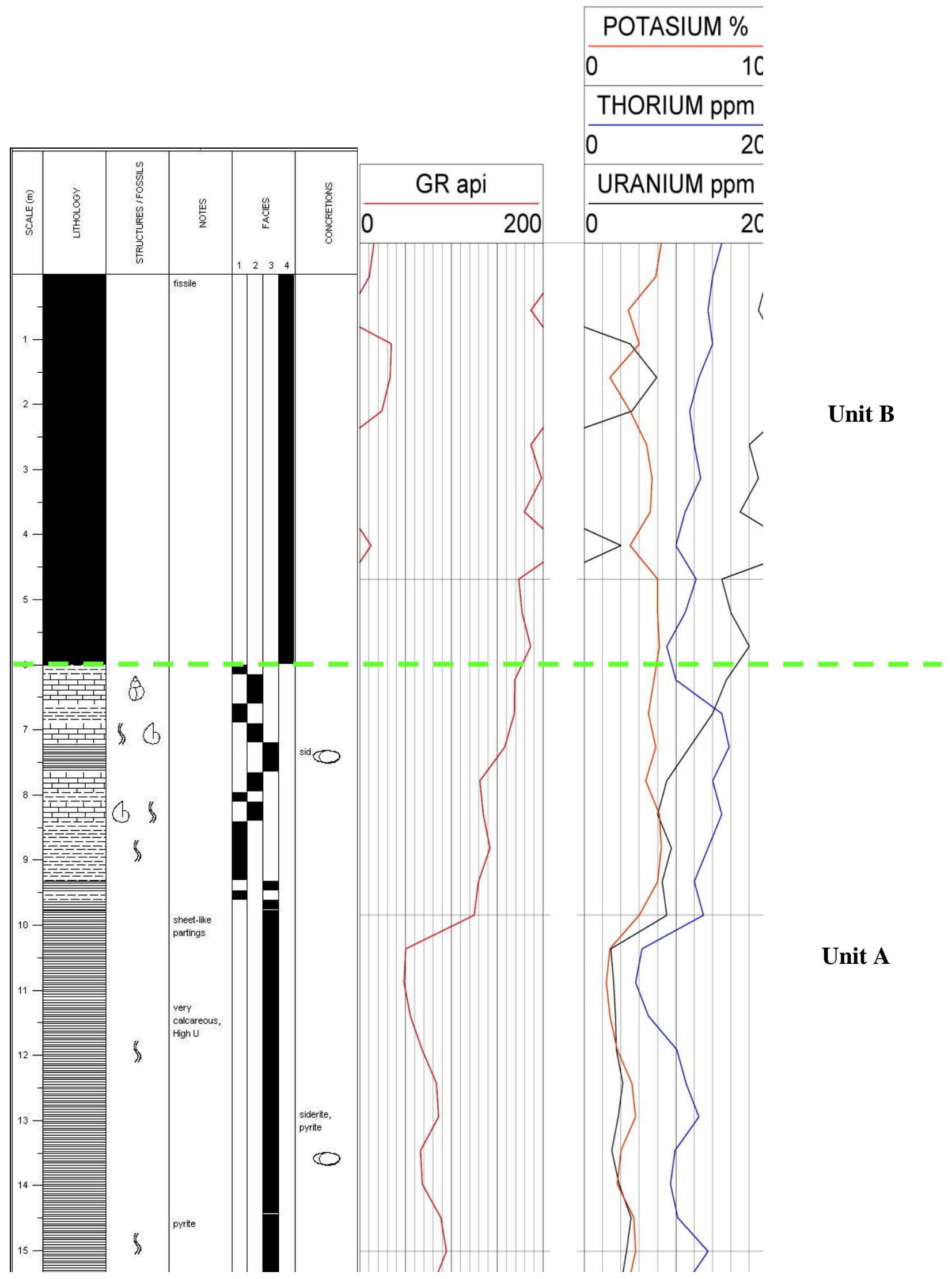

Figure 28. Petersburg North, WV stratigraphic column and spectral gamma-ray curve. 


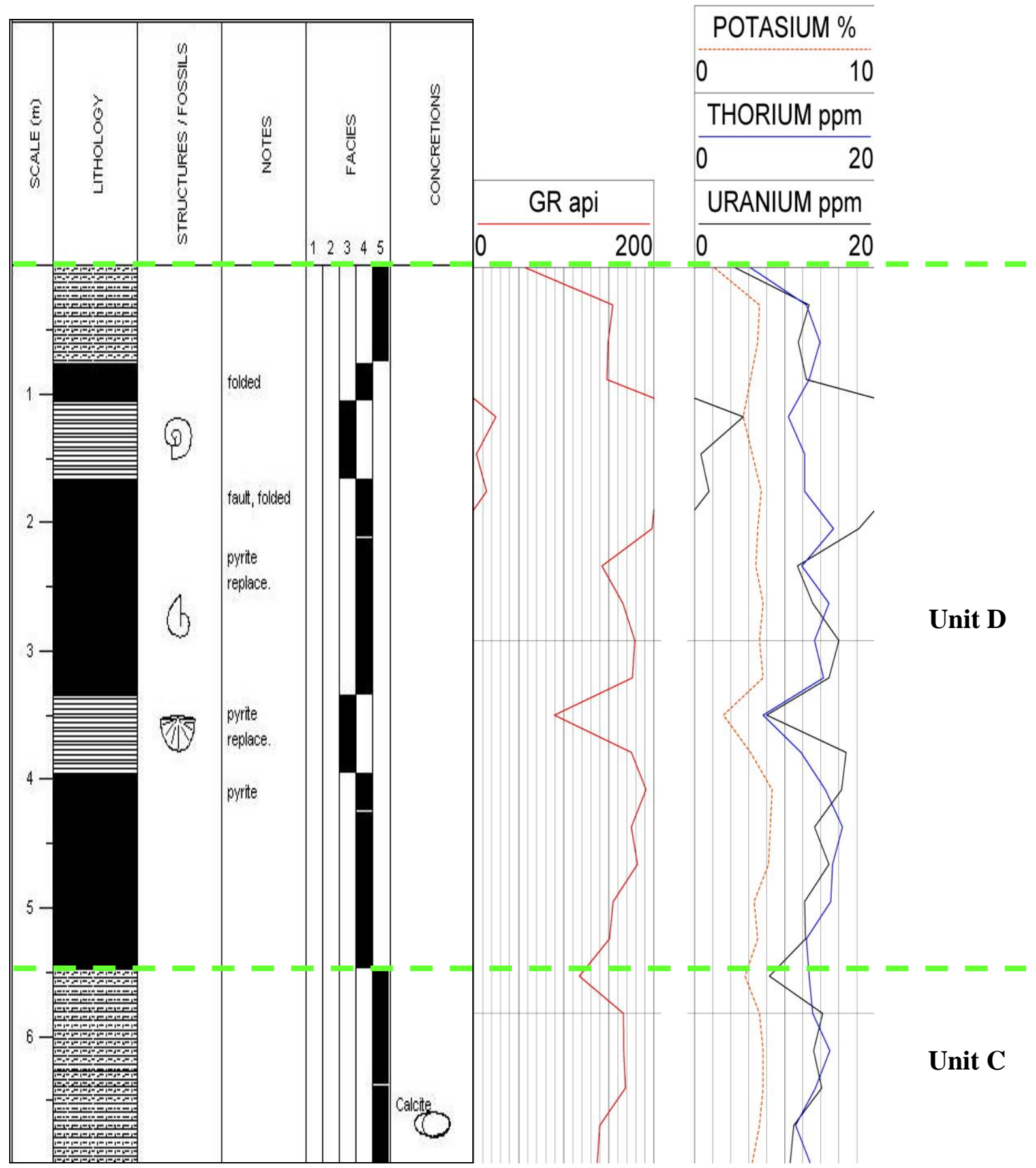

Figure 29. Tyrone, PA stratigraphic column and spectral gamma-ray curve. 


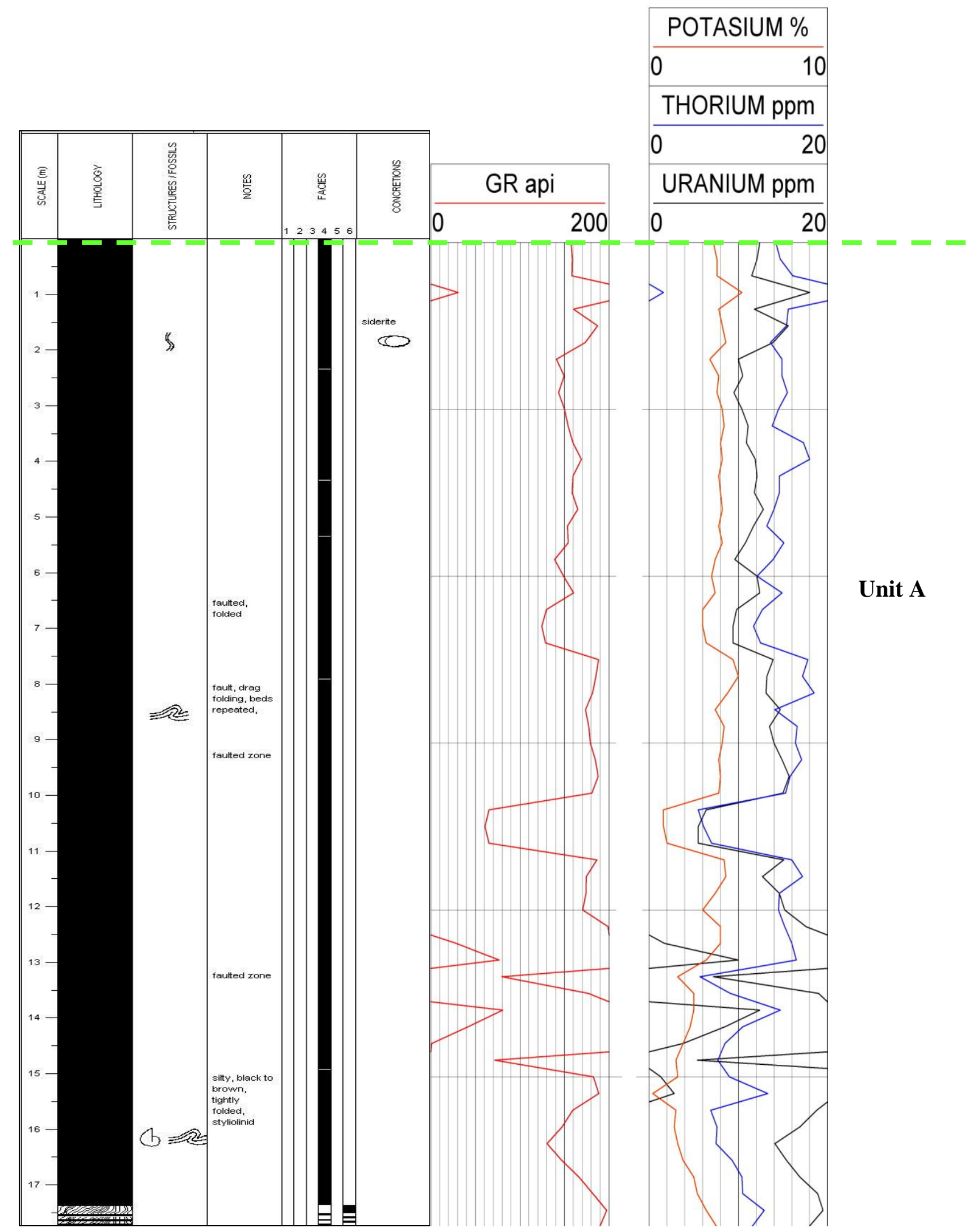

Figure 30. Whip Gap, WV stratigraphic column and spectral gamma-ray curve. 


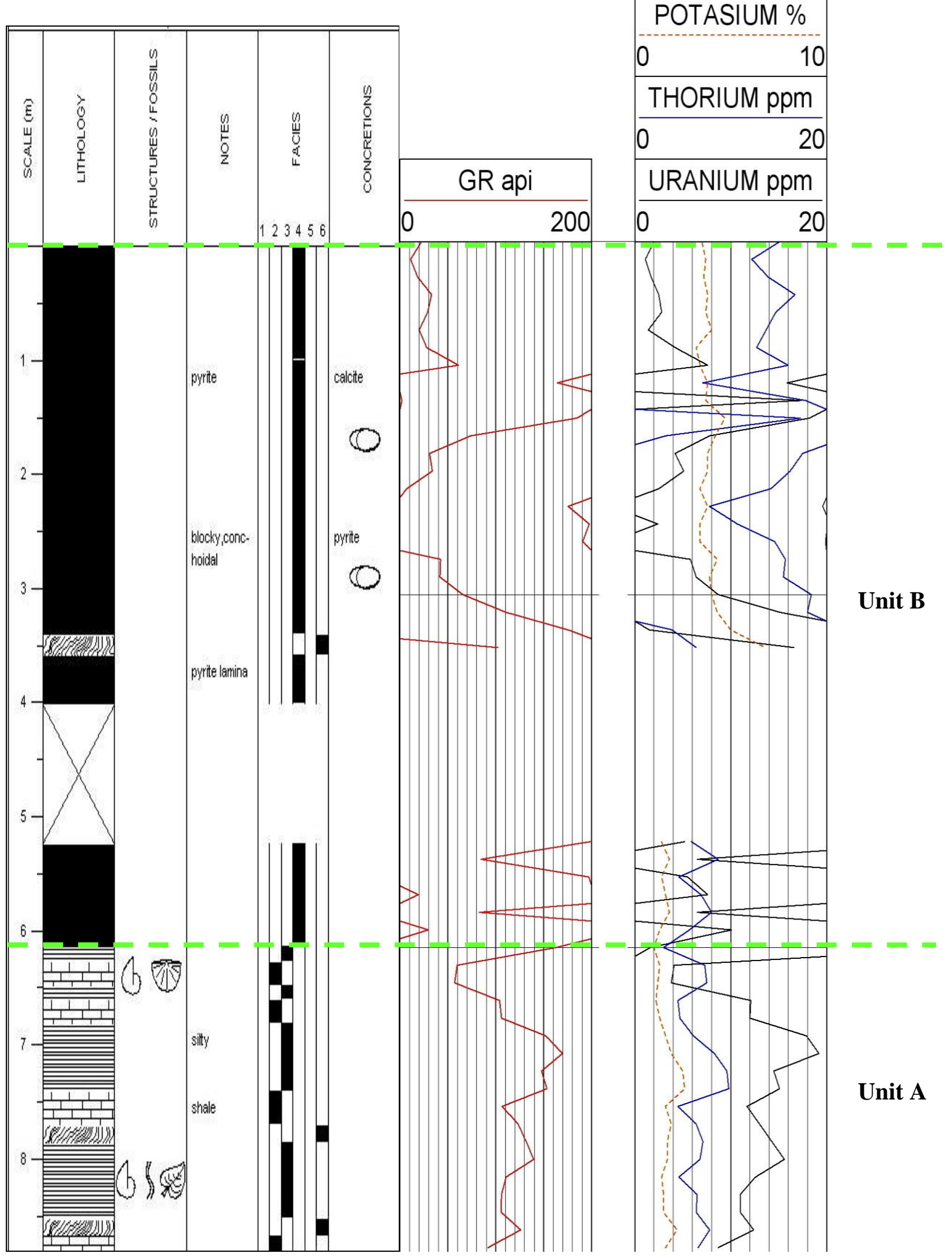

Figure 31. Bedford, PA stratigraphic column and spectral gamma-ray curve. 


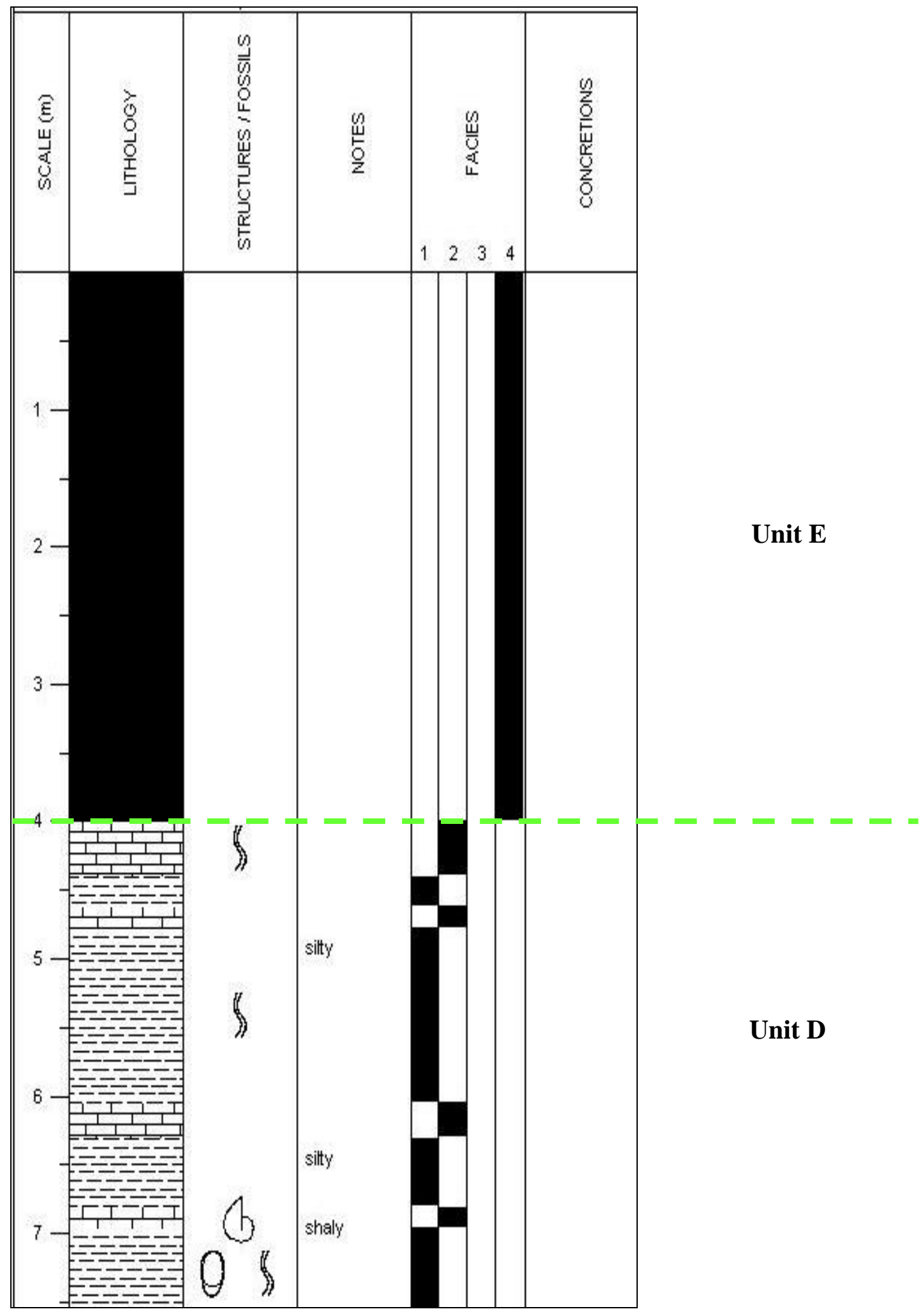

Figure 32. Hiser, WV stratigraphic column. Spectral gamma-ray was not used at this location, 


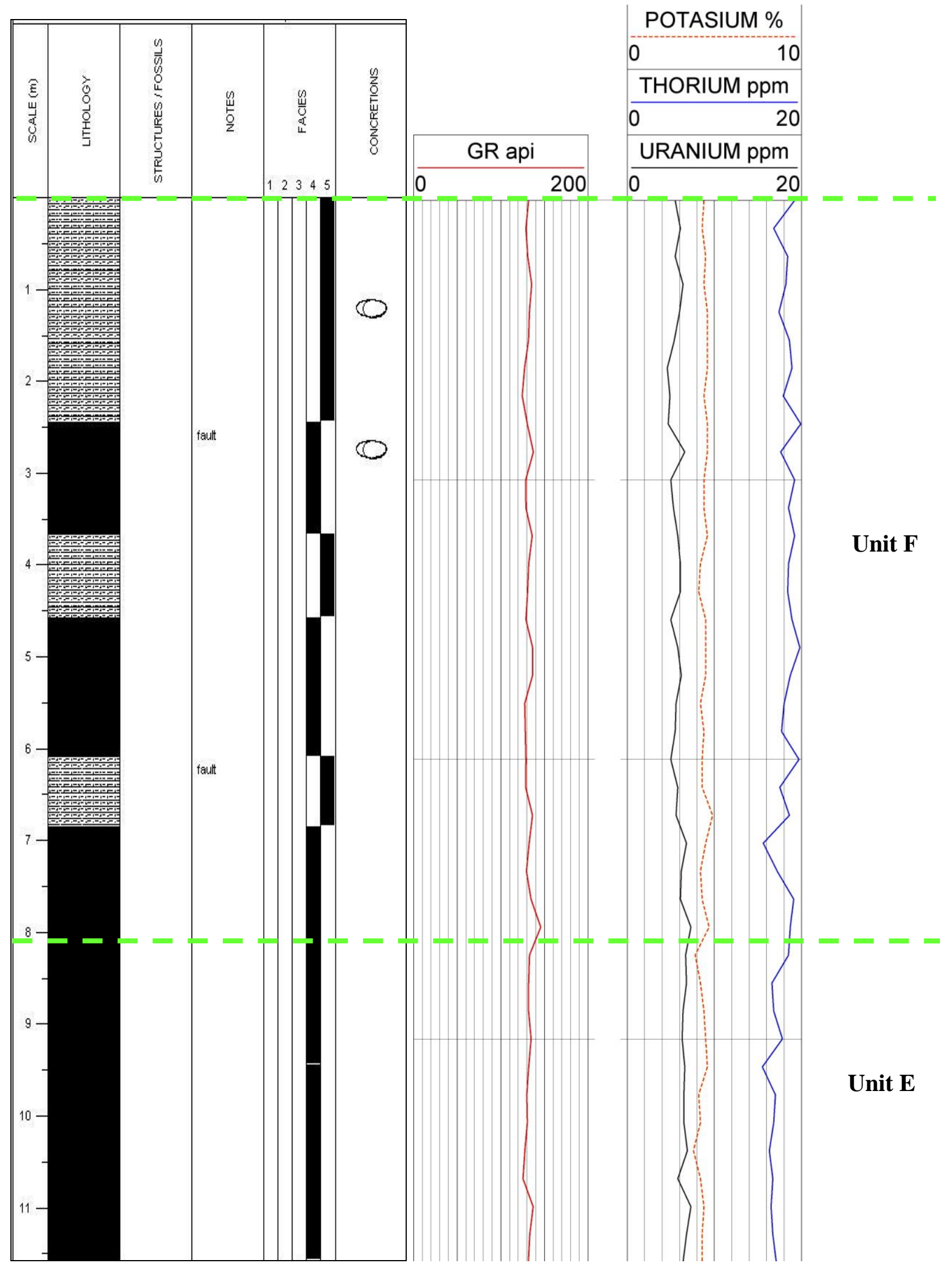

Figure 33. South Branch of the Potomac, WV stratigraphic column and spectral gamma-ray curve. 


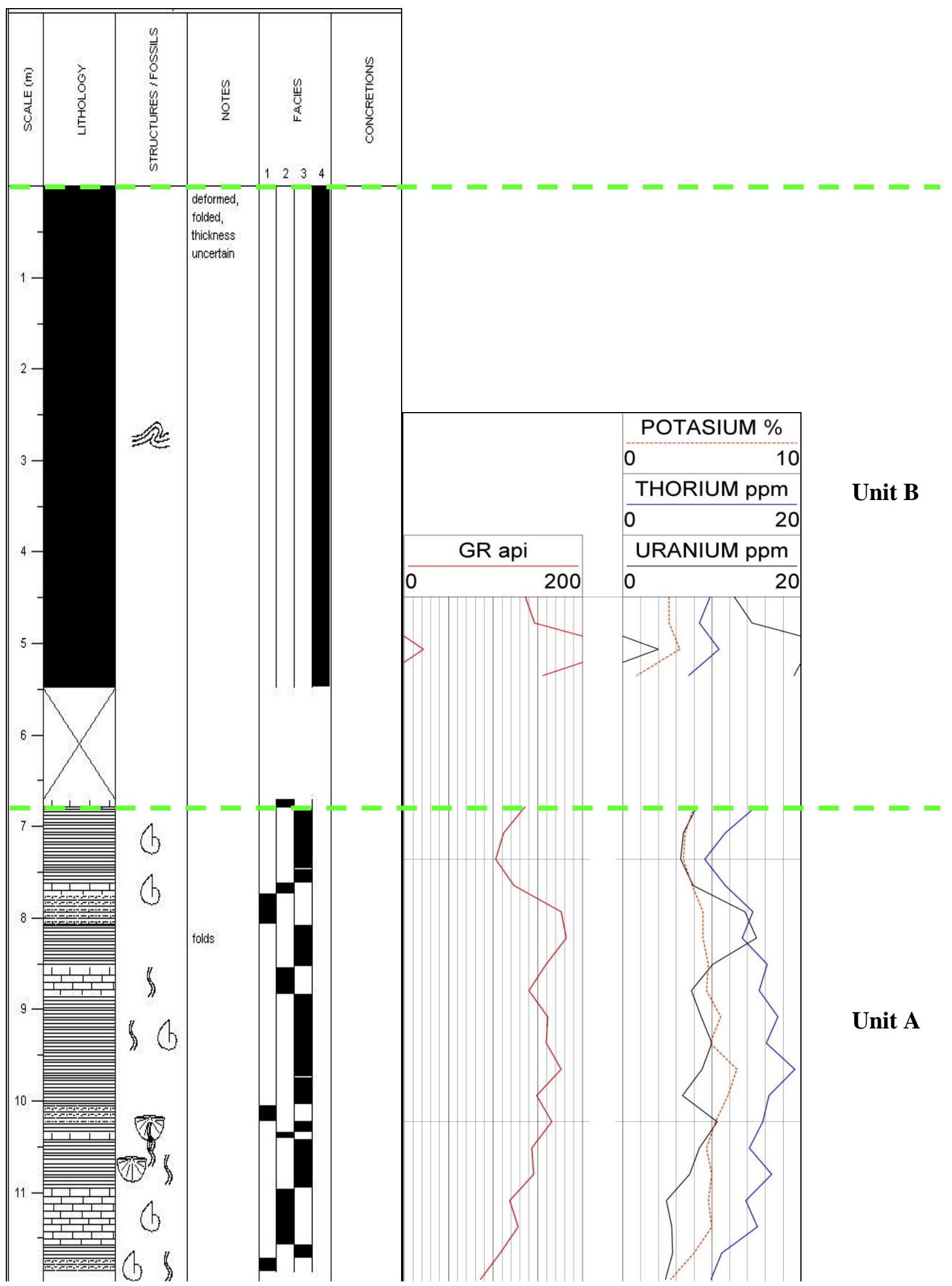

Figure 34. Oak Flat, WV stratigraphic column and spectral gamma-ray curve. 


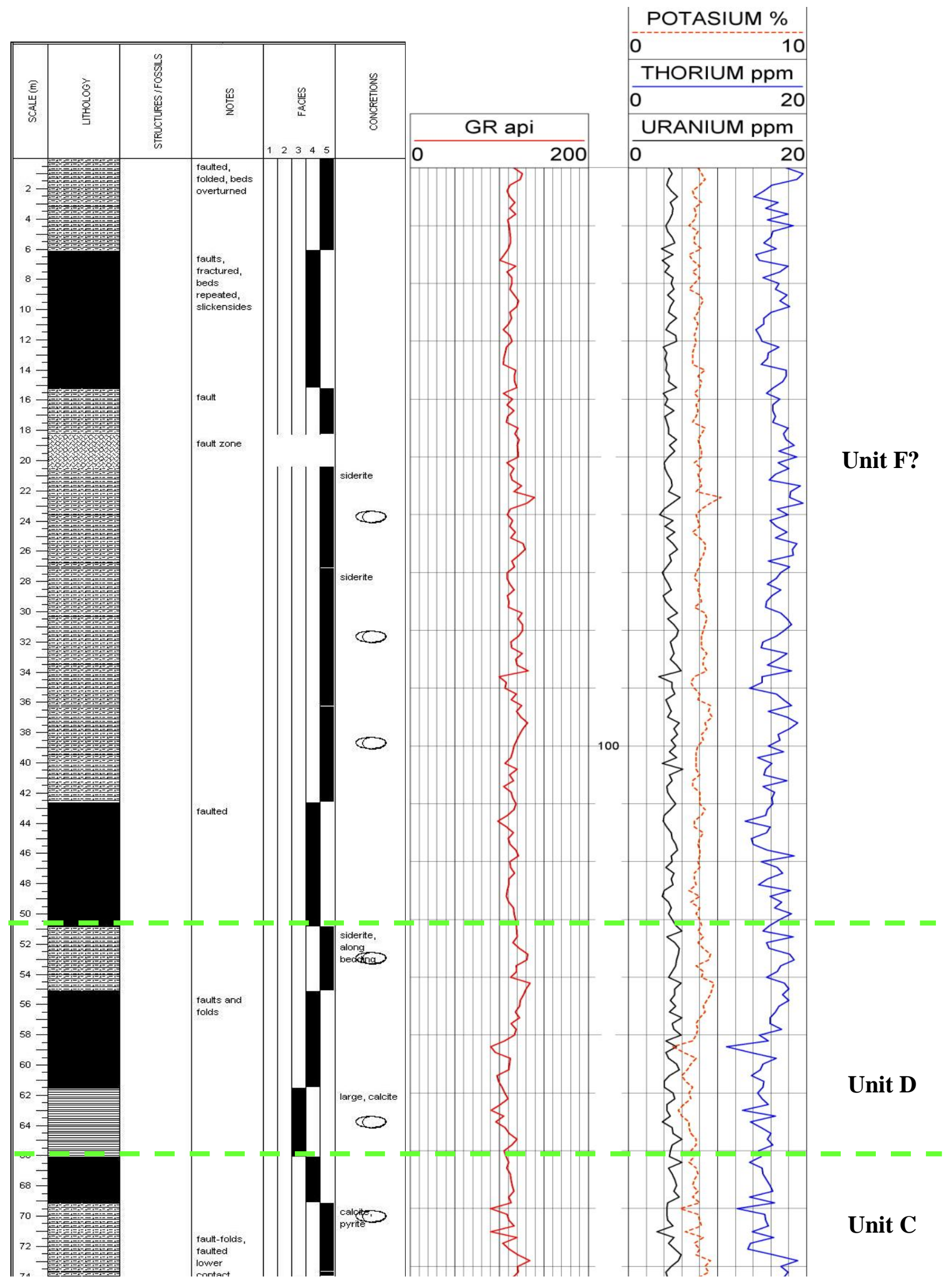

Figure 35. Berkeley Springs, WV stratigraphic column and spectral gamma-ray curve. 


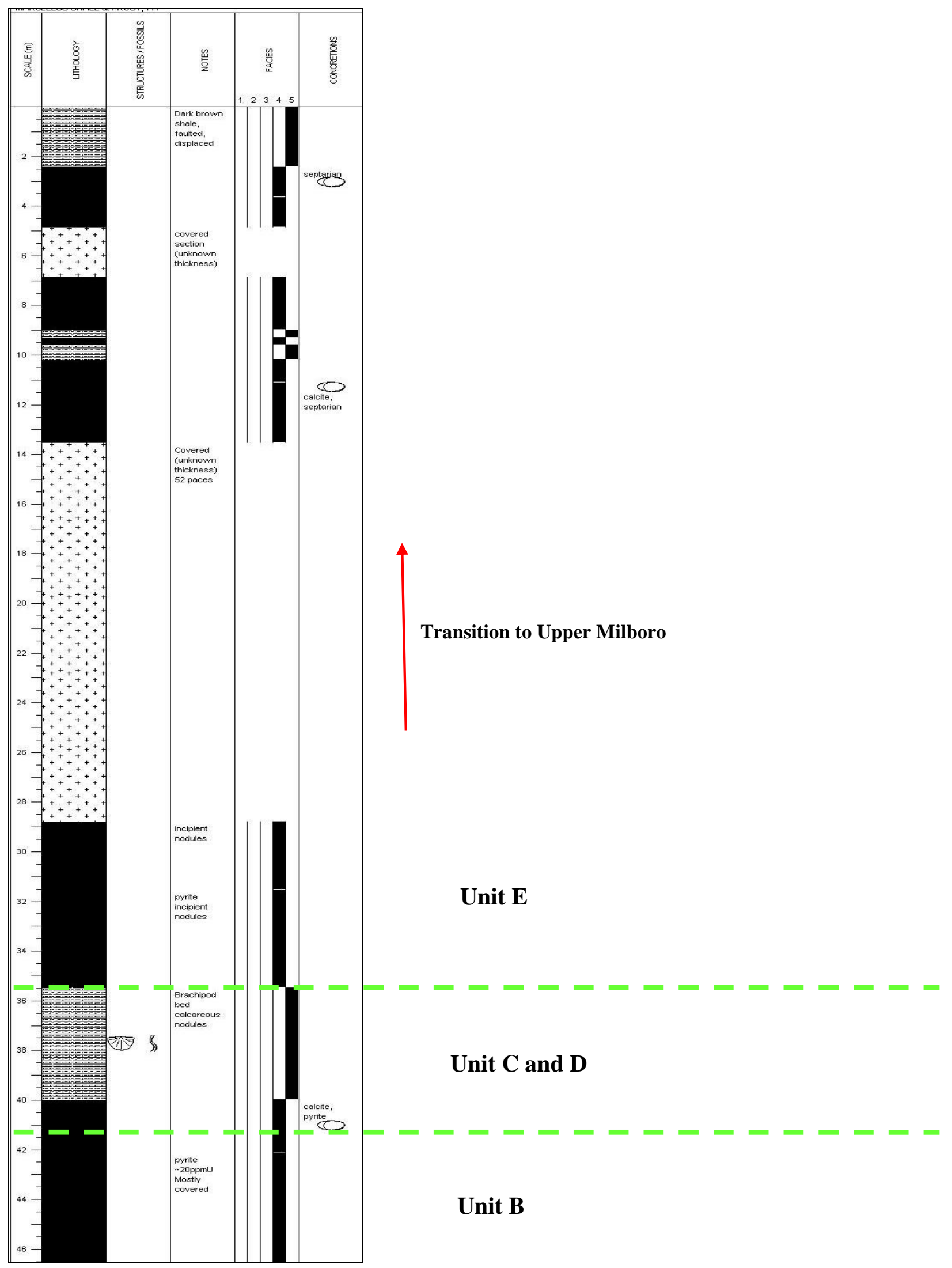

Figure 36. Frost, WV stratigraphic column. Spectral gamma-ray was not used at this location. 


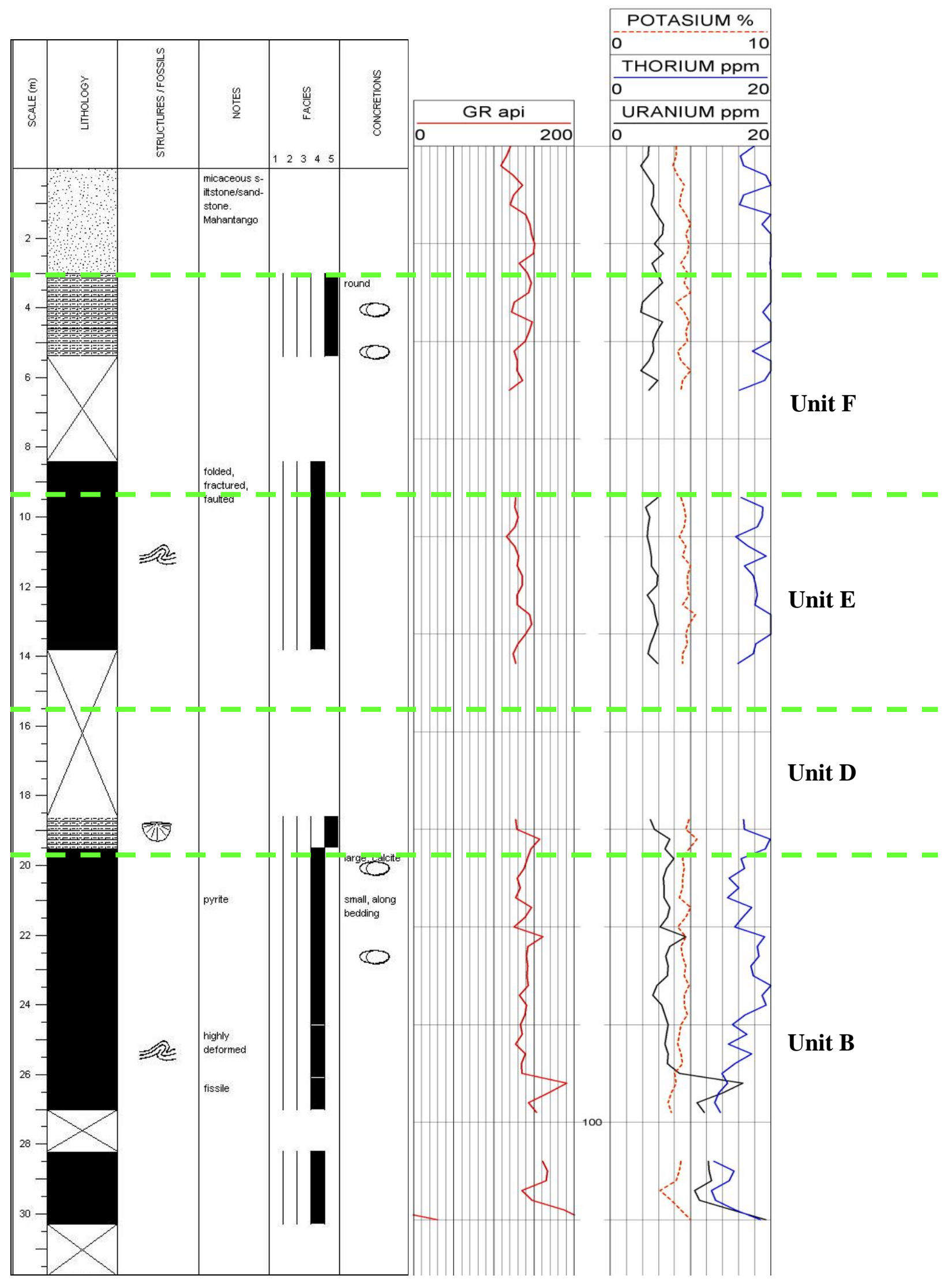

Figure 37. McCoole, MD stratigraphic column and spectral gamma-ray curve. 


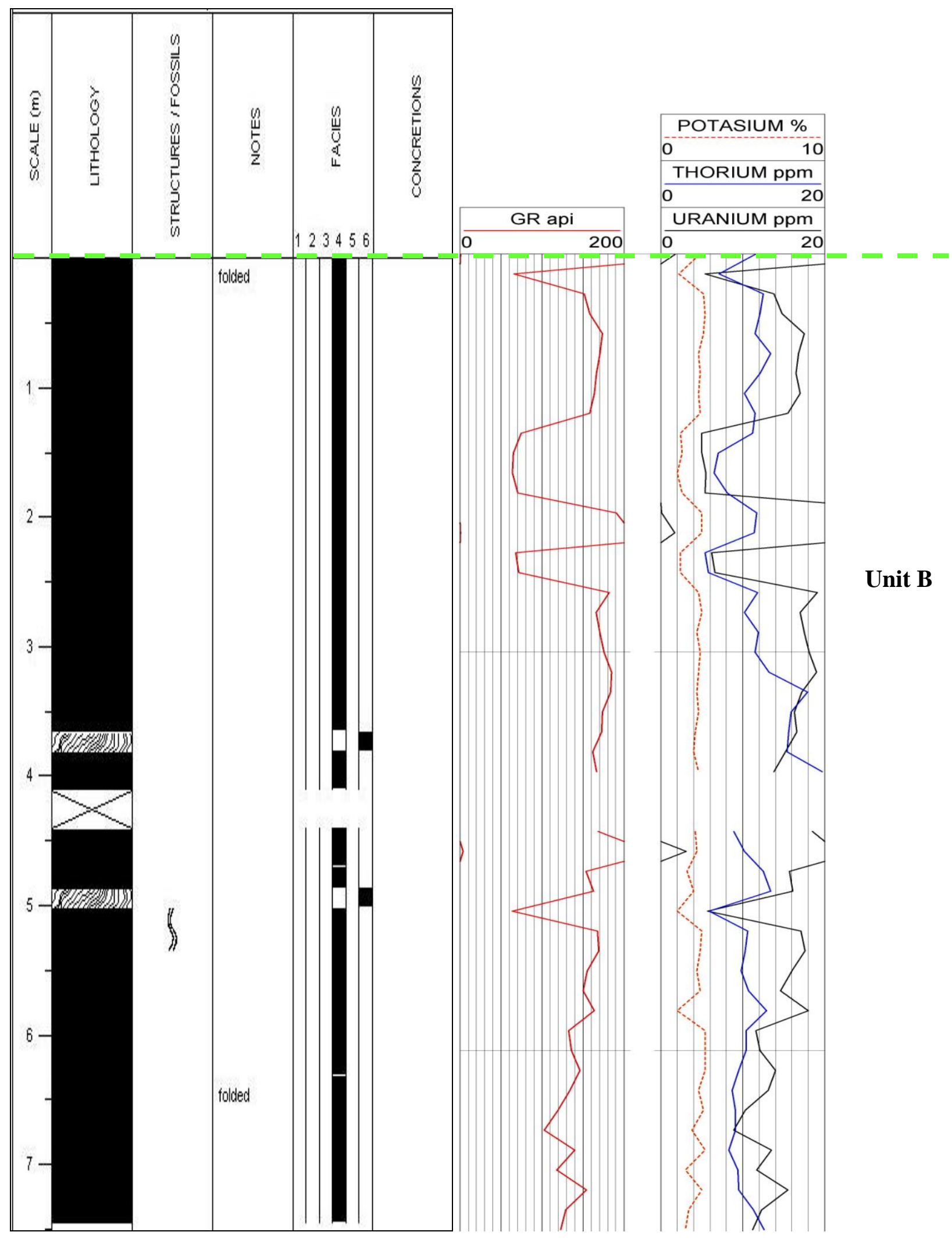

Figure 38. Tomahawk, WV stratigraphic column and spectral gamma-ray curve. 


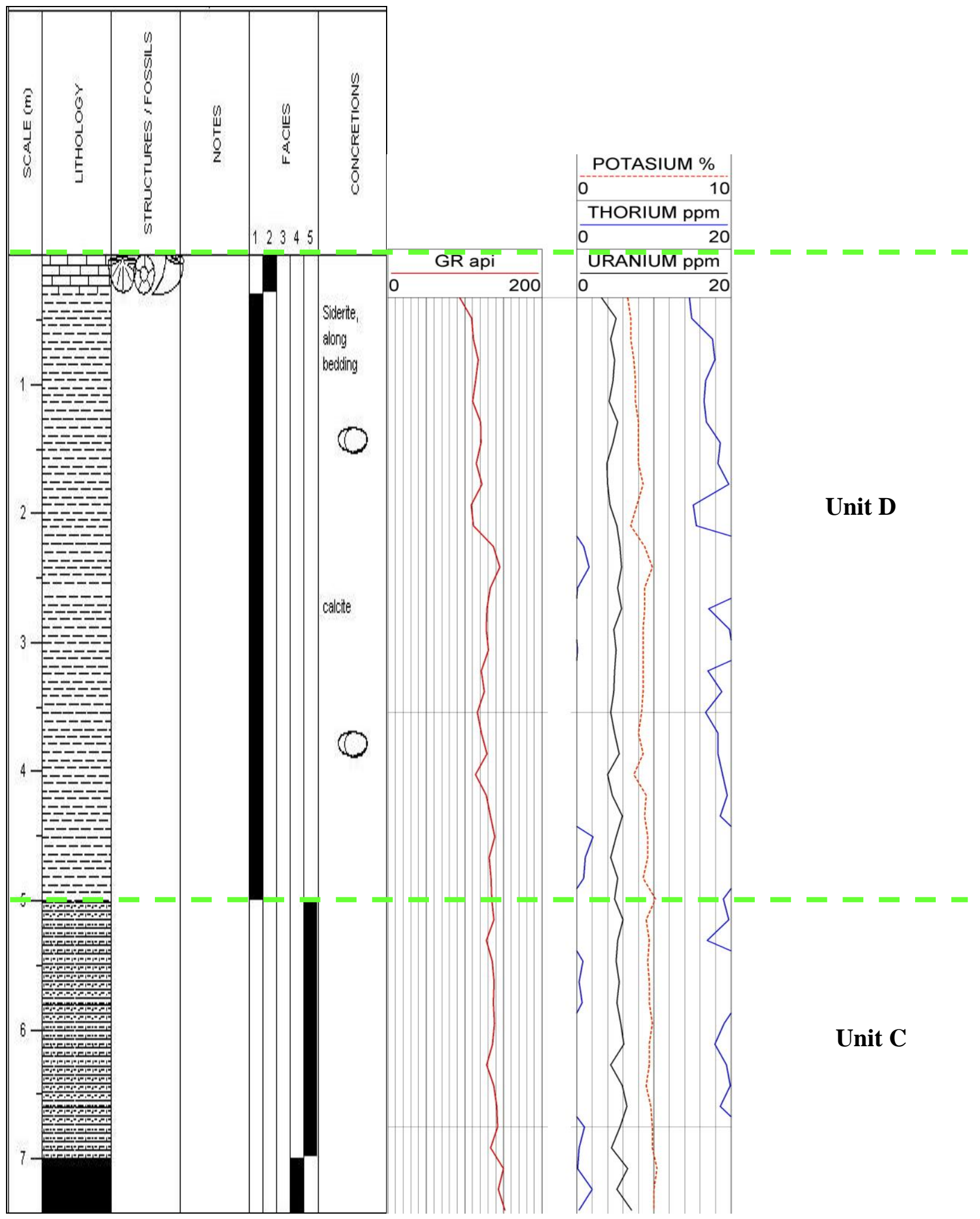

Figure 39. Petersburg West, WV stratigraphic column and spectral gamma-ray curve. 


\section{GAMMA-RAY CORRELATIONS}

Gamma-ray and spectral gamma-ray logs were created from scintillometer data collected at 15 partial outcrops (Fig. 25-39) and a gamma-ray type log was compiled for the composite section of the Marcellus Shale in the study area (Fig. 24). The spectral gamma-ray data for each outcrop was converted to API units using the following parameters: uranium ppm * 6.69 , thorium ppm $* 2.54$, and potassium $\% * 10.54$ (Korsbech, 2002). The outcrop spectral gamma-ray API units were then summed to create a total gamma-ray curve $(\mathrm{U}+\mathrm{Th}+\mathrm{K})$ for each outcrop (track 1). Individual concentrations of radioactive elements including uranium (ppm), thorium (ppm) and potassium (\%) are displayed in track 2 . The Th/U ratio (track 3) is used as a relative measure of redox conditions during deposition. Uranium is insoluble under reducing conditions and soluble under oxidizing conditions whereas thorium ${ }^{4+}$ is insoluble under both reducing and oxidizing conditions. Therefore, comparing the relative amount of thorium to uranium $(\mathrm{Th} / \mathrm{U}$ ratio) results in a relative measure of redox potential for the depositional environment (Adams and Weaver, 1958). A Th/U ratio values of two or less indicates deposition under anoxic conditions whereas values of seven or greater indicates deposition under oxic conditions (Adams and Weaver, 1958). Values between 2 and 7 indicate suboxic to dyoxic conditons. The composite type log was then used to compare and correlate each outcrop unit of the Marcellus Shale to nearby subsurface wells in the Appalachian Basin (Fig. 1).

\section{Unit A}

The type log for Unit A in outcrop has total gamma-ray values that range between 60162 API units (Fig. 24). Though uranium concentrations can be as low as $4.1 \mathrm{ppm}$, there are peaks at 15, 18 and $22 \mathrm{ppm}$. The higher uranium values are associated with black calcareous 
shale (Facies 3), whereas the lower values are typically associated with limestone (Facies 2) and grey calcareous shale (Facies 1). The type log shows an abrupt increase in potassium and thorium concentrations in the middle of the unit. Gamma-ray character and thicknesses change considerably from the outcrop to the subsurface, even between wells spaced 7 miles apart (Fig. 41). Nevertheless, the total subsurface gamma-ray values and uranium concentrations are comparable to the type log and allow for correlation of Unit A into the subsurface. The gammaray profile for the upper contact of this unit is gradational.

The Unit A type log and subsurface logs have similar gamma-ray values; however, the thicknesses and log shape change. Thickness changes can be attributed to sediment supply and shifts in the thermocline. These result in varying development of Facies 1,2 and 3. The overall increase in potassium $(\mathrm{K})$ and thorium $(\mathrm{Th})$ in the type log is related to increased abundance of clastic sediment in Facies 1 towards the top of the unit. Th/U ratio values of roughly two correspond with the increase in $\mathrm{Th}$ and $\mathrm{K}$ in the middle of the unit and suggest a period of slightly less anoxic deposition. The easternmost well (Fig. 40-3) shows similar high redox values indicating deposition under more oxic conditions. However, wells further into the basin (Fig. 401; Fig. 40-2) have redox numbers that represent deposition under anoxic conditions. Therefore, westward, the Marcellus exhibits decreased development of limestone (Facies 2) and grey calcareous shale (Facies 1) and increased development of black calcareous shale (Facies 3) and black non-calcareous shale (Facies 4).

\section{Unit B}

The type log for Unit B in outcrop has total gamma-ray values that range between 170602 API units, although readings are most often greater than 200 API. These elevated gamma- 
ray values are related to increased uranium and thorium concentrations. Outcrop uranium concentrations average $30 \mathrm{ppm}$ and are as high as $77 \mathrm{ppm}$, whereas thorium values reach a maximum of $42 \mathrm{ppm}$. The higher gamma-ray values of Unit B correspond well with nearby subsurface well logs where total gamma-ray values reach 662 API, uranium 77 ppm, and thorium $24 \mathrm{ppm}$. In both the outcrop type log and subsurface well logs, the maximum thorium and uranium values occur together in the base of Unit B (Fig. 40). The average thickness of Unit B in outcrop is roughly 23 feet. Unit B thickness remains similar from outcrop to subsurface; however, high gamma zones ( >200 API) within the unit become thicker westward into the basin. The contact with the overlying unit is gradational (Fig. 40).

The elevated uranium is associated with an increase in organic matter in the rock (Swanson, 1960; Schmoker, 1981). The very high organic content in Unit B creates a rapid increase in the total gamma-ray profile that can be traced into the subsurface. The increased thorium concentrations seen at the base of this unit indicate an increased clay content and may be related to the presence of K-bentonites. The Th/U ratio values are less than one in the outcrop type $\log$ and indicate that Unit B was deposited under consistently anoxic conditions, although small fluctuations existed. The Th/U ratio in subsurface wells indicates deposition under similar consistently anoxic conditions; however, redox values do not fluctuate. Increased thickness of high gamma-ray zones in the subsurface may be associated with deposition in deeper water ( 60 meters) or greater primary productivity in the surface water coupled with diminished clastic influx due to increased distance from the eastern source. Even during periods of low clastic influx, the proximal facies contain more clastics than their distal equivalents. 


\section{Unit C}

The type log for Unit C in outcrop has total gamma-ray values that range between 133186 API units. Uranium values decrease considerably from the underlying unit with an average concentration of $7.7 \mathrm{ppm}$ and a maximum of $16.5 \mathrm{ppm}$. Unit $\mathrm{C}$ is identified in the type $\log$ by an overall decrease in total gamma-ray values from the underlying unit (Fig. 40). Total gamma-ray values in the subsurface likewise decrease from the extremely high values observed in Unit B, although gamma-ray values for Unit $\mathrm{C}$ are greater in the subsurface ( $~ 250$ API units). Unit C thickness in the subsurface varies but generally thins westward. Unit $\mathrm{C}$ is thickest in the northeasternmost well in the study area (Fig. 40-3) which is consistent with the proximity to the terrigenous source to the northeast (Fig. 1) (Ettensohn and Baron, 1981). The upper contact is gradational in the type log and subsurface wells (Fig. 40).

The type log for Unit $\mathrm{C}$ changes in character from the outcrop to the subsurface. The increase in thickness and uranium concentrations in the subsurface can be attributed to the deposition of a more condensed organic-rich section westward into the basin. The type log of Unit $\mathrm{C}$ indicates deposition during periods of increased clastic influx; therefore Unit $\mathrm{C}$, in more proximal areas, is dominated by clastic Facies 5, whereas in more distal wells (Fig. 40-1; Fig. 402) Facies 4 dominates. The facies change laterally because, even during periods of increased clastic influx, little terrigenous clastic sediment reaches the more distal locations in the basin. $\mathrm{The} \mathrm{Th} / \mathrm{U}$ ratio for the type log indicates an upsection change from anoxic $(<2)$ to suboxic $(\sim 4)$ conditions. In the subsurface the same trend is recognized; however redox values $(<2)$ suggest that anoxic conditions persisted throughout Unit $\mathrm{C}$. Unit $\mathrm{C}$ redox values in the most basinward wells (Fig. 40-1; Fig 40-2) are significantly less than one, and indicate more anoxic conditions farther west into the basin, resulting in increased preservation of accumulated organic matter. 


\section{Unit D}

The type log for Unit D in outcrop has total gamma-ray values that range between 106128 API units. As a whole, the gamma-ray profile for this unit is distinctively lower than the surrounding stratigraphic units. Uranium values for this unit are characteristically low, averaging $4.3 \mathrm{ppm}$. Uranium values can be as low as $2.4 \mathrm{ppm}$ and as high as $7 \mathrm{ppm}$. Lower uranium concentrations are related to clean limestones beds of Facies 2 and grey calcareous shale of Facies 1. Although uranium concentrations decrease abruptly from the underlying unit, the gamma-ray profile of the basal contact tends to be gradational. In the outcrop type log the gamma-ray profile exhibits a overall coarsening-upwards trend in the gamma-ray, while the $\mathrm{Th} / \mathrm{U}$ ratio values ( >2-6) indicate deposition under a generally oxic environment (Fig. 24). This unit holds similar character in the subsurface, though the cleaning-upward trend on the gammaray $\log$ is not well defined. Subsurface Th/U ratio values ( >2-6 ) in nearby wells indicate that Unit D was deposited under generally oxic conditions becoming more anoxic basinward $(<2)$ (Fig. 40). Typically, Unit D thins from an average thickness of 30 feet at the outcrop to 15 feet westward into the subsurface. Several adjacent wells in Grant County, West Virginia (Fig. 41-4; Fig. 41-5) show a thickened section; this increase is associated with thrust faulting within the section.

The gradational nature of Unit D is due to a steady fall in relative sea level. The relatively low gamma-ray values and uranium concentrations are related to the increased deposition of carbonate facies above the thermocline. Under normal marine conditions and an oxygenated water column, any organic material that accumulated would be degraded rather than preserved. Thorium values are typically low and indicate a decrease in clastic clay deposition. The decrease 
in thickness from the type log to the subsurface is due to less developed carbonate facies in more distal parts of the basin.

\section{Unit E}

The type log for the black shale of Unit $\mathrm{E}$ in outcrop has total gamma-ray values that range between 112-196 API units. The gamma-ray profile clearly increases from the underlying unit due to increased levels of uranium. Concentrations of uranium in the type log can be as high as $20.5 \mathrm{ppm}$ but average only $9 \mathrm{ppm}$. The type log for Unit E has a notably lower gamma-ray signature than the lower black shale of Unit B, and these concentrations decrease substantially up through Unit E. The thickness of high gamma-ray shale in the Unit E type log is relatively thin ( 6 feet). In adjacent Grant County wells (Fig. 41-4; Fig. 41-5), Unit E has a thicker zone of high gamma-ray values but comparable uranium concentrations. Wells farther away from the outcrop belt, however, exhibit a thicker black shale section with considerably higher uranium concentrations (50 ppm). The sharp basal contact of Unit E correlates well with subsurface logs. The upper contact of this unit is gradational.

Similar to Unit B, Unit E shows a characteristic increase in organic content at the base of the unit that can be correlated to subsurface well logs. The enriched uranium zone of Unit B increases in thickness west into the subsurface, indicating a thickened section of increased organic matter (Fig. 40). Additionally, the subsurface wells exhibit an overall lower Th/U ratio values $(<1)$ indicating increasingly anoxic conditons westward into the basin (Fig. 40). This lateral change is associated with longer periods of deposition under the thermocline, less dilution by terrigenous clastics, and possibly higher primary productivity in the surface water. 


\section{Unit F}

The type log for Unit F in outcrop has total gamma-ray values that range between 128145 API units and a average uranium concentration of $5.6 \mathrm{ppm}$. The type log shows a constant decrease in total gamma-ray and uranium values upward through Unit F. As the uranium value declines, both thorium and potassium values gradually increase, indicating an increase in clastics. Nearby well logs show a similar trend in decreasing uranium and total gamma-ray response as well as a gradual increase in thorium and potassium at the top of the unit (Fig. 41). The subsurface gamma-ray character for Unit F varies, but it typically contains zones of high uranium at the base that are absent in the type log.

The decrease of uranium and increase in thorium and potassium associated with the type $\log$ for Unit F indicates dilution of organic material by clastics during the time of deposition. A gradual increase of thorium in Unit F can be attributed to increased clastic clay. Although the subsurface gamma-ray log indicates increased organic matter westward (i.e. higher uranium concentrations), the $\mathrm{Th} / \mathrm{U}$ ratios both in the outcrop and subsurface still represent deposition under increasingly oxic conditions up the stratigraphic section (Fig. 40). Unit E marks the start of the large scale progradation that deposited the coarser clastic sediments of the Mahantango Formation.

Spectral data, total gamma-ray (API units), and Th/U ratios from the outcrop type section provide useful tools for correlation from the outcrop belt westward to the subsurface well logs. The type log represents a more proximal facies assemblage while the subsurface logs represent a more basinward position. With respect to subsurface terminology for the Marcellus 
Shale, Units A-C correlate to the Union Springs Formation, Unit D the Cherry Valley Member, and Units E-F the Oatka Creek Formation (Ver Straeten et al., 1994). 


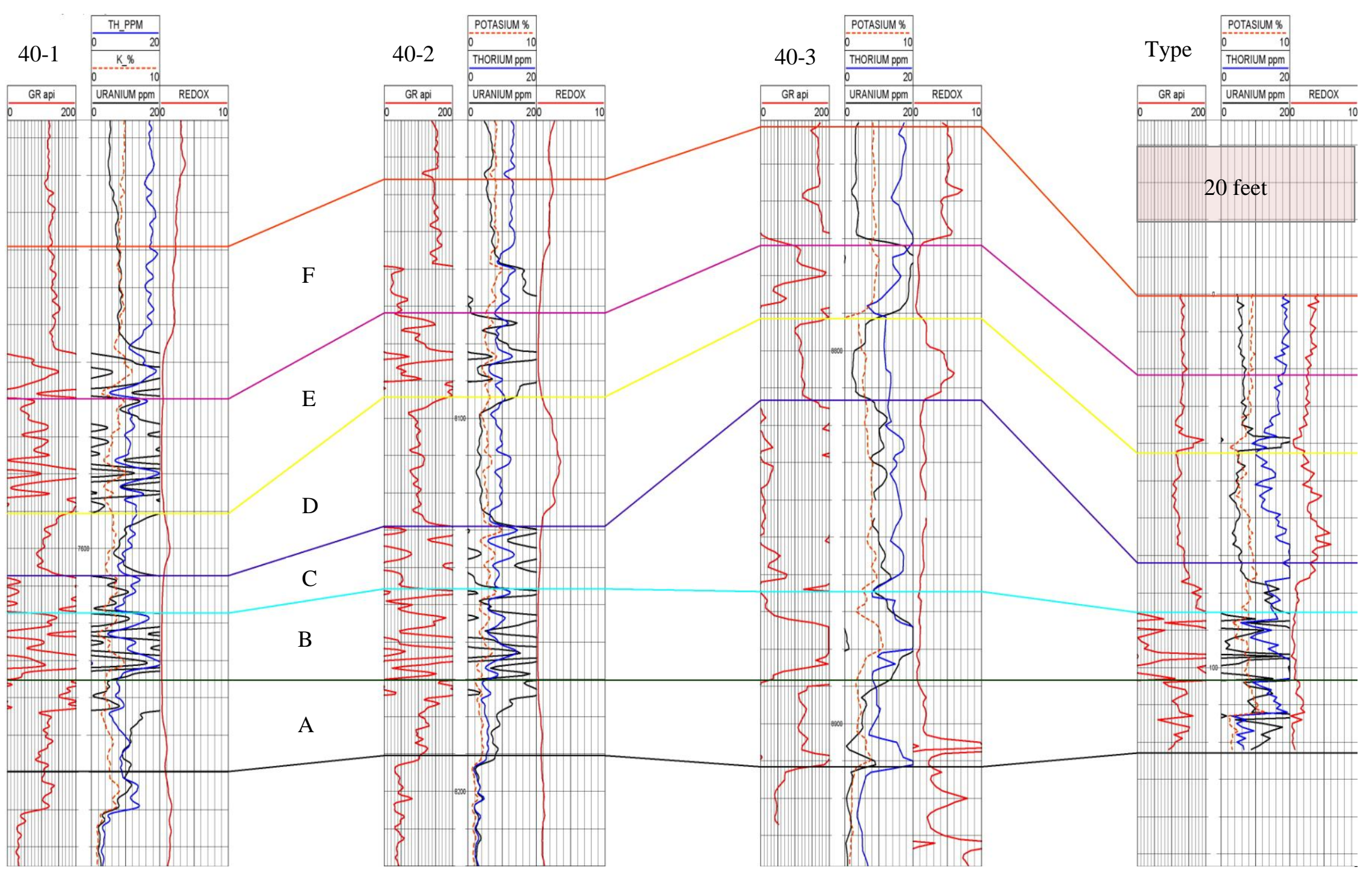

Figure 40. Stratigraphic units A through F in the Marcellus Shale type log (far right) are correlated with three subsurface wells (401, 40-2, 40-3). Total gamma-ray in API units is shown in track 1, concentrations of individual components are displayed in track 2 (i.e., potassium in percent, uranium in ppm, and thorium in $\mathrm{ppm}$ ). The Th/U ratio indicating redox conditions is displayed in track 3. Correlations are based on $\log$ responses and are tied to units defined in the outcrop. For well locations see study area Figure 1. 


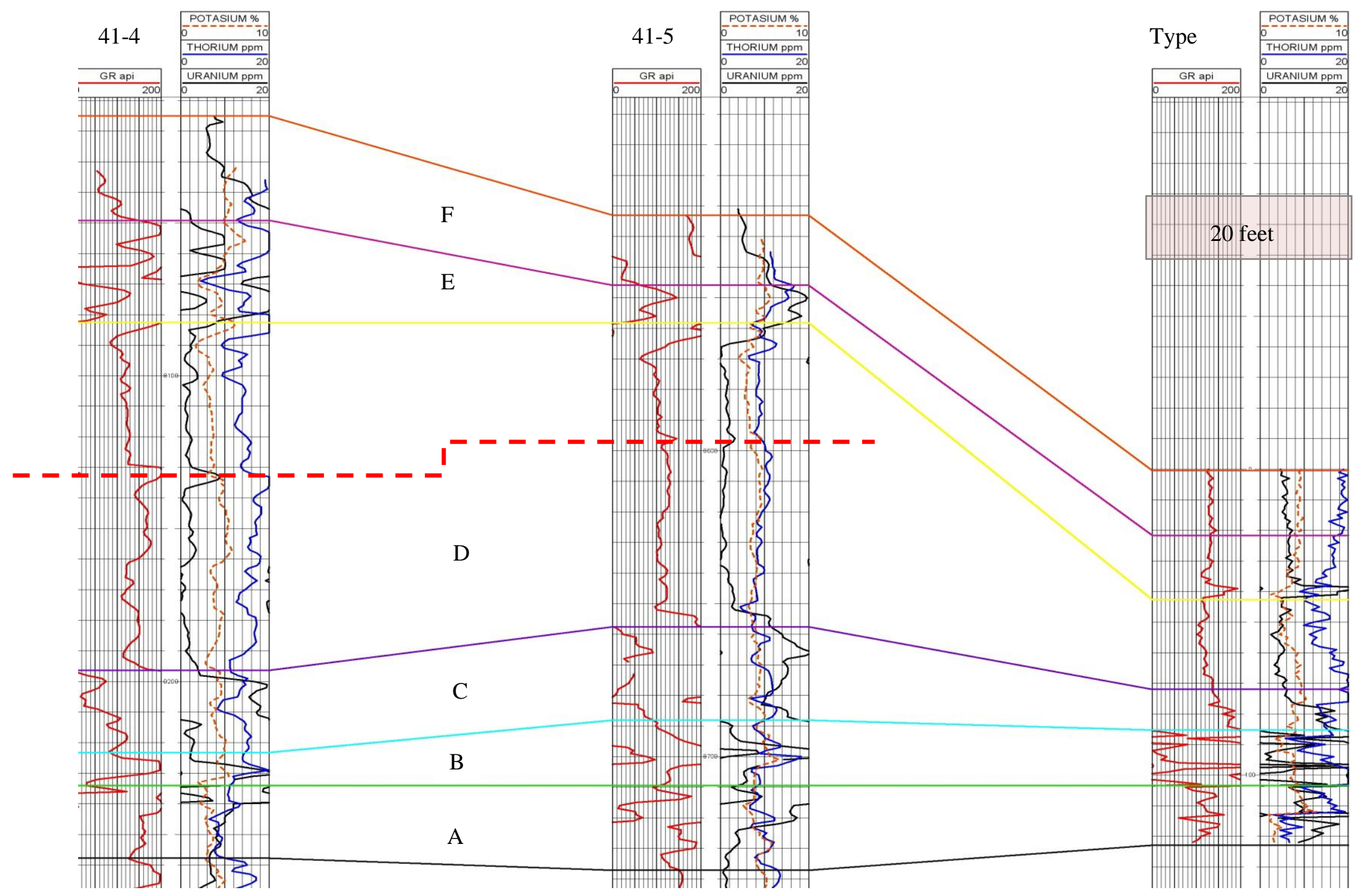

Figure 41. Units (A-F) of the Marcellus Shale type log (far right) are correlated with two adjacent wells in Grant County West Virginia (41-4; 41-5). A thrust fault, interpreted with the dashed red line, more than doubles the thickness of Unit D in the subsurface. For well locations see study area Figure 1. 


\section{CONCLUSIONS}

The Marcellus Shale outcrops in the study area consist of six interbedded lithofacies (Facies 1-6). Facies deposition is primarily based on terrigenous sediment supply and shifts in the location of the thermocline, which is dependent on sea level:

- Facies 1 is light to dark grey, commonly bioturbated, calcareous shale. It was deposited in a foreland ramp environment below wave base ( $\sim 20$ meters) but above the thermocline ( 40 meters) under normal marine conditions with a moderate supply of terrigenous clastic sediment.

- Facies 2 is dark grey to black, micritic, occasionally fossilferous or argillaceous limestone. It was deposited in a foreland ramp environment below wave base and above the thermocline. It commonly formed in pods on a muddy shelf, resulting in a facies mosiac. The fossil assemblage indicates a normal marine, well-oxygenated water column, with low terrigenous input.

- Facies 3 is dark grey to black calcareous shale. It contains rare biotubation, benthonic organisms, and fossil debris. It was typically deposited below the thermocline during times of decreased clastic influx. The bottom water was mostly oxygen-depleted, although seasonal mixing and large storms occasionally disrupted the thermocline and resulted in mixing of oxygen-rich surface water.

- Facies 4 is black to dark grey and occasionally chocolate-brown, non-calcareous shale with rare nektonic fossils. It was deposited during periods of low terrigenous clastic input in oxygen-depleted bottom-water, well below the thermocline. Water depth was roughly 
60 meters, deeper than seasonal mixing depths, but within the depth of maximum effective anoxia in modern seas.

- Facies 5 is light to dark grey, silty, non-calcareous shale. It was typically deposited below the thermocline in place of Facies 3 and 4 during times of increased clastic influx. The water was mostly anoxic, though intermittent storm and seasonal mixing events allowed for deposition in more oxic conditions.

- Facies 6 the Tioga K-bentonite is tan, brown to grey, and composed of clay to sands sized grains of mica. Up to three bentonite ash beds, which were sourced from a volcano in Central Virginia, are identified at the base of the formation.

These lithofacies are stacked vertically into Units A through F, which can be identified in terms of subsurface stratigraphic terminology. The dominant facies in Units A-C, which represent the Union Springs Formation, include black calcareous shale (Facies 3), black noncalcareous shale (Facies 4), and grey non-calcareous shale (Facies 5). The dominant facies in Unit D, which represents the Cherry Valley Member, include limestone (Facies 2) and grey calcareous shale (Facies 1). The dominant facies in Units E-F, which represent the Oatka Creek Formation, include black non-calcareous shale (Facies 4) and grey non-calcareous shale (Facies 5).

The use of a handheld spectral gamma-ray tool to create an outcrop type log allows for stratigraphic correlations from the outcrop belt to the nearby subsurface. Concentrations of radioactive elements in similar facies are approximately the same in the outcrop as in the subsurface. As a result, outcrop Units A-F can be readily identified in the subsurface. Basinward, 
these units exhibit an overall decrease in thickness of clastic-dominated (Facies 5) and carbonate (Facies 1 and 2) lithofacies as well as an increase in organic-rich (Facies 4) lithofacies. These lateral changes correspond with the greater distance from the terrigenous source and deposition in increasingly deep water beneath the thermocline. 


\section{REFERENCES}

Adams, J. A. S., and C. Weaver, 1958, Thorium-to-uranium ratios as indicators of sedimentary processes; example of concept of geochemical facies: Bulletin of the American Association of Petroleum Geologists, v. 42, p. 387-430.

Algeo, T., and S. Scheckler, 1998, Terrestrial-marine teleconnections in the Devonian; links between the evolution of land plants, weathering processes, and marine anoxic events: Philosophical Transactions - Royal Society of London. Biological Sciences, v. 353, p. 113-130.

Basan, P. B., D. L. Kissling, K. D. Hemsley, K. G. Dow, M. S. Chaiffetz, P. Isaacson, S. Barrett, and L. Carne, 1980, Geological study and reservoir evaluation of Early Devonian formations of the Appalachian, Robertson Research (U.S.) Inc., p. 263.

Blakey, R., 2011, Middle Devonian (385Ma), North American Paleogeogprahy. http://jan.ucc.nau.edu/rcb7/nam.html, accessed May 21 ${ }^{\text {st }}, 2011$.

Boswell, R., 1996, Play Uds: Upper Devonian black shales, in Roen, J.B. and Walker, B.J., eds., Atlas of major appalachian gas plays: West Virginia Geologic and Economic Survey, Publication V-25, p. 93-99.

Boyce, M. L., Carr, T. R., Singh, V, 2010, The Depositional Dynamics of the Middle Devonian Marcellus Interval Using a Petrophysical and Stratigraphic Analysis of the Sub-surface in West Virginia and Southwestern Pennsylvania, West Virginia University, dissertation, p. 1-159.

Campbell, C. V., 1967, LAMINA, LAMINASET, BED AND BEDSET: Sedimentology, v. 8, p. 7-26.

Demaison, G., and G. Moore, 1980, Anoxic environments and oil source bed genesis, AAPG Bulletin, United States (USA), American Association of Petroleum Geologists, v. 64, p. 1179-1209.

Dennison, J. M., 1960, Stratigraphy of Devonian Onesquethaw stage in West Virginia, Virginia and Maryland: Dissertation Abstracts, v. 21, no. 3, p. 593; University of WisconsinMadison, unpub. dissertation, p. 339.

Dennison, J., and D. Textoris, 1970, Devonian tioga tuff in Northeastern United States: Bulletin of Volcanology, v. 34, p. 289-294.

Dennison, J. M., and D. A. Textoris, 1977, Tioga Bentonite time-marker associated with Devonian shales in Appalachian Basin: Preprints, First Eastern gas shales symposium, p. 113-129. 
Dennison, J., 1985, Catskill Delta shallow marine strata, in Woodrow, D.L., and Sevon, W.D., eds., The Catskill Delta: Geological Society of America special paper 201, p. 91-106

De Witt, W., Jr., W. Perry, and L. Wallace, 1975, Oil and gas data from Devonian and Silurian rocks in the Appalachian Basin, Miscellaneous Investigations Series - U. S. Geological Survey, United States U. S. Geological Survey, Reston, VA, United States

De Witt, W., Jr., J. Roen, and L. Wallace, 1993, Stratigraphy of Devonian black shales and associated rocks in the Appalachian Basin, in J. Roen, and R. Kepferle, eds., U. S. Geological Survey Bulletin, United States, U. S. Geological Survey, Reston, VA, United States p. B1-B57.

Engelder, T., 2008, Structural geology of the Marcellus and other Devonian gas shales, geologic conundrums involving joints, layer-parallel shortening strain, and the contemporary tectonic stress field: Eastern Section Meeting Field Trip AAPG-SEG, p. 96.

Engelder, T., G.G. Lash, 2011, Thickness trends and sequence stratigraphy of the Middle Devonian Marcellus Formation, Appalachian Basin: Implications for Acadian foreland basin evolution, AAPG Bulletin p. 61-103.

Ettensohn, F.R., 1985, The Catskill Delta complex and the Acadian orogeny, in Woodrow, D.L., and Sevon, W.D., eds., The Catskill Delta: Geological Society America Special paper 201, p. 39-49

Ettensohn, F., 1987, Rates of relative plate motion during the Acadian Orogeny based on the spatial distribution of black shales: Journal of Geology, v. 95, p. 572-582.

Ettensohn, F., 1998, Compressional tectonic controls on epicontinental black-shale deposition; Devonian-Mississippian examples from North America in J. Schieber, W. Zimmerle, and P. Sethi, eds., Shales and mudstones; I, Basin studies, sedimentology, and paleontology, E. Schweizerbart'sche Verlagsbuchhandlung Naegele u. Obermiller, Stuttgart, p. 109128.

Ettensohn, F., 2008, Tectonism, estimated water depths, and the accumulation of organic matter in the Devonian-Mississippian black shales of the Northern Appalachian Basin, AAPG, Eastern Section Meeting, Pittsburgh PA.

Ettensohn, F., and L. Barron, 1981, Tectono-climatic model for origin of DevonianMississippian black gas shales of east-central United States: AAPG Bulletin, v. 65, p. 183.

Ettensohn, F. R., Miller, M.L., Dillman, S.B., Elam, T.D., Geller, K.L., Swager, D.R., Markowitz, G., Woock, R.D., and Barron, L.S. 1988, Characterization and implications of the Devonian-Mississippian black shale sequence, eastern and central Kentucky, U.S.A. : Pycnocline, transgression, regression, and tectonism, in McMillan, N.J., Embry, 
A.F., and Glass, D.J., eds., Devonian of the World: Canadian Society of Petroleum Geologists Memoir 14, v. 2, p. 323-345.

Faill, R. T., 1985, The Acadian orogeny and the Catskill delta, inWoodrow, D. L., and Sevon,W. D., eds., The Catskill Delta: Geological Society of America Special Paper 201, p. 15-37.

Faill, R., 1997, A geologic history of the north-central Appalachians; Part 2, The Appalachian Basin from the Silurian through the Carboniferous: American Journal of Science, v. 297, p. 729-761.

Gao, D., R. C. Shumaker, and T. H. Wilson, 2000, Along-Axis Segmentation and Growth History of the Rome Trough in the Central Appalachian Basin: AAPG Bulletin, v. 84, p. 75-99.

Harper, J.A., 1999, Devonian, in Shultz, C.H., ed., The geology of Pennsylvania: Pennsylvania Geological Survey and Pittsburgh Geological Society, p. 108-127.

Harper, J., 2008, The Marcellus Shale; an old "new" gas reservoir in Pennsylvania: Pennsylvania Geology, v. 38, p. 2-13.

Heckel, P., and B. Witzke, 1979, Devonian world palaeogeography determined from distribution of carbonates and related lithic palaeoclimatic indicators, in House, M.R., Scrutton, C.T., and Basset, M.G., eds., The Devonian System: London, Special Papers in Palaeontology, no.23, p. 99-123.

Kara, A. B., R. W. Helber, T. P. Boyer, and J. B. Elsner, 2009, Mixed layer depth in the Aegean, Marmara, Black and Azov Seas: Part I: General features: Journal of Marine Systems, v. 78, p. S169-S180.

Korsbech, U., 2002, Spectral Natural Gamma-ray logs (SNG-logs), http://server4.oersted.dtu.dk/research/RI/SNG/SNG-logs.html, accessed February 22, 2011.

Ingram, R., 1953, Fissility of mudrocks: Geological Society of America Bulletin, v. 64, p. 869878.

Lash, G. G., 2008, Stratigraphy and fracture history of Middle and Upper Devonian succession, western New York significance to basin evolution and hydrocarbon potential: Pittsburgh Association Petroleum Geologists Spring Field Trip, p. 88.

Lazar, R., K. Bohacs, J.H.S. Macquaker, and J. Schieber, 2010, Fine-grained Rocks in Outcrops:Classification and Description Guidelines, in Schieber, J., Lazar, R., and Bohacs, K. eds., Sedimentology and stratigraphy of shales: American Association Petroleum Geologists 2010 Annual Convention in New Orleans Field Guide for PostConvention Field Trip 10, p. 3-14.

McCollum, L. B., 1988, A shallow epeiric sea interpretation for an offshore Middle Devonian black shale facies in eastern North America, in McMillian, N.J., Embry, A.F., and Glass, 
D.J., editors, Devonian of the World II: Canadian Society of Petroleum Geologists Memoir, 14, p. 347-355.

Milici, R.C., and Swezey, C.S., 2006, Assessment of Appalachian basin oil and gas resources; Devonian Shale-Middle and Upper Paleozoic total petroleum system: U.S. Geological Survey Open-File Report 2006-1237, 70 p. Available only online at http://pubs.usgs.gov/of/2006/1237/.

Nielsen Leth, B., L. Lovborg, P. Sorensen, and E. Mose, 1987, Gamma-Ray Analysis for U, TH, and K on Bulk Cutting Samples from Deep Wells in the Danish Subbasin and the North German Basin, Roskilde, Denmark, Riso National Laboratory, p. 1-85.

Pedersen, T. F., and S. E. Calvert, 1990, Anoxia vs productivity; what controls the formation of organic-carbon-rich sediments and sedimentary rocks?: AAPG Bulletin, v. 74, p. 454466.

Potter, P. E., J. B. Maynard, and W. A. Pryor, 1980, Sedimentology of Shale: New York, Springer-Verlag, p. 1-306.

Prave, A. R., W. L. Duke, and W. Slattery, 1996, A depositional model for storm- and tideinfluenced prograding siliciclastic shorelines from the Middle Devonian of the central Appalachian foreland basin, USA: Sedimentology, v. 43, p. 611-629.

Provo, L. J., 1978, Stratigraphy and sedimentology of radioactive Devonian-Mississippian shales of the Central Appalachian Basin, Ph.D. Dissertation, University of Cincinnati, Cincinnati, Ohio, p. 128.

Roen, J., 1984, Geology of the Devonian black shales of the Appalachian Basin: Organic Geochemistry, v. 5, p. 241-254.

Sageman, B., A. Murphy, J. Werne, C. Ver Straeten, D. Hollander, and T. Lyons, 2003, A tale of shales; the relative roles of production, decomposition, and dilution in the accumulation of organic-rich strata, Middle-Upper Devonian, Appalachian Basin: Chemical Geology, v. 195 , p. 229-273.

Schieber, J., D. Krinsley, and L. Riciputi, 2000, Diagenetic origin of quartz silt in mudstones and implications for silica cycling: Nature, v. 406, p. 981-985.

Schmoker, J., 1981, Determination of organic-matter content of Appalachian Devonian shales from gamma-ray logs: AAPG Bulletin, v. 65, p. 1285-1298.

Schwietering, J.F., 1977, Preliminary model of Catskill Delta in West Virginia in Proceedings, Eastern Gas Shales Symposium, $1^{\text {st }}$ : U.S. Department of Energy, MERC/SP-77/5. p. 195205. 
Schwietering, J. F., and R. B. Erwin, 1981, The occurrence of oil and gas in Devonian shales and equivalents in West Virginia: final report, United States. Department of Energy.

Technical Information, Center. DOE/ET/12130-T13, p. 1-44.

Sherrard, S. J., and M. T. Heald, 1984, Petrology of the Huntersville Chert: Southeastern Geology, v. 25, p. 37-47.

Slattery, W., 1995, Depositional cycles and sequence stratigraphy of the upper Hamilton Group (Givetian) of Pennsylvania and New York, eustatically driven?: Northeastern Geology, v. 17, p. 422-430.

Smith, and Leone, 2010, Utica and Marcellus Potential in New York State American Association Petroleum Geologists Annual Meeting, New Orleans, NO http://esogis.nysm.nysed.gov/esogisdata/downloads/talks/Smith_1130_Weds_AAPG_Shale.pdf, accessed February 22, 2011.

Swanson, V., 1960, Oil yield and uranium content of black shales: U. S. Geological Survey Professional Paper, 356-A, p. 1-44.

Tyson, R.V., and Pearson, T.H., 1991, Modern and ancient continental shelf anoxia: an overview, in Tyson, R.V., and Pearson, T.H., eds., Modern and ancient continental shelf anoxia: Geological Society London Special Publication No. 58, p. 1-24.

Ver Straeten, C. A., D. H. Griffing, and C. E. Brett, 1994, The lower part of the Middle Devonian Marcellus "Shale," central to western New York State; stratigraphy and depositional history: Guidebook - New York State Geological Association, Meeting, v. 66, p. 271-271-323.

Ver Straeten, C., 2004, K-bentonites, volcanic ash preservation, and implications for Early to Middle Devonian volcanism in the Acadian Orogen, eastern North America: Geological Society of America Bulletin, v. 116, p. 474-489.

Ver Straeten, C., 2007, Basinwide stratigraphic synthesis and sequence stratigraphy, upper Pragian, Emsian and Eifelian stages (Lower to Middle Devonian), Appalachian Basin, in R. Becker, and W. Kirchgasser, eds., Devonian events and correlations: Geological Society Special Publications, p. 39-81.

Werne, J., B. Sageman, T. Lyons, and D. Hollander, 2002, An integrated assessment of a "type euxinic" deposit; evidence for multiple controls on black shale deposition in the Middle Devonian Oatka Creek Formation: American Journal of Science, v. 302, p. 110-143.

Willard, B., 1935, Hamilton group of central Pennsylvania: Geological Society of America Bulletin, v. 46, p. 195-224.

Woodrow, D.L., and Sevon, W.D., eds., 1985, The Catskill Delta: Geological Society of America, Special Paper 201, 246 p. 
Woodward, H.P., 1943, Devonian system of West Virginia: West Virginia Geological Survey Vol. XV, $655 \mathrm{p}$.

Wrightstone, G., 2009, Marcellus Shale geologic controls on production: Independent Oil Gas Association West Virginia Winter Meeting, Charleston, WV, http://www.iogawv.com/pdfs/Wrightstone_For_Distribution_IOGAWV_2009.pdf, accessed February 22, 2011.

Wrightstone, G. R., 2010, Bloomin'Algae! How paleogeography and algal blooms may have significantly impacted deposition and preservation of the Marcellus Shale.

http://www.papgrocks.org/Bloomin\%20Algae.pdf, accessed February 22, 2011.

Ziegler, A., C. Scotese, W. McKerrow, M. Johnson, and R. Bambach, 1979, Paleozoic paleogeography: Annual Review of Earth and Planetary Sciences, v. 7, p. 473-502 


\section{APPENDIX-OUTCROP DESCRIPTIONS}




\section{BURLINGTON WV, OUTCROP}

\section{Location: .9 miles East of \\ Burlington, WV on Rt. 50/220 \\ Latitude/Longitude: \\ 39.330279/-78.887382}

Unit Number: 1

Unit Thickness: 3 feet

Facies Number: 4

Rock Type: non-calcareous

shale

Interbeds: none

Color Fresh: dark grey to black

Color Weathered: orange, white

Grain Size: N/A

Visible Minerals: none

Parting Thickness: platy, (1-

2mm)

Parting Geometry: parallel,

continuous, and broken by

deformation

Bedding Planes: regular, smooth

Sedimentary Structures: none

Fossil Content: none

Color When Powdered: dark

brown

Luster of Streak: very waxy

Other: locally deformed, parting

weather in irregular shapes

\section{Unit Number: 2}

Unit Thickness: 2 feet

Facies Number: 4

Rock Type: non-calcareous

shale

Interbeds: none

Color Fresh: dark grey to black

Color Weathered: orange

Grain Size: N/A

Visible Minerals: none

Parting Thickness: platy, (1-

2mm)

Parting Geometry: parallel, continuous

Bedding Planes: regular,

relatively smooth

Sedimentary Structures: none

Fossil Content: none

Color When Powdered:

chocolate brown - black

Luster of Streak: waxy

Other: very similar to unit 1 ,

partings break in angular shards, parting bedsets $\sim 3$ inches
Unit Number: 3

Unit Thickness: 2 feet

Facies Number: 5

Rock Type: non-calcareous shale

Interbeds: none

Color Fresh: dark grey

Color Weathered: orange, white

Grain Size: N/A

Visible Minerals: none

Parting Thickness: fissile

(<1mm)

Parting Geometry:

discontinuous

Bedding Planes: irregular

Sedimentary Structures: none

Fossil Content: none

Color When Powdered: brown

Luster of Streak: waxy

Other: weathers in very small

irregular fragments $\sim 1$ inch

\section{Unit Number: 4}

Unit Thickness: 5 foot

Facies Number: N/A

Rock Type: covered interval

Interbeds: N/A

Color Fresh: N/A

Color Weathered: N/A

Grain Size: N/A

Visible Minerals: N/A

Parting Thickness: N/A

Parting Geometry: N/A

Bedding Planes: N/A

Sedimentary Structures: N/A

Fossil Content: N/A

Color When Powdered: N/A

Luster of Streak: N/A

Other: very soft, probably same as unit 3

Unit Number: 5

Unit Thickness: 1 foot

Facies Number: 1

Rock Type: calcareous shale

Interbeds: none

Color Fresh: N/A

Color Weathered: brown

Grain Size: silty

Visible Minerals: N/A

Parting Thickness: platy- flaggy

(2mm-10mm)
Parting Geometry:

discontinuous

Bedding Planes: irregular

Sedimentary Structures: none

Fossil Content: none

Color When Powdered: light

brown, $\tan$

Luster of Streak: semi-waxy

Other: none

Unit Number: 6

Unit Thickness: 1.5 feet

Facies Number: 2 and 1

Rock Type: Limestone

Interbeds: calcareous shale

Color Fresh: dark grey

Color Weathered: N/A

Grain Size: N/A

Visible Minerals: small shiny grains (calcite)

Parting Thickness: interbeds: platy $(1-2 \mathrm{~mm})$

Parting Geometry: interbeds:

discontinuous

Bedding Planes: N/A

Sedimentary Structures:

calcareous nodules

Fossil Content: none

Color When Powdered:

interbeds: brown, tan

Luster of Streak: interbeds: semi

waxy

Other: limestone ranges from very thinly bedded $(1-3 \mathrm{~cm})$ to medium bedded $(16 \mathrm{~cm})$, limestone consist of large calcareous concretions $\sim 10 \mathrm{~cm}$ in width, limestone appear to thin

Unit Number: 7

Unit Thickness: 1.5 feet

Facies Number: 1

Rock Type: calcareous shale

Interbeds: none

Color Fresh: grey

Color Weathered: N/A

Grain Size: N/A

Visible Minerals: none

Parting Thickness: fissile (.5-

$1 \mathrm{~mm})$ platy $(1-5 \mathrm{~mm})$

Parting Geometry: fissile:

flakey, parallel, platy: irregular 
Bedding Planes: N/A

Sedimentary Structures: nodules

Fossil Content: none

Color When Powdered: fissile

shale: tan, platy shale: light

Luster of Streak: fissile shale:

peels, platy shale: powdery

Other: fissile shale directly

overlies limestone bed with

nodules and grades upwards to

party shale, nodules non-

calcareous $\sim 1$ inch and form

along bedding planes

Unit Number: 8

Unit Thickness: .5 feet

Facies Number: 1

Rock Type: calcareous shale

Interbeds: none

Color Fresh: grey- brown

Color Weathered: N/A

Grain Size: N/A

Visible Minerals: none

Parting Thickness: papery, (<

$.5 \mathrm{~mm})$

Parting Geometry: N/A

Bedding Planes: N/A

Sedimentary Structures: none

Fossil Content: none

Color When Powdered: N/A

Luster of Streak: N/A

Other: partings break off in soft, papery pieces

Unit Number: 9

Unit Thickness: .5 feet

Facies Number: 2 and 1

Rock Type: limestone

Interbeds: calcareous shale

Color Fresh: N/A

Color Weathered: N/A

Grain Size: N/A

Visible Minerals: N/A

Parting Thickness: N/A

Parting Geometry: N/A

Bedding Planes: N/A

Sedimentary Structures: none

Fossil Content: possible skeletal

debris, orange, red oxidized

Color When Powdered: tan

Luster of Streak: semi waxy

Other: limestone is very thinly

bedded (.5-1 inch)
Unit Number: 10

Unit Thickness: 1 foot

Facies Number: 2

Rock Type: limestone

Interbeds: none

Color Fresh: dark grey

Color Weathered: N/A

Grain Size: N/A

Visible Minerals: calcite

Parting Thickness: none

Parting Geometry: none

Bedding Planes: N/A

Sedimentary Structures:

nodules

Fossil Content: crinoid stems,

rugose corals

Color When Powdered: N/A

Luster of Streak: N/A

Other: fossils replaced with

crystalline calcite

Unit Number: 11

Unit Thickness: 1 foot

Facies Number: 1

Rock Type: calcareous shale

Interbeds: none

Color Fresh: brown to grey

Color Weathered: N/A

Grain Size: N/A

Visible Minerals: none

Parting Thickness: platy, (2-

$5 \mathrm{~mm})$

Parting Geometry:

discontinuous

Bedding Planes: N/A

Sedimentary Structures: none

Fossil Content: none

Color When Powdered: tan to

brown

Luster of Streak: mid-luster to

waxy

Other: shale draped over Unit 10

Unit Number: 12

Unit Thickness: 2 feet

Facies Number: covered interval

Rock Type: N/A

Interbeds: N/A

Color Fresh: N/A

Color Weathered: N/A

Grain Size: N/A

Visible Minerals: N/A

Parting Thickness: N/A

Parting Geometry: N/A

Bedding Planes: N/A
Sedimentary Structures: N/A

Fossil Content: N/A

Color When Powdered: N/A

Luster of Streak: N/A

Other: probably soft shale

Unit Number: 13

Unit Thickness: 1 foot

Facies Number: 2

Rock Type: limestone

Interbeds: none

Color Fresh: grey

Color Weathered: N/A

Grain Size: N/A

Visible Minerals: crystalline

calcite

Parting Thickness: N/A

Parting Geometry: N/A

Bedding Planes: N/A

Sedimentary Structures: N/A

Fossil Content: crinoids stems common

Color When Powdered: N/A

Luster of Streak: N/A

Other: fossils are becoming

more abundant than previous

limestone units, randomly

distributed

Unit Number: 14

Unit Thickness: 12 feet

Facies Number: N/A

Rock Type: covered section

Interbeds: N/A

Color Fresh: N/A

Color Weathered: N/A

Grain Size: N/A

Visible Minerals: N/A

Parting Thickness: N/A

Parting Geometry: N/A

Bedding Planes: N/A

Sedimentary Structures: N/A

Fossil Content: N/A

Color When Powdered: N/A

Luster of Streak: N/A

Other: soft shale similar to units 11 and 12

Unit Number: 15

Unit Thickness: 4 feet

Facies Number: 1

Rock Type: slightly calcareous

shale

Interbeds: none

Color Fresh: grey 
Color Weathered: tan, green

Grain Size: N/A

Visible Minerals: none

Parting Thickness: platy, (2-

5mm)

Parting Geometry: parallel

Bedding Planes: regular, smooth

Sedimentary Structures:

horizontal laminations

Fossil Content: none

Color When Powdered: light

brown

Luster of Streak: semi-waxy

Other: shale very slightly

calcareous, breaks into small $\sim 1$ -

2 inch pieces, some bed set $\sim 2-3$

$\mathrm{cm}$

Unit Number: 16

Unit Thickness: 4 feet

Facies Number: 1 and 2

Rock Type: calcareous shale

Interbeds: argillaceous

limestone

Color Fresh: grey, interbeds:

grey to dark grey

Color Weathered: N/A

Grain Size: N/A

Visible Minerals: none

Parting Thickness: platy, (1-

5mm)

Parting Geometry:

discontinuous

Bedding Planes: N/A

Sedimentary Structures:

interbeds: concretions

Fossil Content: none

Color When Powdered: light

brown, interbeds: white to light

$\tan$

Luster of Streak: semi-waxy,

interbeds: dull

Other: more competent shale

than unit 15 , interbeds: very thin

to thinly bedded argillaceous

limestone $\sim 2-4 \mathrm{~cm}$

Unit Number: 17

Unit Thickness: 10 feet

Facies Number: 3 and 2

Rock Type: calcareous shale

Interbeds: argillaceous

limestone

Color Fresh: grey to black, interbeds: dark grey
Color Weathered: N/A

Grain Size: N/A

Visible Minerals: none

Parting Thickness: papery to

fissile .1- $1 \mathrm{~mm}$

Parting Geometry: continuous

Bedding Planes: regular, smooth

Sedimentary Structures:

Fossil Content: interbeds:

crinoid stems, fossil debris

Color When Powdered: tan

Luster of Streak: semi-waxy

Other: fossils found on bedding

planes, shale breaks in soft

sheets, interbeds: argillaceous

limestone $\sim .5$ - 1 inch in

thickness

Unit Number: 18

Unit Thickness: 1 foot

Facies Number: 1

Rock Type: calcareous shale

Interbeds: N/A

Color Fresh: grey

Color Weathered: N/A

Grain Size: possible silt sized

grains

Visible Minerals: pyrite in

nodules

Parting Thickness: platy $\sim 2 \mathrm{~mm}$

Parting Geometry:

discontinuous

Bedding Planes: N/A

Sedimentary Structures: pyrite

nodules

Fossil Content: none

Color When Powdered: tan

Luster of Streak: semi- waxy

Other: possibly silty, pyrite

nodules could be replaced shell

debris

Unit Number: 19

Unit Thickness: 1 foot

Facies Number: 1

Rock Type: calcareous shale

Interbeds: none

Color Fresh: grey

Color Weathered: N/A

Grain Size: silt sized grains

Visible Minerals: pyrite in

nodules

Parting Thickness: platy, $\sim 5 \mathrm{~mm}$

Parting Geometry: N/A

Bedding Planes: N/A
Sedimentary Structures: pyrite nodules

Fossil Content: none

Color When Powdered: tan

Luster of Streak: semi- waxy

Other: thicker partings, more silt

sized grains than unit 18 , pyrite

concretions possibly replaced

shell debris

Unit Number: 20

Unit Thickness: 2 feet

Facies Number: 1 and 2

Rock Type: limestone

Interbeds: calcareous shale

Color Fresh: dark grey,

interbeds: grey

Color Weathered: N/A

Grain Size: N/A

Visible Minerals: calcite

Parting Thickness: platy

Parting Geometry:

discontinuous

Bedding Planes: N/A

Sedimentary Structures: none

Fossil Content: none

Color When Powdered: N/A

Luster of Streak: N/A

Other: limestone range from

thinly laminated $\sim 1 \mathrm{~cm}$ to thinly

bedded $\sim 3 \mathrm{~cm}$; shale is usually

more thinly laminated directly

overlying limestone bodies

Unit Number: 21

Unit Thickness: 5 feet

Facies Number: 1 and 2

Rock Type: limestone

Interbeds: calcareous shale

Color Fresh: interbeds: grey

Color Weathered: interbeds:

brown

Grain Size: N/A

Visible Minerals: N/A

Parting Thickness: no distinct

partings, bioturbated

Parting Geometry: N/A

Bedding Planes: irregular

Sedimentary Structures:

limestone beds are made of

nodules, lenticular shaped

limestone bodies, interbeds:

burrows

Fossil Content: small

brachiopods 
Color When Powdered:

interbeds: brown

Luster of Streak: interbeds:

waxy

Other: limestone beds are much

larger than in Unit $20 \sim .8-1.5$

feet, interbeds: calcareous shale

also contains more carbonate

rich beds $\sim 2-3 \mathrm{~cm}$, burrows

filled with lighter color mud

from above or below

Unit Number: 22

Unit Thickness: 1 foot

Facies Number: 1

Rock Type: calcareous shale

Interbeds: none

Color Fresh: grey

Color Weathered: brown, white

Grain Size: N/A

Visible Minerals: none

Parting Thickness: slabby $\sim 10$

$\mathrm{mm}$

Parting Geometry:

discontinuous

Bedding Planes: irregular

Sedimentary Structures:

flattened, calcareous, and oblong concretions, burrows

Fossil Content: none

Color When Powdered: brown

Luster of Streak: waxy

Other: concretion has especially high specific gravity for size, shale is only slightly calcareous, and shale contains red/orange oxidized burrows

\section{Unit Number: 23}

Unit Thickness: 9 feet

Facies Number: 1 and 2

Rock Type: calcareous shale

Interbeds: limestone

Color Fresh: grey to dark grey

interbeds: very dark grey

Color Weathered: N/A

Grain Size: N/A

Visible Minerals: interbeds:

calcite

Parting Thickness: papery to

platy

Parting Geometry:

discontinuous

Bedding Planes: irregular
Sedimentary Structures:

bioturbated

Fossil Content: none

Color When Powdered: tan

Luster of Streak: semi- waxy

Other: interbeds: limestone is

very thinly bedded $\sim 2-3 \mathrm{~cm}$, red

to orange oxidized burrows in

shale, shale begins to get darker

towards Unit 24

Unit Number: 24

Unit Thickness: 10 feet

Facies Number: 2

Rock Type: argillaceous

limestone

Interbeds: none

Color Fresh: black

Color Weathered: N/A

Grain Size: N/A

Visible Minerals: N/A

Parting Thickness: N/A

Parting Geometry: N/A

Bedding Planes: irregular

Sedimentary Structures: siderite

nodules, possible oxidized

burrows

Fossil Content: bivalve, styliolinids

Color When Powdered: brown

Luster of Streak: dull

Other: limestone is very thinly

bedded, nodules very heavy,

slightly calcareous, oval shaped

range from .4-.7 feet in size

Unit Number: 25

Unit Thickness: 2 feet

Facies Number: 1

Rock Type: calcareous shale

Interbeds: none

Color Fresh: brown

Color Weathered: N/A

Grain Size: N/A

Visible Minerals: N/A

Parting Thickness: N/A

Parting Geometry: N/A

Bedding Planes: N/A

Sedimentary Structures:

calcareous nodules

Fossil Content: some shell

debris

Color When Powdered: N/A

Luster of Streak: N/A

Other: partially covered 


\section{SPRINGFIELD WV, OUTCROP}

\author{
Location: 3 miles Northeast of \\ Springfield, WV on Co. Rt.1 \\ Latitude/ \\ Longitude:39.483756/- \\ 78.664749
}

\section{Unit Number: 1}

Unit Thickness: $92 \mathrm{~cm}$

Facies Number:1

Rock Type: calcareous shale

Interbeds: none

Color Fresh: grey

Color Weathered: brown

Grain Size: N/A

Visible Minerals: none

Parting Thickness: thick

partings

Parting Geometry: N/A

Bedding Planes: N/A

Sedimentary Structures: none

Fossil Content: none

Color When Powdered: N/A

Luster of Streak: N/A

Other: first bed along railroad tracks

Unit Number: 2

Unit Thickness: $45 \mathrm{~cm}$

Facies Number: 5

Rock Type: non-calcareous

shale

Interbeds: none

Color Fresh: dark grey

Color Weathered: N/A

Grain Size: N/A

Visible Minerals: none

Parting Thickness: N/A

Parting Geometry: N/A

Bedding Planes: N/A

Sedimentary Structures:

laminated

Fossil Content: styliolinid, possible small ammonoid

Color When Powdered: N/A

Luster of Streak: N/A

Other: contact with underlying

unit appears to be gradational

\section{Unit Number: 3}

Unit Thickness: $16 \mathrm{~cm}$

Facies Number: 1

Rock Type: calcareous shale (silty)

Interbeds: none

Color Fresh: grey

Color Weathered: brown

Grain Size: possibly silt sized

grains

Visible Minerals: none

Parting Thickness: N/A

Parting Geometry: N/A

Bedding Planes: N/A

Sedimentary Structures:

extensively burrowed

Fossil Content: none

Color When Powdered: N/A

Luster of Streak: N/A

Other: contact with underlying

unit appears to be gradational

Unit Number: 4

Unit Thickness: $130 \mathrm{~cm}$

Facies Number: 2 and 1

Rock Type: limestone,

grainstone

Interbeds: calcareous shale

Color Fresh: black to dark grey

Color Weathered: N/A

Grain Size: pebble like grains in

base of limestone bed

Visible Minerals: none

Parting Thickness: N/A

Parting Geometry: N/A

Bedding Planes: N/A

Sedimentary Structures: none

Fossil Content: ambeocela,

brachiopods

Color When Powdered: N/A

Luster of Streak: N/A

Other: limestone $\sim 10-22 \mathrm{~cm}$

with thin interbeds of shale,

three limestone beds: $(19 \mathrm{~cm}$,

$14 \mathrm{~cm}, 8 \mathrm{~cm}$ ), middle limestone

bed contains unknown brown

stick like features

Unit Number: 5

Unit Thickness: $100 \mathrm{~cm}$

Facies Number: 1 and 2

Rock Type: Covered section, limestone

Interbeds: calcareous shale

Color Fresh: N/A

Color Weathered: N/A
Grain Size: N/A

Visible Minerals: N/A

Parting Thickness: N/A

Parting Geometry: N/A

Bedding Planes: N/A

Sedimentary Structures: N/A

Fossil Content: N/A

Color When Powdered: N/A

Luster of Streak: N/A

Other: N/A

Unit Number: 6

Unit Thickness: $70 \mathrm{~cm}$

Facies Number: 2

Rock Type: limestone, three

beds

Interbeds: none

Color Fresh: N/A

Color Weathered: N/A

Grain Size: N/A

Visible Minerals: calcite

Parting Thickness: N/A

Parting Geometry: N/A

Bedding Planes: N/A

Sedimentary Structures:

abundant siderite molds

Fossil Content: re-crystallized

cephalopod, calcite-filled

structures, shell debris

Color When Powdered: N/A

Luster of Streak: N/A

Other: limestone bodies are possibly wedge shaped, two generations of vertical fractures backfilled with calcite

Unit Number: 7

Unit Thickness: $303 \mathrm{~cm}$

Facies Number: 5

Rock Type: non-calcareous

shale, mostly covered

Interbeds: none

Color Fresh: grey

Color Weathered: brown

Grain Size: N/A

Visible Minerals: N/A

Parting Thickness: N/A

Parting Geometry: N/A

Bedding Planes: N/A

Sedimentary Structures:

laminated

Fossil Content: none

Color When Powdered: N/A 
Luster of Streak: N/A

Other: low density, platy

Unit Number: 8

Unit Thickness: $60 \mathrm{~cm}$

Facies Number: 4

Rock Type: non-calcareous

Interbeds: none

Color Fresh: black

Color Weathered: N/A

Grain Size: N/A

Visible Minerals: none

Parting Thickness: N/A

Parting Geometry: N/A

Bedding Planes: N/A

Sedimentary Structures:

laminated, siderite concretions

Fossil Content: none

Color When Powdered: N/A

Luster of Streak: N/A

Other: shiny and deformed

around siderite concretions

Unit Number: 9

Unit Thickness: $400 \mathrm{~cm}$

Facies Number: 4

Rock Type: non-calcareous

Interbeds: none

Color Fresh: black

Color Weathered: N/A

Grain Size: N/A

Visible Minerals: none

Parting Thickness: platy, 1-

$4 \mathrm{~mm}$

Parting Geometry: N/A

Bedding Planes: N/A

Sedimentary Structures:

laminated

Fossil Content: none

Color When Powdered: N/A

Luster of Streak: N/A

Other: minor deformation, possible limestone lense one meter above this unit 


\section{GREENSPRING WV, OUTCROP}

Location: 1.4 miles Southwest of Greenspring, WV on Co.

Rt. 1

Latitude/Longitude:

39.517384/-78.632605

Unit Number: 1

Unit Thickness: 10.25 feet

Facies Number: 5

Rock Type: non-calcareous

shale

Interbeds: none

Color Fresh: medium to dark

grey

Color Weathered: orange,

maroon

Grain Size: N/A

Visible Minerals: none

Parting Thickness: platy to

slabby, 2-10mm

Parting Geometry:

discontinuous

Bedding Planes: N/A

Sedimentary Structures: bedded nodules, horizontal laminea

Fossil Content: part of unknown crustacean (Nektonic).

Color When Powdered: light tan

Luster of Streak: dull

Other: black and red weathering around nodules, oblong shaped

$\sim 2$ inches-1 foot

Unit Number: 2

Unit Thickness: 1.08 feet

Facies Number: 5

Rock Type: non-calcareous

shale

Interbeds: none

Color Fresh: dark grey

Color Weathered: yellow, red

Grain Size: N/A

Visible Minerals: none

Parting Thickness: platy, (2-

3mm)

Parting Geometry: non- parallel, discontinuous

Bedding Planes: irregular, bumpy

Sedimentary Structures:

horizontal bioturbation

Fossil Content: none
Color When Powdered: tan

Luster of Streak: dull

Other: Iridescent stains and

white crystal precipitate on

bedding surfaces.

Unit Number: 3

Unit Thickness: 3.42 feet

Facies Number: 5

Rock Type: non- calcareous

shale

Interbeds: none

Color Fresh: light-dark grey

Color Weathered: orange, red

Grain Size: N/A

Visible Minerals: none

Parting Thickness: platy, $\sim 1 \mathrm{~mm}$

Parting Geometry:

discontinuous

Bedding Planes: N/A

Sedimentary Structures:

nodules

Fossil Content: None

Color When Powdered: light

grey

Luster of Streak: intermediate

luster

Other: nodules randomly

distributed, shale beds draped

overtop

Unit Number: 4

Unit Thickness: 1.42 feet

Facies Number: 5

Rock Type: non-calcareous

shale

Interbeds: none

Color Fresh: light- dark grey

Color Weathered: orange, red,

white

Grain Size: N/A

Visible Minerals: unknown silt

sized grains

Parting Thickness: platy to

flaggy (1mm-5mm)

Parting Geometry:

discontinuous

Bedding Planes: N/A

Sedimentary Structures: none

Fossil Content: none

Color When Powdered: tan

Luster of Streak: dull
Other: grey shale is silty, distinct contact between facies 3 and 4

Unit Number: 5

Unit Thickness: 3 feet

Facies Number: 5 and 4

Rock Type: non-calcareous

shale

Interbeds: none

Color Fresh: grey to black

Color Weathered: white, grey

Grain Size: N/A

Visible Minerals: none

Parting Thickness: platy, (1-

$5 \mathrm{~mm}$ )

Parting Geometry:

discontinuous

Bedding Planes: N/A

Sedimentary Structures: none

Fossil Content: none

Color When Powdered: tan-

grey

Luster of Streak: semi waxy, mid luster

Other: very similar to Unit 4, weathers into irregular,

discontinuous chips

Unit Number: 6

Unit Thickness: 3 feet

Facies Number: 5

Rock Type: non-calcareous

shale

Interbeds: bedded siderite

Color Fresh: dark grey

Color Weathered: orange, red

Grain Size: N/A

Visible Minerals: none

Parting Thickness: platy

5mm, interbeds: < $5 \mathrm{~mm}$

Parting Geometry: sheet like,

Bedding Planes: irregular

Sedimentary Structures: $7 \mathrm{ft}$ long

bedded siderite nodules

Fossil Content: none

Color When Powdered: light

Luster of Streak: dull, interbeds:

semi-waxy

Other: lense shaped interbeds

range from 1- 5 inches 
Unit Number: 7

Unit Thickness: 6 feet

Facies Number: 5

Rock Type: dark grey to black

non-calcareous shale

Interbeds: none

Color Fresh: grey- black

Color Weathered: white, yellow

Grain Size: may contain silt

sized grains

Visible Minerals: N/A

Parting Thickness: platy, (2 -

5mm)

Parting Geometry:

discontinuous

Bedding Planes: irregular, wavy

Sedimentary Structures: none

Fossil Content: none

Color When Powdered: tan

Luster of Streak: semi waxy

Other: beds weathered into 1

inch lense-like features, gritty

Unit Number: 8

Unit Thickness: 5 feet

Facies Number: 5

Rock Type: Light non-

calcareous shale

Interbeds: none

Color Fresh: light to dark grey

Color Weathered: N/A

Grain Size: may contain silt

sized grains

Visible Minerals: N/A

Parting Thickness: platy to

flaggy (5-10mm)

Parting Geometry:

discontinuous

Bedding Planes: N/A

Sedimentary Structures: none

Fossil Content: none

Color When Powdered: white

Luster of Streak: dull

Other: lense like features larger

(1-5 inches), .partings are found

in .5-1 foot bedsets, gritty 


\section{PETERSBURG NORTH WV, OUTCROP}

\section{Location: 1.5 miles North of Petersburg, WV on Rt. 42 \\ Latitude/Longitude: $39.011781 /-79.131689$}

Unit Number: 1

Unit Thickness: 2.5 feet

Facies Number: 3

Rock Type: calcareous shale Interbeds: none

Color Fresh: black

Color Weathered: N/A

Grain Size: N/A

Visible Minerals: calcite

Parting Thickness: no distinct partings

Parting Geometry: N/A

Bedding Planes: N/A

Sedimentary Structures:

possible bioturbation

Fossil Content: possible calcite replaced fossils

Color When Powdered: tan, white

Luster of Streak: dull

Other: calcite veins, shale is

crumble and smudges fingers

\section{Unit Number: 2}

Unit Thickness: .5 feet

Facies Number: 3

Rock Type: calcareous shale

Interbeds: none

Color Fresh: black to grey

Color Weathered: tan

Grain Size: N/A

Visible Minerals: calcite

Parting Thickness: fissile to

platy, .5-3mm

Parting Geometry: slightly

irregular (shell debris), wavy

Bedding Planes: bumpy

Sedimentary Structures: N/A

Fossil Content: possible shell

debris

Color When Powdered: tan

Luster of Streak: intermediate

Other: small calcite filled veins

Unit Number: 3

Unit Thickness: 5.5 feet

Facies Number: 3
Rock Type: calcareous shale

Interbeds: none

Color Fresh: dark grey to black

Color Weathered: N/A

Grain Size: N/A

Visible Minerals: concretion:

calcite and pyrite

Parting Thickness: N/A

Parting Geometry:

discontinuous

Bedding Planes: irregular

Sedimentary Structures: bedded

concretions, randomly

distributed concretions

Fossil Content: none

Color When Powdered: light tan

Luster of Streak: dull

Other: oval concretions are heavy and contain visible crystals of pyrite and calcite $\sim 1$ 4inches and are only slightly calcareous, one concretions $\sim 1 \mathrm{ft}$ with shale draped over the top, base of unit shale breaks blocky and grades into more platy partings at the top of section

\section{Unit Number: 4}

Unit Thickness:

Facies Number: 3

Rock Type: calcareous shale

Interbeds: none

Color Fresh: black, brown, dark

grey

Color Weathered: N/A

Grain Size: N/A

Visible Minerals: none

Parting Thickness: N/A

Parting Geometry: N/A

Bedding Planes: semi-regular

Sedimentary Structures: small

reddish nodule

Fossil Content: none

Color When Powdered:

medium brown

Luster of Streak: medium waxy, peels

Other: very calcareous, partings

thinner than Unit 3, shale is

crumbly and partings bedding

surfaces are more regular than

Unit 3
Unit Number: 5

Unit Thickness: 5 feet

Facies Number: 1

Rock Type: calcareous shale/

mudstone

Interbeds: none

Color Fresh: dark grey

Color Weathered: tan to white

Grain Size: N/A

Visible Minerals: none

Parting Thickness: platy to

flaggy > 5mm

Parting Geometry: non-parallel, discontinuous

Bedding Planes: very irregular

Sedimentary Structures:

possible bioturbation,

Fossil Content: none

Color When Powdered: light

brown to tan

Luster of Streak: dull- slightly

waxy

Other: breaks in irregulars

chunks, little to no obvious

partings

Unit Number: 6

Unit Thickness: 1 foot

Facies Number: 3

Rock Type: calcareous shale

Interbeds: none

Color Fresh: black

Color Weathered: N/A

Grain Size: N/A

Visible Minerals: none

Parting Thickness: platy, $\sim 2-$

$3 \mathrm{~mm}$

Parting Geometry: irregular

Bedding Planes: irregular

Sedimentary Structures: none

Fossil Content: none

Color When Powdered: dark

brown, peels

Luster of Streak: waxy

Other: shale is soft and crumbly, breaks in angular pieces, leaves

black smudges on hands

Unit Number: 7

Unit Thickness: .5 feet

Facies Number: 1

Rock Type: calcareous shale 
Interbeds: none

Color Fresh: dark grey

Color Weathered: brown, tan, green

Grain Size: N/A

Visible Minerals: none

Parting Thickness: platy, 2-

$4 \mathrm{~mm}$

Parting Geometry: continuous, parallel

Bedding Planes: irregular surface

Sedimentary Structures: none

Fossil Content: none

Color When Powdered: tan

Luster of Streak: dull-

intermediate

Other: obvious change in parting

size from Unit 6

Unit Number: 8

Unit Thickness: .3 feet

Facies Number: 3

Rock Type: calcareous shale

Interbeds: none

Color Fresh: black

Color Weathered: N/A

Grain Size: N/A

Visible Minerals: none

Parting Thickness: platy, 2-3

$\mathrm{mm}$

Parting Geometry: platy,

Bedding Planes: N/A

Sedimentary Structures: none

Fossil Content: none

Color When Powdered: brown, peels

Luster of Streak: waxy

Other: same as Unit 6

Unit Number: 9

Unit Thickness: 2.7 feet

Facies Number: 1

Rock Type: calcareous shale

Interbeds: none

Color Fresh: grey

Color Weathered: none

Grain Size: N/A

Visible Minerals: none

Parting Thickness: platy, $\sim 1$ -

$2 \mathrm{~mm}$

Parting Geometry: N/A

Bedding Planes: semi-regular

Sedimentary Structures:

possible insipient nodules
Fossil Content: none

Color When Powdered: tan

Luster of Streak: medium waxy

Other: same as Unit 7, breaks in

larger sheets than Unit 6 and 8

Unit Number: 10

Unit Thickness: .5 feet

Facies Number: 3

Rock Type: calcareous shale

Interbeds: none

Color Fresh: black to brown

Color Weathered: N/A

Grain Size: N/A

Visible Minerals: none

Parting Thickness: N/A

Parting Geometry: N/A

Bedding Planes: N/A

Sedimentary Structures: none

Fossil Content: none

Color When Powdered: brown, peels

Luster of Streak: waxy

Other: second measured section, continuous with lower section

Unit Number: 11

Unit Thickness: 1 foot

Facies Number: 2 and 1

Rock Type: argillaceous

Limestone

Interbeds: calcareous shale

Color Fresh: dark grey

Color Weathered: tan

Grain Size: N/A

Visible Minerals: calcite

Parting Thickness: N/A

Parting Geometry: N/A

Bedding Planes: interbeds: very bumpy

Sedimentary Structures:

interbeds: bioturbation

Fossil Content: none

Color When Powdered: N/A

Luster of Streak: N/A

Other: limestone appears to be continuous, very thin layer calcareous shale separate

limestone beds, limestone beds

$\sim .33$ and .66 feet

Unit Number: 12

Unit Thickness: .5 feet

Facies Number: 1

Rock Type: calcareous shale
Interbeds: none

Color Fresh: grey

Color Weathered: N/A

Grain Size: N/A

Visible Minerals: none

Parting Thickness: platy, $\sim 4-5$

$\mathrm{mm}$

Parting Geometry:

discontinuous

Bedding Planes: N/A

Sedimentary Structures: none

Fossil Content: none

Color When Powdered: tan

Luster of Streak: dull to

intermediate

Other: none

Unit Number: 13

Unit Thickness: 1 foot

Facies Number: 2

Rock Type: argillaceous

limestone

Interbeds: none

Color Fresh: dark grey

Color Weathered: N/A

Grain Size: N/A

Visible Minerals: none

Parting Thickness: N/A

Parting Geometry: N/A

Bedding Planes: N/A

Sedimentary Structures:

possible scour

Fossil Content: none

Color When Powdered: N/A

Luster of Streak: N/A

Other: base of limestone bed is

curved, scoured into underlying shale

Unit Number: 14

Unit Thickness: 1.5 feet

Facies Number: 1

Rock Type: calcareous shale

Interbeds: none

Color Fresh: dark grey

Color Weathered: tan

Grain Size: N/A

Visible Minerals: none

Parting Thickness: platy, $\sim 5 \mathrm{~mm}$

Parting Geometry:

discontinuous

Bedding Planes: irregular

Sedimentary Structures: red, orange nodules, bioturbation

Fossil Content: none 
Color When Powdered: brown, peels

Luster of Streak: waxy

Other: none

Unit Number: 15

Unit Thickness: 1 foot

Facies Number: 2

Rock Type: limestone

Interbeds: none

Color Fresh: grey to dark grey

Color Weathered: N/A

Grain Size: N/A

Visible Minerals: calcite

Parting Thickness: N/A

Parting Geometry: N/A

Bedding Planes: N/A

Sedimentary Structures:

possible bioturbation, reddish

nodules

Fossil Content: possible

oxidized fossils

Color When Powdered: tan

Luster of Streak: dull

Other: round bumps possible

calcite replaced fossil debris

Unit Number: 16

Unit Thickness: .5 feet

Facies Number: 1

Rock Type: calcareous shale

Interbeds: none

Color Fresh: grey

Color Weathered: grey, tan,

yellow

Grain Size: N/A

Visible Minerals: none

Parting Thickness: platy, $\sim 2-3$

$\mathrm{mm}$

Parting Geometry: N/A

Bedding Planes: N/A

Sedimentary Structures: none

Fossil Content: none

Color When Powdered: medium

brown

Luster of Streak: intermediate

Other: none

Unit Number: 17

Unit Thickness: .5 feet

Facies Number: 1

Rock Type: calcareous shale

Interbeds: none

Color Fresh: grey to dark grey

Color Weathered: N/A
Grain Size: N/A

Visible Minerals: none

Parting Thickness: fissile to

platy, $\sim 1-2 \mathrm{~mm}$

Parting Geometry: N/A

Bedding Planes: N/A

Sedimentary Structures: none

Fossil Content: none

Color When Powdered: brown, peels

Luster of Streak: waxy

Other: thinner partings than

underlying Unit 16

Unit Number: 18

Unit Thickness: 1.5 feet

Facies Number: 2

Rock Type: limestone

Interbeds: none

Color Fresh: dark grey

Color Weathered: $\tan$

Grain Size: N/A

Visible Minerals: calcite

Parting Thickness: N/A

Parting Geometry: N/A

Bedding Planes: N/A

Sedimentary Structures: none

Fossil Content: gastropod mold, calcite replaced fossils

Color When Powdered: N/A

Luster of Streak: N/A

Other: limestone body thickness

changes laterally, very

competent, calcite filled veins

Unit Number: 19

Unit Thickness: .5 feet

Facies Number: 1

Rock Type: calcareous shale

Interbeds: none

Color Fresh: grey

Color Weathered: N/A

Grain Size: N/A

Visible Minerals: none

Parting Thickness: platy, 2-3

mm

Parting Geometry: N/A

Bedding Planes: irregular

Sedimentary Structures: none

Fossil Content: none

Color When Powdered: N/A

Luster of Streak: N/A

Other: none
Unit Number: 20

Unit Thickness: 4 feet

Facies Number: 4

Rock Type: non-calcareous

shale

Interbeds: none

Color Fresh: black to dark grey

Color Weathered: orange, red,

yellow, white

Grain Size: N/A

Visible Minerals: none

Parting Thickness: fissile to

platy, $\sim .5-1 \mathrm{~mm}$

Parting Geometry: parallel,

continuous

Bedding Planes: regular- semi

regular

Sedimentary Structures: none

Fossil Content: none

Color When Powdered: dark

brown

Luster of Streak: very waxy

Other: some slightly waxy

features on bedding planes

Unit Number: 21

Unit Thickness: 16 feet

Facies Number: 4

Rock Type: non- calcareous

shale

Interbeds: none

Color Fresh: black to dark grey

Color Weathered: tan to orange

Grain Size: N/A

Visible Minerals: none

Parting Thickness: platy-

flaggy, 2-10mm (un-weathered)

Parting Geometry: N/A

Bedding Planes: mostly regular

Sedimentary Structures: none

Fossil Content: none

Color When Powdered: dark

brown

Luster of Streak: waxy, peels

Other: parting not distinctive on

lower un-weathered portion of

outcrop, shale breaks in very

blocky irregular shards, upper 6

feet of unit is more weathered

and has slightly more platy

partings (2-5 mm), XRD

samples taken a 14 feet 


\section{TYRONE PA, OUTCROP}

Location: Tyrone, PA Auto

Salvage

Latitude/Longitude: $40^{\circ} 38^{\prime}$

55. 28"/ 78 16'11.78"

Notes: Outcrop is measured in two separate sections. Beds are both dipping nearly vertically and upper portion of outcrop cannot be accessed from the ground.

Unit Number: 1

Unit Thickness: 2 feet

Facies Number: 5

Rock Type: non-calcareous

shale

Interbeds: none

Color Fresh: dark grey

Color Weathered: orange

Grain Size: N/A

Visible Minerals: none

Parting Thickness: platy, 3-

$4 \mathrm{~mm}$

Parting Geometry: N/A

Bedding Planes: irregular, wavy

Sedimentary Structures: large

calcareous concretions

Fossil Content: none

Color When Powdered: medium

to dark brown

Luster of Streak: semi-waxy

Other: concretions in section

are large, not enough section is

exposed see entire concretions, concretions found in float nearby are calcareous, oval shaped and measure up to 5 feet in length.

Unit Number: 2

Unit Thickness: 4 feet

Facies Number: 5

Rock Type: non-calcareous

shale

Interbeds: none

Color Fresh: dark grey

Color Weathered: nodules

weather orange

Grain Size: N/A

Visible Minerals: none
Parting Thickness: platy, 1$4 \mathrm{~mm}$

Parting Geometry: N/A

Bedding Planes: semi-regular

Sedimentary Structures: slightly

calcareous pseudo nodules

Fossil Content: none

Color When Powdered: dark

brown

Luster of Streak: waxy

Other: un-weathered shale does

not break into partings and

contains internal laminations

Unit Number: 3

Unit Thickness: 4 feet

Facies Number: 5

Rock Type: non-calcareous

shale

Interbeds: none

Color Fresh: very dark grey

Color Weathered: white, orange, nodules have iridescent

brown, maroon and white stains

Grain Size: N/A

Visible Minerals: calcite in

veins

Parting Thickness: fissile to

platy, .5-2mm

Parting Geometry:

discontinuous

Bedding Planes: irregular, wavy, nodules

Sedimentary Structures:

incipient nodules, oval shaped

lumps on surface

Fossil Content: none

Color When Powdered: dark

brown

Luster of Streak: waxy

Other: shale breaks into small

chips, oxidizing halos around

incipient nodules, small calcite

filled veins present

Unit Number: 4

Unit Thickness: 1 foot

Facies Number: 4

Rock Type: non-calcareous

shale

Interbeds: none

Color Fresh: black
Color Weathered: N/A

Grain Size: N/A

Visible Minerals: pyrite

Parting Thickness: fissile to

platy, .5-2mm

Parting Geometry: continuous

Bedding Planes: regular

Sedimentary Structures:

insipient nodules

Fossil Content: none

Color When Powdered: N/A

Luster of Streak: N/A

Other: shale is brittle

Unit Number: 5

Unit Thickness: 2 feet

Facies Number: 3

Rock Type: calcareous shale

Interbeds: none

Color Fresh: dark grey to black

Color Weathered: white, orange

Grain Size: N/A

Visible Minerals: pyrite

Parting Thickness: no apparent

parting

Parting Geometry: N/A

Bedding Planes: N/A

Sedimentary Structures: pyrite

nodules or replaced shell debris,

internal laminations

Fossil Content: small

brachiopods

Color When Powdered: dark

brown

Luster of Streak: waxy

Other: some shale is only

slightly calcareous

Unit Number: 6

Unit Thickness: 4 feet

Facies Number: 4

Rock Type: non-calcareous

shale

Interbeds: none

Color Fresh: black

Color Weathered: white, orange

Grain Size: N/A

Visible Minerals: pyrite

Parting Thickness: platy, 2-

$4 \mathrm{~mm}$

Parting Geometry: N/A

Bedding Planes: mostly regular 
Sedimentary Structures: pyrite nodules or replaced shell debris Fossil Content: calcareous bumps

Color When Powdered: medium to dark brown

Luster of Streak: semi-waxy Other: pyrite is seen in nodule like forms on bedding partings, some large pyrite cubes

Unit Number: 7

Unit Thickness: 1.5 feet

Facies Number: 4

Rock Type: non-calcareous

shale

Interbeds: none

Color Fresh: black

Color Weathered: white, yellow bubbly precipitate on surface

Grain Size: N/A

Visible Minerals: calcite in healed veins

Parting Thickness: papery, mostly destroyed

Parting Geometry: N/A

Bedding Planes: N/A

Sedimentary Structures: none

Fossil Content: none

Color When Powdered: dark

brown

Luster of Streak: waxy

Other: fault gauge present, beds are very deformed, shale is sooty and coaly, uranium 25ppm

Unit Number: 8

Unit Thickness: 2 feet

Facies Number: 3

Rock Type: calcareous shale

Interbeds: none

Color Fresh: dark grey

Color Weathered: yellow

Grain Size: N/A

Visible Minerals: pyrite

Parting Thickness: no

distinctive partings

Parting Geometry: N/A

Bedding Planes: N/A

Sedimentary Structures: pyrite nodules or replaced fossil debris Fossil Content: replaced fossil debris

Color When Powdered: medium brown
Luster of Streak: semi-waxy

Other: some shale is only

slightly calcareous

Unit Number: 9

Unit Thickness: 1 foot

Facies Number: 4

Rock Type: non-calcareous

Interbeds: none

Color Fresh: black

Color Weathered:

Grain Size: N/A

Visible Minerals: none

Parting Thickness: papery to

fissile $\sim .5-1 \mathrm{~mm}$

Parting Geometry: N/A

Bedding Planes: regular, flat

Sedimentary Structures: none

Fossil Content: two large

ammonoids

Color When Powdered: medium

brown

Luster of Streak: semi-waxy

Other: very deformed, very

similar to unit 7

Unit Number: 10

Unit Thickness: 2.5 feet

Facies Number: 5

Rock Type: non-calcareous

shale

Interbeds: none

Color Fresh: dark grey

Color Weathered: brown,

maroon, and iridescent staining

Grain Size: N/A

Visible Minerals: none

Parting Thickness: platy, 1-

$3 \mathrm{~mm}$

Parting Geometry: wavy

Bedding Planes: irregular, ridges

Sedimentary Structures: none

Fossil Content: none

Color When Powdered: brown

Luster of Streak: waxy

Other: none 


\section{WHIP GAP WV, OUTCROP}

\section{Location: 5.1 miles Southwest of Antioch, WV on Co. Rt. 7 (Whip Gap, Knobly Road) Latitude/Longitude: 39.269075/-79.066308}

\section{Unit Number: 1}

Unit Thickness: 3 feet Facies Number: Needmore Shale

Rock Type: non calcareous mudstone

Interbeds: none

Color Fresh: brown, tan, Color Weathered: green, tan

clay

Grain Size: N/A

Visible Minerals: none

Parting Thickness: some platy, 2-4mm

Parting Geometry: non parallel, discontinuous

Bedding Planes: irregular

Sedimentary Structures:

bioturbation

Fossil Content: brachiopods, trilobites

Color When Powdered: N/A

Luster of Streak: N/A

Other: none

\section{Unit Number: 2}

Unit Thickness: 6 feet

Facies Number: N/A

Rock Type: covered section

Interbeds: N/A

Color Fresh: N/A

Color Weathered: N/A

Grain Size: N/A

Visible Minerals: N/A

Parting Thickness: N/A

Parting Geometry: N/A

Bedding Planes: N/A

Sedimentary Structures: N/A

Fossil Content: N/A

Color When Powdered: N/A

Luster of Streak: N/A

Other: covered section consists

of Needmore/Marcellus contact and possible bentonites beds.

Unit Number: 3

Unit Thickness: 2 feet
Facies Number: 4 and 6

Rock Type: non- calcareous

black shale

Interbeds: bentonite

Color Fresh: black, interbeds:

tan

Color Weathered: N/A,

interbeds: tan to brown clay

Grain Size: interbeds: sand sized

grains

Visible Minerals: interbeds:

mica

Parting Thickness: papery <

$.5 \mathrm{~mm}$

Parting Geometry: N/A

Bedding Planes: N/A

Sedimentary Structures: N/A

Fossil Content: none

Color When Powdered: black

Luster of Streak: waxy to semi-

waxy

Other: interbeds: 3 bentonite

beds ranging up to $\sim .5$ feet,

some black shale is coaly and

crumbles instead of parting,

black shale is sooty and

smudges fingers

Unit Number: 4

Unit Thickness: 8 feet

Facies Number: 4

Rock Type: non -calcareous

shale

Interbeds: none

Color Fresh: black/brown

Color Weathered: N/A

Grain Size: some tan silt sized

grains

Visible Minerals: tan grains

Parting Thickness: fissile to

platy $\sim 4 \mathrm{~mm}$ and less

Parting Geometry: N/A

Bedding Planes: N/A

Sedimentary Structures: internal

discontinuous laminations

Fossil Content: styliolinid,

bryozoans (coquina?)

Color When Powdered: dark

brown

Luster of Streak: waxy

Other: thinly bedded shale with

internal platy partings $\sim 3-4 \mathrm{~mm}$,

unit contains an anomalous brown bed of very low density homogenous material, shale breaks blocky, locally deformed 2 feet repeat

Unit Number: 5

Unit Thickness: 6 feet

Facies Number: 4

Rock Type: non-calcareous

shale

Interbeds: none

Color Fresh: black

Color Weathered: tan, white

Grain Size: N/A

Visible Minerals: none

Parting Thickness: platy $\sim 2 \mathrm{~mm}$

Parting Geometry: N/A

Bedding Planes: N/A

Sedimentary Structures: none

Fossil Content: none

Color When Powdered: brown-

black

Luster of Streak: N/A

Other: deformed fault zone 22-

26 feet, some beds $\sim 2-3 \mathrm{~cm}$ are more massive, coaly and scratch black, some beds $\sim 2 \mathrm{~cm}$ have internal partings $\sim 2-3 \mathrm{~mm}$ and have lighter powder

Unit Number: 6

Unit Thickness: 4 feet

Facies Number: 4

Rock Type: non-calcareous

shale

Interbeds: none

Color Fresh: black

Color Weathered: tan, white, green

Grain Size: N/A

Visible Minerals: none

Parting Thickness: platy, $2-4 \mathrm{~mm}$

Parting Geometry: not parallel

Bedding Planes: relatively

smooth

Sedimentary Structures: none

Fossil Content: none

Color When Powdered: brown

Luster of Streak: waxy

Other: Fault between 25-26 feet, possible at of section, thicker bedsets $\sim 8-10 \mathrm{~cm}$ with internal partings $\sim 2-4 \mathrm{~mm}$ 


\author{
Unit Number: 7 \\ Unit Thickness: 10 feet \\ Facies Number: 4 \\ Rock Type: non-calcareous \\ shale \\ Interbeds: none \\ Color Fresh: black \\ Color Weathered: red, orange, \\ white \\ Grain Size: N/A \\ Visible Minerals: none \\ Parting Thickness: platy, 2-3mm \\ Parting Geometry: \\ discontinuous \\ Bedding Planes: relatively \\ smooth \\ Sedimentary Structures: none \\ Fossil Content: none \\ Color When Powdered: dark \\ brown to black \\ Luster of Streak: waxy \\ Other: fault between 32-33 feet, \\ shale breaks jagged and sharp, \\ 38-42 feet deformed by drag \\ fold fault possibly repeated \\ section
}

\section{Unit Number: 8}

Unit Thickness: 5 feet

Facies Number: 4

Rock Type: non-calcareous

shale

Interbeds: none

Color Fresh: black

Color Weathered: grey, white, yellow

Grain Size: N/A

Visible Minerals: none

Parting Thickness: platy,

$2 \mathrm{~mm}$

Parting Geometry: deformed

Bedding Planes: deformed

Sedimentary Structures: none

Fossil Content: none

Color When Powdered: medium

brown

Luster of Streak: semi-waxy

Other: fault between 42-43 feet,

fault gauge deformed bedding

partings, some shale shows

bedding $3 \mathrm{~cm}$ with $\sim 2 \mathrm{~mm}$

internal partings
Unit Number: 9

Unit Thickness: 10 feet

Facies Number: 4

Rock Type: non-calcareous

shale

Interbeds: none

Color Fresh: black

Color Weathered: white, yellow

Grain Size: N/A

Visible Minerals: none

Parting Thickness: platy, 1 -

$3 \mathrm{~mm}$

Parting Geometry: continuous

Bedding Planes: irregular,

curved

Sedimentary Structures:

nodules

Fossil Content: none

Color When Powdered: dark

brown

Luster of Streak: semi-waxy

Other: shale breaks into

irregular discontinuous pieces, oval nodules create

discontinuity.

Unit Number: 10

Unit Thickness: 11 feet

Facies Number: 4

Rock Type: non-calcareous

shale

Interbeds: none

Color Fresh: black

Color Weathered: N.A

Grain Size: N/A

Visible Minerals: none

Parting Thickness: fissile to

platy, .5-2mm

Parting Geometry:

discontinuous, non-parallel

Bedding Planes: irregular,

curved, but smooth

Sedimentary Structures:

possible horizontal bioturbation, soft red nodule- like feature

possibly siderite

Fossil Content: none

Color When Powdered: brown

to black

Luster of Streak: waxy, come

off in peels

Other: brown and black marks

may indicate horizontal

bioturbation on bedding planes 


\section{BEDFORD PA, OUTCROP}

Location: 10.9 miles

Northwest of Bedford, PA on

PA-56/US 220 (PJ's

Contracting Services)

Latitude/Longitude:

40.138302/-78.583749

Unit Number: 1

Unit Thickness: .75 feet

Facies Number: 2

Rock Type: Limestone

Interbeds: None

Color Fresh: dark grey

Color Weathered: light grey

Grain Size: N/A

Visible Minerals: mica,

crystalline calcite

Parting Thickness: N/A

Parting Geometry: N/A

Bedding Planes: N/A

Sedimentary Structures: none

Fossil Content: None

Color When Powdered: N/A

Luster of Streak: N/A

Other: Mica (Biotite present in vertical vein)

Unit Number: 2

Unit Thickness: 2.67 feet

Facies Number: 3

Rock Type: calcareous shale

Interbeds: none

Color Fresh: black to dark grey

Color Weathered: N/A

Grain Size: N/A

Visible Minerals: N/A

Parting Thickness: platy $\sim 1 \mathrm{~mm}$,

locally papery partings $\sim .5 \mathrm{~mm}$

Parting Geometry: non parallel, wavy, discontinuous

Bedding Planes: N/A

Sedimentary Structures: none

Fossil Content: rare brown shell

fragments

Color When Powdered: white

Luster of Streak: dull

Other: none

\section{Unit Number: 3}

Unit Thickness: .083 feet

Facies Number: 6

Rock Type: micaceous

claystone, bentonite
Interbeds: none

Color Fresh: very light grey to

brown

Color Weathered: tan

Grain Size: fine sand

Visible Minerals: micas

Parting Thickness: N/A

Parting Geometry: N/A

Bedding Planes: N/A

Sedimentary Structures: none

Fossil Content: none

Color When Powdered: off -

white

Luster of Streak: shiny, waxy

Other: Unit weathers to tan clay

Unit Number: 4

Unit Thickness: 1 foot

Facies Number: 2

Rock Type: limestone

Interbeds: none

Color Fresh: dark grey

Color Weathered: light grey

Grain Size: N/A

Visible Minerals: crystalline

calcite

Parting Thickness: N/A

Parting Geometry: N/A

Bedding Planes: N/A

Sedimentary Structures: scour

base

Fossil Content: none

Color When Powdered: N/A

Luster of Streak: N/A

Other: scours into underlying

Unit 2: papery shale $\sim .5 \mathrm{~mm}$

partings

Unit Number: 5

Unit Thickness: 1.08 feet

Facies Number: 6

Rock Type: bentonite

Interbeds: None

Color Fresh: brown

Color Weathered: off -white to $\tan$

Grain Size: very fine to coarse

sand sized mica grains

Visible Minerals: mica, pyrite

Parting Thickness: N/A

Parting Geometry: N/A

Bedding Planes: N/A

Sedimentary Structures: none
Fossil Content: none

Color When Powdered: N/A

Luster of Streak: N/A

Other: sharp contact with

underlying unit

Unit Number: 6

Unit Thickness: .75 feet

Facies Number: 3

Rock Type: calcareous shale

Interbeds: None

Color Fresh: dark grey to black

Color Weathered: red, orange

Grain Size: occasional silt sized

grains

Visible Minerals: N/A

Parting Thickness: Platy $\sim$ -

$5 \mathrm{~mm}$

Parting Geometry:

discontinuous

Bedding Planes: N/A

Sedimentary Structures: none

Fossil Content: none

Color When Powdered: dark

Luster of Streak: semi- waxy

Other: beds $\sim 1$ inch of internal

platy partings

Unit Number: 7

Unit Thickness: 2.25 feet

Facies Number: 2, 3 and 4

Rock Type: Limestone

Interbeds: dark grey to black

calcareous to non-calcareous

shale

Color Fresh: N/A

Color Weathered: N/A

Grain Size: N/A

Visible Minerals: Calcite

Parting Thickness: interbeds:

papery to fissile $(.5 \mathrm{~mm}-1 \mathrm{~mm})$

Parting Geometry: interbeds:

parallel

Bedding Planes: interbeds:

regular

Sedimentary Structures:

lenticular limestone bodies.

Fossil Content: some

fragmented shell debris

Color When Powdered: N/A

Luster of Streak: N/A

Other: beds of limestone range

from 1-5 inches in width and $\sim 3$ 
feet in length. Shale at top of unit is in 1inch books and grades from calcareous to noncalcareous shale.

\section{Unit Number: 8}

Unit Thickness: 2 feet

Facies Number: 4 and 5

Rock Type: non-calcareous shale

Interbeds: non-calcareous shale (silty)

Color Fresh: black, interbeds:

dark grey

Color Weathered: yellow, orange

Grain Size: N/A

Visible Minerals: none

Parting Thickness: papery to

fissile $(.5-1 \mathrm{~mm})$

Parting Geometry: parallel

Bedding Planes: regular, flat

Sedimentary Structures:

concretion $\sim 1 \mathrm{ft}$ in length

Fossil Content: none

Color when powdered:

interbeds: light

Luster of Streak: interbeds: dull

Other: black non-calcareous

shale comes in $\sim 1$ inch books.

\section{Unit Number: 9}

Unit Thickness: .59 feet

Facies Number: 4

Rock Type: non-calcareous

shale

Interbeds: none

Color Fresh: black

Color Weathered: yellow, orange

Grain Size: N/A

Visible Minerals: none

Parting Thickness: papery

(.5mm or less)

Parting Geometry: parallel, discontinuous

Bedding Planes: regular

Sedimentary Structures: none

Fossil Content: none

Color When Powdered: N/A

Luster of Streak: N/A

Other: none
Unit Number: 10

Unit Thickness: 3- 5 feet

estimated

Facies Number: N/A

Rock Type: covered section

Interbeds: N/A

Color Fresh: N/A

Color Weathered: N/A

Grain Size: N/A

Visible Minerals: N/A

Parting Thickness: N/A

Parting Geometry: N/A

Bedding Planes: N/A

Sedimentary Structures: N/A

Fossil Content: N/A

Color When Powdered: N/A

Luster of Streak: N/A

Other: N/A

\section{Unit Number: 11}

Unit Thickness: 1.33 feet

Facies Number: 4

Rock Type: non-calcareous

shale

Interbeds: none

Color Fresh: black

Color Weathered: white

Grain Size: N/A

Visible Minerals: pyrite

Parting Thickness: N/A

Parting Geometry: blocky

Bedding Planes: regular

Sedimentary Structures:

horizontal laminations, pyrite

laminations

Fossil Content: none

Color When Powdered: dark

brown

Luster of Streak: waxy

Other: white weathering on bedding planes; no horizontal bedding partings observed, breaks in blocky shapes.

\section{Unit Number: 12}

Unit Thickness: 67 feet

Facies Number: 6

Rock Type: bentonite

Interbeds: none

Color Fresh: tan to grey

Color Weathered: tan clay

Grain Size: clay- very fine sand

(whole range)

Visible Minerals: mica, pyrite

Parting Thickness: N/A
Parting Geometry: N/A

Bedding Planes: N/A

Sedimentary Structures: graded

Fossil Content: None

Color When Powdered: N/A

Luster of Streak: N/A

Other: graded from brown

claystone to micaceous sandstone. (zircon age data on this unit.)

\section{Unit Number: 13}

Unit Thickness: 1.33 feet

Facies Number: 4

Rock Type: non-calcareous

shale

Interbeds: none

Color Fresh: black

Color Weathered: N/A

Grain Size: N/A

Visible Minerals: pyrite

Parting Thickness: platy,

$1 \mathrm{~mm}$

Parting Geometry: N/A

Bedding Planes: semi- irregular

Sedimentary Structures: pyrite

nodules, fine laminations.

Fossil Content: none

Color When Powdered: brown

luster of Streak: waxy

Other: pyrite nodules $\sim 5 \mathrm{~mm}$,

black shale comes in 1-4 inch

competent packages.

\section{Unit Number: 14}

Unit Thickness: 9.84 feet

Facies Number: 4

Rock Type: non-calcareous

shale

Interbeds: none

Color Fresh: black

Color Weathered: yellow,

orange, white

Grain Size: N/A

Visible Minerals: pyrite

Parting Thickness: platy, $\sim 1 \mathrm{~mm}$

Parting Geometry: parallel,

discontinuous

Bedding Planes: regular

Sedimentary Structures:

carbonate concretions (6 inches-

1 foot), internal laminations

Fossil Content: none

Color When Powdered: N/A

Luster of Streak: N/A 
Other: 1 inch books with

internal laminations, breaks in angular fragments. 


\section{HISER WV, OUTCROP}

Location: 3.3 miles Southeast of Petersburg, WV on Co. Rt. 9

Latitude/Longitude:38.957940/

$\mathbf{- 7 9 . 1 1 2 8 0 6}$

Unit Number: 1

Unit Thickness: $66 \mathrm{~cm}$

Facies Number: 1

Rock Type: calcareous shale

Interbeds: none

Color Fresh: grey

Color Weathered: N/A

Grain Size: silt sized grains

Visible Minerals: N/A

Parting Thickness: N/A

Parting Geometry: N/A

Bedding Planes: irregular,

bumpy

Sedimentary Structures:

bioturbated

Fossil Content: none

Color When Powdered: N/A

Luster of Streak: N/A

Other: none

Unit Number: 2

Unit Thickness: $15 \mathrm{~cm}$

Facies Number: 2

Rock Type: limestone, marl

Interbeds: none

Color Fresh: N/A

Color Weathered: brown

Grain Size: N/A

Visible Minerals: none

Parting Thickness: N/A

Parting Geometry: N/A

Bedding Planes: irregular

bumpy

Sedimentary Structures: none

Fossil Content: one shell found

Color When Powdered: N/A

Luster of Streak: N/A

Other: brown, shaley, slightly

fossiliferous limestone

Unit Number: 3

Unit Thickness: $50 \mathrm{~cm}$

Facies Number: 1

Rock Type: calcareous shale

Interbeds: none

Color Fresh: grey

Color Weathered: N/A
Grain Size: silty

Visible Minerals: N/A

Parting Thickness: N/A

Parting Geometry: N/A

Bedding Planes: N/A

Sedimentary Structures: none

Fossil Content: none

Color When Powdered: N/A

Luster of Streak: N/A

Other: N/A

Unit Number: 4

Unit Thickness: $26 \mathrm{~cm}$

Facies Number: 2

Rock Type: limestone

Interbeds: none

Color Fresh: very dark grey

Color Weathered: N/A

Grain Size: N/A

Visible Minerals: N/A

Parting Thickness: N/A

Parting Geometry: N/A

Bedding Planes: N/A

Sedimentary Structures: none

Fossil Content: none

Color When Powdered: N/A

Luster of Streak: N/A

Other: limestone is micritic

Unit Number: 5

Unit Thickness: $126 \mathrm{~cm}$

Facies Number: 1

Rock Type: calcareous shale, marl

Interbeds: none

Color Fresh: grey

Color Weathered: N/A

Grain Size: silty

Visible Minerals: N/A

Parting Thickness: N/A

Parting Geometry: N/A

Bedding Planes: irregular, bumpy

Sedimentary Structures: vertical burrows

Fossil Content: none

Color When Powdered: N/A

Luster of Streak: N/A

Other: none

Unit Number: 6

Unit Thickness: $12 \mathrm{~cm}$
Facies Number: 2

Rock Type: limestone

Interbeds: none

Color Fresh: N/A

Color Weathered: N/A

Grain Size: N/A

Visible Minerals: N/A

Parting Thickness: N/A

Parting Geometry: N/A

Bedding Planes: N/A

Sedimentary Structures: none

Fossil Content: none

Color When Powdered: N/A

Luster of Streak: N/A

Other: none

Unit Number: 7

Unit Thickness: $22 \mathrm{~cm}$

Facies Number: 1

Rock Type: calcareous shale,

marl

Interbeds: none

Color Fresh: grey

Color Weathered: brown

Grain Size: N/A

Visible Minerals: N/A

Parting Thickness: N/A

Parting Geometry: N/A

Bedding Planes: N/A

Sedimentary Structures: none

Fossil Content: none

Color When Powdered: N/A

Luster of Streak: N/A

Other: none

Unit Number: 8

Unit Thickness: $27-40 \mathrm{~cm}$

Facies Number: 2

Rock Type: limestone

Interbeds: none

Color Fresh: N/A

Color Weathered: N/A

Grain Size: N/A

Visible Minerals: N/A

Parting Thickness: N/A

Parting Geometry: N/A

Bedding Planes: N/A

Sedimentary Structures: tracks

and trails

Fossil Content: none

Color When Powdered: N/A

Luster of Streak: N/A 
Other: limestone body thins

Unit Number: 9

Unit Thickness: N/A

Facies Number: 4

Rock Type: non-calcareous

shale

Interbeds: none

Color Fresh: black

Color Weathered: orange

Grain Size: N/A

Visible Minerals: none

Parting Thickness: fissile

Parting Geometry: N/A

Bedding Planes: N/A

Sedimentary Structures:

laminated

Fossil Content: none

Color When Powdered: N/A

Luster of Streak: N/A

Other: orange oxidizing halos 


\section{SOUTH BRANCH OF THE POTAMAC WV, OUTCROP}

Location: 1.9 miles South of

Fort Seybert, WV on Co.

Rt.34 (South Branch)

Latitude/Longitude:38.674019/

$-79.203486$

Unit Number: 1

Unit Thickness: 7 feet

Facies Number: 4

Rock Type: non-calcareous

shale

Interbeds: none

Color Fresh: very black

Color Weathered: orange,

white, and maroon to brown

staining

Grain Size: N/A

Visible Minerals: quartz

Parting Thickness: no

distinctive partings

Parting Geometry: N/A

Bedding Planes: N/A

Sedimentary Structures: none

Fossil Content: none

Color When Powdered: dark

brown

Luster of Streak: waxy

Other: shale breaks into

irregular pieces $1-3 \mathrm{~cm}$, beds are

deformed $\sim 45$ degrees, vertical

fractures cut section, quartz

filled veins

Unit Number: 2

Unit Thickness: 4 feet

Facies Number: 4

Rock Type: non-calcareous

shale

Interbeds: none

Color Fresh: black

Color Weathered: orange,

maroon to brown

Grain Size: N/A

Visible Minerals: none

Parting Thickness: platy, 1-

$3 \mathrm{~mm}$

Parting Geometry: N/A

Bedding Planes: slightly

irregular, smooth ridges on

bedding surfaces

Sedimentary Structures: none

Fossil Content: none

Color When Powdered: dark brown

Luster of Streak: semi waxy

Other: none

Unit Number: 3

Unit Thickness: 4.5 feet

Facies Number: 4

Rock Type: non-calcareous

shale

Interbeds: none

Color Fresh: black to dark grey

Color Weathered: N/A

Grain Size: N/A

Visible Minerals: none

Parting Thickness: fissile to

platy, < 1mm

Parting Geometry: parallel,

continuous

Bedding Planes: regular, nearly

smooth

Sedimentary Structures: none

Fossil Content: none

Color When Powdered: medium

brown

Luster of Streak: semi-waxy

Other: shale breaks into fissile

sheets, shale partings are in

competent books, small fault

after this unit

\section{Unit Number: 4}

Unit Thickness: 2.5 feet

Facies Number: 5

Rock Type: non-calcareous

shale

Interbeds: none

Color Fresh: medium grey

Color Weathered: orange, red

Grain Size: N/A

Visible Minerals: none

Parting Thickness: platy, 1-

$5 \mathrm{~mm}$

Parting Geometry: N/A

Bedding Planes: mostly regular, some wavy ridges on surface

Sedimentary Structures: none

Fossil Content: none

Color When Powdered: light

brown

Luster of Streak: dull

Other: small fault directly before this unit
Unit Number: 5

Unit Thickness: 5 feet

Facies Number: 4

Rock Type: non-calcareous

Interbeds: none

Color Fresh: black to dark grey

Color Weathered: N/A

Grain Size: N/A

Visible Minerals: none

Parting Thickness: platy, 2-

$3 \mathrm{~mm}$

Parting Geometry:

discontinuous

Bedding Planes: slightly bumpy

and irregular, ridges

Sedimentary Structures: small

nodules on bedding planes

Fossil Content: none

Color When Powdered: medium

brown

Luster of Streak: semi-waxy

Other: nodules are raised bumps

on bedding planes (incipient)

Unit Number: 6

Unit Thickness: 3 feet

Facies Number: 5

Rock Type: non-calcareous

shale

Interbeds: none

Color Fresh: medium grey

Color Weathered: grey

Grain Size: N/A

Visible Minerals: none

Parting Thickness: platy to

flaggy, 2-10mm

Parting Geometry:

discontinuous

Bedding Planes: irregular

Sedimentary Structures: none

Fossil Content: none

Color When Powdered: tan to

light brown

Luster of Streak: intermediate

Other: partings less distinctive

than underlying unit

Unit Number: 7

Unit Thickness: 2 feet

Facies Number: 4

Rock Type: non-calcareous

shale 
Interbeds: none

Color Fresh: dark grey to black

Color Weathered: N/A

Grain Size: N/A

Visible Minerals: none

Parting Thickness: platy, 1-

2mm

Parting Geometry:

discontinuous

Bedding Planes: regular, some ridges

Sedimentary Structures: none

Fossil Content: none

Color When Powdered: medium brown

Luster of Streak: semi-waxy

Other: shale is brittle

\section{Unit Number: 8}

Unit Thickness: 2 feet

Facies Number: 4

Rock Type: non-calcareous

shale

Interbeds: none

Color Fresh: dark grey to black

Color Weathered: N/A

Grain Size: N/A

Visible Minerals: none

Parting Thickness: fissile to

platy, .5-1mm

Parting Geometry: N/A

Bedding Planes: N/A

Sedimentary Structures:

concretion, $\sim 4$ inches

Fossil Content: none

Color When Powdered: N/A

Luster of Streak: N/A

Other: first .3 feet of unit is

crumbly fault gauge, bedding is destroyed and a white to tan weathering on surface, shale is soft and flaky

\section{Unit Number: 9}

Unit Thickness: 8 feet

Facies Number: 4 and 5

Rock Type: non-calcareous

shale

Interbeds: none

Color Fresh: grey to black

Color Weathered: light grey,

white, orange, and maroon

Grain Size: N/A

Visible Minerals: concretion:

calcite and pyrite
Parting Thickness: fissile to

platy, .5-2mm

Parting Geometry:

discontinuous

Bedding Planes: mostly regular, some ridges

Sedimentary Structures: large

concretion $\sim 2$ feet

Fossil Content: none

Color When Powdered:

medium brown

Luster of Streak: semi-waxy

Other: concretions are oval

shaped and formed along

bedding planes, Concretions

contain calcite and pyrite 


\section{OAK FLAT WV, OUTCROP}

\section{Location: 1.4 miles West of Oak Flat, WV on U.S. 33 \\ Latitude/Longitude:38.658471/ $-79.234750$}

\section{Unit Number: 1}

Unit Thickness: 2 feet

Facies Number: 2

Rock Type: argillaceous

limestone

Interbeds: none

Color Fresh: dark to medium

grey

Color Weathered: off white

Grain Size: silt, clay sized grains

Visible Minerals: calcite

Parting Thickness: N/A

Parting Geometry: N/A

Bedding Planes: N/A

Sedimentary Structures: none

Fossil Content: black fossil

fragments, the underlying

calcareous shale contains

chondrites and trilobite

fragments

Color When Powdered: N/A

Luster of Streak: N/A

Other: calcite filled veins, some

more clay rich partings in

limestone

Unit Number: 2

Unit Thickness: .5 feet

Facies Number: 2

Rock Type: argillaceous

limestone

Interbeds: none

Color Fresh: medium to dark

grey

Color Weathered: N/A

Grain Size: N/A

Visible Minerals: none

Parting Thickness: platy,

$5 \mathrm{~mm}$

Parting Geometry:

discontinuous, wavy

Bedding Planes: irregular, bumpy

Sedimentary Structures: none Fossil Content: oxidized and replaced fossil debris

Color When Powdered: light brown to grey
Luster of Streak: dull

Other: none

Unit Number: 3

Unit Thickness: .5 feet

Facies Number: 3

Rock Type: calcareous shale

Interbeds: none

Color Fresh: dark grey to black

Color Weathered: N/A

Grain Size: N/A

Visible Minerals: none

Parting Thickness: platy to

flaggy, 5-10mm

Parting Geometry:

discontinuous

Bedding Planes: irregular

Sedimentary Structures:

burrows

Fossil Content: small black

fossils, possible linguloid

Color When Powdered: medium

brown

Luster of Streak: semi-waxy

Other: none

Unit Number: 4

Unit Thickness: 1 foot

Facies Number: 1 and 2

Rock Type: calcareous shale

Interbeds: argillaceous

limestone

Color Fresh: grey, interbeds:

dark grey

Color Weathered: interbeds: red

stains

Grain Size: limestone: silt sized

grains

Visible Minerals: interbeds:

calcite

Parting Thickness: partings not

distinctive

Parting Geometry: N/A

Bedding Planes: N/A

Sedimentary Structures:

interbred: burrows

Fossil Content: none

Color When Powdered: medium

brown, interbeds: light

Luster of Streak: semi waxy,

interbeds: dull

Other: upper .2 feet of unit is

very dark grey bioturbated

limestone bed
Unit Number: 5

Unit Thickness: .4 feet

Facies Number: 1

Rock Type: calcareous shale

Interbeds: none

Color Fresh: dark grey

Color Weathered: N/A

Grain Size: N/A

Visible Minerals: none

Parting Thickness: platy, $\sim 1$ -

$3 \mathrm{~mm}$

Parting Geometry: N/A

Bedding Planes: irregular, bumpy

Sedimentary Structures: none

Fossil Content: rare shell

debris, brachiopods

Color When Powdered: light

brown

Luster of Streak: semi-waxy

Other: none

Unit Number: 6

Unit Thickness: .6 feet

Facies Number: 3

Rock Type: calcareous shale

Interbeds: none

Color Fresh: black to dark grey

Color Weathered: white, orange

Grain Size: N/A

Visible Minerals: none

Parting Thickness: platy, 2-

$3 \mathrm{~mm}$

Parting Geometry: N/A

Bedding Planes: moderately

irregular

Sedimentary Structures: none

Fossil Content: none

Color When Powdered: N/A

Luster of Streak: N/A

Other: slightly to moderately

calcareous on fresh surface

\section{Unit Number: 7}

Unit Thickness: 1 foot

Facies Number: 3

Rock Type: calcareous shale

Interbeds: none

Color Fresh: black to dark grey

Color Weathered: yellow,

white, orange

Grain Size: N/A

Visible Minerals: none 
Parting Thickness: papery to

fissile, $\sim .1 \mathrm{~mm}$ or less

Parting Geometry: parallel

Bedding Planes: regular, flat

Sedimentary Structures: none

Fossil Content: none

Color When Powdered: N/A

Luster of Streak: N/A

Other: fresh surface is very calcareous, shale in books $\sim 1-$ 6 inches, some grey shale with platy parting $\sim 3-5 \mathrm{~mm}$.

\section{Unit Number: 8}

Unit Thickness: 2 feet

Facies Number: 3

Rock Type: calcareous shale

Interbeds: none

Color Fresh: dark grey

Color Weathered: grey to blue, white

Grain Size: none

Visible Minerals: none

Parting Thickness: platy to

flaggy, 2-10mm

Parting Geometry: wavy,

discontinuous

Bedding Planes: irregular,

bumpy

Sedimentary Structures:

oxidized burrows, nodules

Fossil Content: none

Color When Powdered: brown, peels

Luster of Streak: semi-waxy

Other: burrows have red orange

weathering, nodules are flat,

oval shaped and have high

specific gravity, last foot of unit

has no distinctive parting

thickness and may be

bioturbated: has a dull streak

and white powder.

\section{Unit Number: 9}

Unit Thickness: 2 feet

Facies Number: 3

Rock Type: calcareous shale

Interbeds: none

Color Fresh: dark grey

Color Weathered: N/A

Grain Size: sand sized

Visible Minerals: calcite

Parting Thickness: flaggy,

$10 \mathrm{~mm}$, or no distinctive partings
Parting Geometry: N/A

Bedding Planes: irregular

Sedimentary Structures:

oxidized horizontal and vertical

burrows, nodules

Fossil Content: some black

shell debris

Color When Powdered: light

Luster of Streak: dull

Other: nodules are flat, oval

shaped and have high specific

gravity, upper foot of unit is

very weathered and crumbly,

breaks into nodule like pieces

Unit Number: 10

Unit Thickness: 1.5 feet

Facies Number: 3

Rock Type: calcareous shale

Interbeds: N/A

Color Fresh: black

Color Weathered: white and

orange crust on surface

Grain Size: N/A

Visible Minerals: none

Parting Thickness: platy, 1-

$2 \mathrm{~mm}$

Parting Geometry: deformed

Bedding Planes: deformed

Sedimentary Structures: small

siderite concretions

Fossil Content: none

Color When Powdered: N/A

Luster of Streak: N/A

Other: beds deformed, very

black and coaly

Unit Number: 11

Unit Thickness: 1.1 feet

Facies Number: 1

Rock Type: calcareous shale

Interbeds: none

Color Fresh: medium to dark

grey

Color Weathered: light grey

Grain Size: N/A

Visible Minerals: none

Parting Thickness: platy, 2-

$5 \mathrm{~mm}$

Parting Geometry: non-parallel

Bedding Planes: irregular,

bumpy

Sedimentary Structures:

oxidized burrows

Fossil Content: none
Color When Powdered: medium

blue to grey

Luster of Streak: semi-waxy

Other: partings become thinner

towards top of unit $\sim 2 \mathrm{~mm}$

Unit Number: 12

Unit Thickness: .4 feet

Facies Number: 2

Rock Type: limestone

Interbeds: none

Color Fresh: dark grey

Color Weathered: N/A

Grain Size: sand sized

Visible Minerals: calcite

Parting Thickness: N/A

Parting Geometry: N/A

Bedding Planes: N/A

Sedimentary Structures: N/A

Fossil Content: fossil debris

Color When Powdered: N/A

Luster of Streak: N/A

Other: limestone bed pinches

out

Unit Number: 13

Unit Thickness: .5 feet

Facies Number: 3

Rock Type: calcareous shale

Interbeds: none

Color Fresh: black to dark grey

Color Weathered: N/A

Grain Size: N/A

Visible Minerals: none

Parting Thickness: platy to

flaggy, 3-10mm

Parting Geometry:

discontinuous

Bedding Planes: irregular

Sedimentary Structures: N/A

Fossil Content: possible fossil

debris

Color When Powdered: N/A

Luster of Streak: N/A

Other: N/A

Unit Number: 14

Unit Thickness: 2.5 feet

Facies Number: 3

Rock Type: calcareous shale

Interbeds: none

Color Fresh: dark grey

Color Weathered: N/A

Grain Size: N/A

Visible Minerals: none 
Parting Thickness: platy, 1-

$5 \mathrm{~mm}$

Parting Geometry: not parallel

Bedding Planes: irregular,

bumpy

Sedimentary Structures: none

Fossil Content: possible fossil debris

Color When Powdered: N/A

Luster of Streak: N/A

Other: some more competent, very thin, micritic limestone beds in this section

Unit Number: 15

Unit Thickness: 4 feet

Facies Number: N/A

Rock Type: Covered section

Interbeds: N/A

Color Fresh: N/A

Color Weathered: N/A

Grain Size: N/A

Visible Minerals: N/A

Parting Thickness: N/A

Parting Geometry: N/A

Bedding Planes: N/A

Sedimentary Structures: N/A

Fossil Content: N/A

Color When Powdered: N/A

Luster of Streak: N/A

Other: estimated 4 feet, lies

between previous unit and

deformed black shale

\section{Unit Number: 16}

Unit Thickness: estimated $\sim 18$

feet of shale

Facies Number: 4

Rock Type: non-calcareous

shale

Interbeds: none

Color Fresh: black

Color Weathered: yellow,

white, orange

Grain Size: N/A

Visible Minerals: none

Parting Thickness: platy, 2-3m

Parting Geometry: continuous

Bedding Planes: flat, regular

Sedimentary Structures:

Fossil Content: none

Color When Powdered: dark

Luster of Streak: semi-waxy

Other: repeated section, shale is

highly deformed and kink folded, parting and bedding

characteristics have been mostly destroyed, stratigraphic order and thickness is unknown due to high degree of deformation 


\section{BERKELEY SPRINGS WV, OUTCROP}

Location: U.S. Silica Quarry 3.3 miles North of Berkeley Springs, WV on U.S. Rt. 522 Latitude/Longitude:39.669142/ $-78.200169$

Notes: Both Oriskany/Needmore and Needmore/ Marcellus contacts are exposed. Beds of the Marcellus change dig rapidly throughout section 45- 90 degrees. Very hot (high uranium) black shale from base of Marcellus seem to be missing. Large fault is found at base of section near the Needmore/Marcellus contact. Upper section of Marcellus/ Mahantango is extremely folded and faulted. Large recumbent fold and high displacement thrust faults have made it difficult to determine true stratigraphic order of beds measured. Lower portion of sections seems to be in correct stratigraphic order.

Unit Number: 1

Unit Thickness: $\sim 40$ feet

Facies Number: N/A

Rock Type: Needmore shale, non-calcareous

Interbeds: calcareous shale, argillaceous limestone

Color Fresh: medium grey to blue

Color Weathered: light grey, buff, tan, white

Grain Size: N/A

Visible Minerals: calcite

Parting Thickness: not

distinctive

Parting Geometry:

discontinuous

Bedding Planes: irregular, wavy

Sedimentary Structures: burrows

Fossil Content: brachiopods,

trilobites, cephalopods

Color When Powdered: light tan to white

Luster of Streak: dull
Other: burrows filled with darker mud from below, fault plane observed between Needmore shale and Marcellus shale, contact looks abrupt

Unit Number: 2

Unit Thickness: 1 foot

Facies Number: 4

Rock Type: non-calcareous

Interbeds: none

Color Fresh: dark grey to black

Color Weathered: grey, orange, and red

Grain Size: N/A

Visible Minerals: none

Parting Thickness: papery, .5

mm

Parting Geometry:

discontinuous, soft and flaky

Bedding Planes: mostly flat and regular

Sedimentary Structures: none

Fossil Content: none

Color When Powdered: light to

medium grey

Luster of Streak: semi -waxy

Other: this unit is the along the

Needmore/Marcellus contact,

movement along contact, shale

is flaky and soft

Unit Number: 3

Unit Thickness: 9 feet

Facies Number: 5

Rock Type: non-calcareous

shale

Interbeds: none

Color Fresh: medium to dark

grey

Color Weathered: tan, orange

Grain Size: N/A

Visible Minerals: calcite in fault gauge, small unknown crystals on bedding planes

Parting Thickness: papery to

fissile, $.5-1 \mathrm{~mm}$

Parting Geometry: N/A

Bedding Planes: regular to

slightly irregular

Sedimentary Structures: nodule

Fossil Content: none

Color When Powdered: N/A
Luster of Streak: N/A

Other: 4- 5 feet of fault gauge, fault gauge has calcite filled veins, beds deformed and locally change dip

Unit Number: 4

Unit Thickness: 6 feet

Facies Number: 5

Rock Type: non-calcareous

shale

Interbeds: none

Color Fresh: dark grey

Color Weathered: grey, nodules

weather tan

Grain Size: N/A

Visible Minerals: nodule: calcite and pyrite

Parting Thickness: papery to

fissile, $\sim .5-1 \mathrm{~mm}$

Parting Geometry:

discontinuous

Bedding Planes: irregular

Sedimentary Structures:

concretions and nodules

Fossil Content: small shell

fragments in concretions

Color When Powdered: N/A

Luster of Streak: N/A

Other: small calcareous nodule

is very black and contains

euhedral pyrite cubes, large dark grey concretions are very calcareous, oval shaped, contain small white shell fragments and are $~ 1-2$ feet in length, flaky grey shale directly above large concretions.

Unit Number: 5

Unit Thickness: 10 feet

Facies Number: 4

Rock Type: non-calcareous

shale

Interbeds: none

Color Fresh: dark grey to black

Color Weathered: orange, red,

white, yellow

Grain Size: N/A

Visible Minerals: unknown mineral on parting surfaces Parting Thickness: platy, 1$2 \mathrm{~mm}$ 
Parting Geometry: N/A

Bedding Planes: regular, flat

Sedimentary Structures: none

Fossil Content: none

Color When Powdered: light to

medium brown

Luster of Streak: dull

Other: precipitate crystals on

bedding planes, crystals have

pearly luster and basal cleavage, thin veins of white and yellow

weathering on partings surfaces

\section{Unit Number: 6}

Unit Thickness: 15 feet

Facies Number: 3 and 4

Rock Type: non-calcareous to

slightly calcareous

Interbeds: none

Color Fresh: dark grey to black

Color Weathered: grey

Grain Size: N/A

Visible Minerals: calcite

Parting Thickness: papery to

fissile, $\sim .5 \mathrm{~mm}$

Parting Geometry:

discontinuous

Bedding Planes: relatively

regular

Sedimentary Structures: large

calcareous concretions

Fossil Content: none

Color When Powdered: light to

medium brown

Luster of Streak: dull

Other: Two distinctive beds of

large oval shaped nodules $\sim 1-5$

feet in length, shale is more

calcareous near concretions, and

concretions contain numerous

large and small calcite filled

veins

Unit Number: 7

Unit Thickness: 21 feet

Facies Number: 4

Rock Type: non-calcareous

Interbeds: none

Color Fresh: dark grey to black

Color Weathered: orange,

maroon, tan

Grain Size: N/A

Visible Minerals: quartz in

healed fractures and veins
Parting Thickness: 1) platy,

$2 \mathrm{~mm}$ or 2) papery to fissile, .5-

$1 \mathrm{~mm}$

Parting Geometry: 1)

continuous or 2) discontinuous

Bedding Planes: 1) regular or 2)

irregular

Sedimentary Structures: dark

grey, round, calcareous

concretions

Fossil Content: none

Color When Powdered: light to medium brown

Luster of Streak: dull

Other: the shale throughout this

unit alternates between two

parting styles ( 1and 2), unit

contains faults and folds and

large cross cutting quartz veins,

concretions found in lower 2

feet of unit

Unit Number: 8

Unit Thickness: 14 feet

Facies Number: 5

Rock Type: non-calcareous

shale

Interbeds: none

Color Fresh: dark grey

Color Weathered: N/A

Grain Size: silt sized grains

Visible Minerals: quartz in

healed veins

Parting Thickness: platy, 2-

$5 \mathrm{~mm}$

Parting Geometry:

discontinuous

Bedding Planes: N/A

Sedimentary Structures: bedded

nodules (siderite?)

Fossil Content: none

Color When Powdered: light

Luster of Streak: dull

Other: nodules are non-

calcareous to slightly calcareous

on fresh surface, dark grey and

flattened, some layers of

concretions form thin beds, unit

contains fault gauge and quartz

filled veins

Unit Number: 9

Unit Thickness: 27 feet

Facies Number: 5

Rock Type: non-calcareous shale (silty)
Interbeds: none

Color Fresh: dark grey

Color Weathered: N/A

Grain Size: N/A

Visible Minerals: quartz in

healed fractures

Parting Thickness: platy, 1-

$2 \mathrm{~mm}$

Parting Geometry: N/A

Bedding Planes: regular to

slightly irregular

Sedimentary Structures: bedded

calcareous nodules (siderite?)

Fossil Content: none

Color When Powdered: light,

$\tan$

Luster of Streak: dull

Other: first two feet of unit are

fault gauge, fault gauge has

quartz filled veins and orange

weathering, nodules form beds

that can be traced through the

outcrop, grey non-calcareous

shale is interbedded with

calcareous nodule beds $\sim 5 \mathrm{~mm}$

to 2 inch thick

\section{Unit Number: 10}

Unit Thickness: 4 feet

Facies Number: 5 and 1

Rock Type: non-calcareous

shale (silty)

Interbeds: calcareous mudstone

or bedded calcareous nodules

Color Fresh: medium to dark

grey, interbeds: light grey

Color Weathered: interbeds: tan

Grain Size: silty sized grains

Visible Minerals: N/A

Parting Thickness: platy to

flaggy, $\sim 1-10 \mathrm{~mm}$ or no

distinctive partings

Parting Geometry:

discontinuous

Bedding Planes: slightly

irregular

Sedimentary Structures: none

Fossil Content: none

Color When Powdered: light

brown

Luster of Streak: dull

Other: interbeds only fizz when

fresh surface is tested could be

bedded nodules 


\section{Unit Number: 11}

Unit Thickness: 10 feet

Facies Number: 5

Rock Type: non-calcareous

shale

Interbeds: none

Color Fresh: dark grey

Color Weathered: white residue,

tan, orange

Grain Size: N/A

Visible Minerals: none

Parting Thickness: platy, 2-

$5 \mathrm{~mm}$

Parting Geometry:

discontinuous

Bedding Planes: slightly

irregular

Sedimentary Structures: black, bedded, calcareous nodules

Fossil Content: none

Color When Powdered: tan

Luster of Streak: dull

Other: same as unit 9, bedded

coalesced nodules are slightly to

very calcareous and can be

traced a crossed outcrop

Unit Number: 12

Unit Thickness: 16 feet

Facies Number: 5

Rock Type: non-calcareous

shale

Interbed: non-calcareous shale

(2 feet)

Color Fresh: dark grey

Color Weathered: orange, tan

Grain Size: N/A

Visible Minerals: none

Parting Thickness: platy,

interbed: fissile to platy $\sim 1 \mathrm{~mm}$

Parting Geometry:

discontinuous, wavy, interbed:

continuous

Bedding Planes: semi-irregular, interbed: regular

Sedimentary Structures: none

Fossil Content: none

Color When Powdered: blue to

tan, interbed: medium brown

Luster of Streak: intermediate, interbed: dull

Other: interbed is dark grey, has thinner partings and is brittle
Unit Number: 12

Unit Thickness: 30 feet

Facies Number: 5

Rock Type: non-calcareous

shale

Interbeds: none

Color Fresh: medium to dark

grey

Color Weathered: grey to tan, nodules weather orange and

black

Grain Size: N/A

Visible Minerals: none

Parting Thickness: platy, 1-

$3 \mathrm{~mm}$

Parting Geometry: continuous

Bedding Planes: mostly regular, some ridges on surface

Sedimentary Structures: bedded

calcareous nodules, 1-6 inches

Fossil Content: none

Color When Powdered: light

$\tan$

Luster of Streak: dull

Other: calcite filled veins,

calcareous nodules are darker

than surrounding shale, shale

layers are draped over nodules, and last ten feet of unit contain bedsets of partings and fewer

bedded nodules

Unit Number: 14

Unit Thickness: 22 feet

Facies Number: 5

Rock Type: non-calcareous

shale (silty)

Interbeds: $\mathrm{n}$ one

Color Fresh: medium to dark

grey

Color Weathered: N/A

Grain Size: silty sized grains

Visible Minerals: N/A

Parting Thickness: platy, 2-

$5 \mathrm{~mm}$

Parting Geometry:

discontinuous

Bedding Planes: irregular

Sedimentary Structures: wavy

laminations

Fossil Content: none

Color When Powdered: tan

Luster of Streak: dull

Other: visible bedsets
Unit Number: 15

Unit Thickness: 7 feet

Facies Number: N/A

Rock Type: fault gauge

Interbeds: N/A

Color Fresh: N/A

Color Weathered: N/A

Grain Size: N/A

Visible Minerals: N/A

Parting Thickness: no

distinctive partings

Parting Geometry: deformed

Bedding Planes: deformed

Sedimentary Structures: N/A

Fossil Content: N/A

Color When Powdered: N/A

Luster of Streak: N/A

Other: beds change dip very

quickly and contain many

healed quartz veins; fault

through section has caused

deformation and displacement

Unit Number: 16

Unit Thickness: 13 feet

Facies Number: 5

Rock Type: non-calcareous

shale

Interbeds: none

Color Fresh: dark grey

Color Weathered: N/A

Grain Size: N/A

Visible Minerals: none

Parting Thickness: platy to

flaggy, 2-10mm

Parting Geometry:

discontinuous

Bedding Planes: irregular

Sedimentary Structures: none

Fossil Content: none

Color When Powdered: tan

Luster of Streak: dull

Other: large fault between this

unit and unit 15 .

\section{Unit Number: 17}

Unit Thickness: $10-30$ feet

Facies Number: 4

Rock Type: non-calcareous

shale

Interbeds: none

Color Fresh: black, nodule: light

grey

Color Weathered: maroon,

orange, yellow 
Grain Size: N/A

Visible Minerals: pyrite

Parting Thickness: papery to

fissile, . $5-2 \mathrm{~mm}$

Parting Geometry:

Bedding Planes: mostly regular, deformed

Sedimentary Structures: non-

calcareous pyrite nodule

Fossil Content: none

Color When Powdered: medium

brown

Luster of Streak: waxy

Other: very deformed unit is 10

feet at top of the outcrop and 30

feet at the base were the section

is measured, repeated section,

beds locally change dip rapidly, unit is highly fractured, slick $\mathrm{n}$

slides and iridescent stain

present on parting surfaces,

pyrite fill in veins and present in small nodule

Unit Number: 18

Unit Thickness: 20-30 feet

Facies Number: 5

Rock Type: non-calcareous

shale

Interbeds: none

Color Fresh: dark grey

Color Weathered: N/A

Grain Size: N/A

Visible Minerals: none

Parting Thickness: platy, 1-

$5 \mathrm{~mm}$

Parting Geometry: N/A

Bedding Planes: N/A

Sedimentary Structures: none

Fossil Content: none

Color When Powdered: light

Luster of Streak: dull

Other: large fault between unit

17 and unit 18 . This section is a large recumbent fold; section is doubled and may not be in stratigraphic order 


\section{FROST WV, OUTCROP}

\author{
Location: 1.1 miles Northwest \\ of Frost, WV on Co. Rt. 13 \\ (Quarry Measured Section 1) \\ Latitude/ \\ Longitude:38.28330/- \\ $\mathbf{7 9 . 8 8 5 2 2 4}$
}

Unmeasured section notes:

Needmore and Marcellus

contact is covered. The first

distinctive Marcellus exposure

consists of Facies 4, non-

calcareous black shale with high

uranium reading ( $20 \mathrm{ppm})$.

The shale partings are platy and

discontinuous ( 1-2mm) and

parting surfaces are mostly

regular and smooth. Shale

weathers orange to maroon and

small traces of pyrite are seen on

bedding planes. Large

calcareous concretion $\sim 4$ feet in

size is found in this section. Up

section $\sim 15$ feet from first

measured section, Facies 5, non-

calcareous medium grey shale

contains several thin beds of

abundant brachiopod fossils of a

single species. Shale also

contains mud filled or red

oxidized burrow. The bedding

partings are platy $5 \mathrm{~mm}$ and

parting surfaces are bumpy and

irregular. The shale streak is

very waxy and the powder color

is medium to dark brown. Up

section: calcareous nodules are

found in float and protruding

from covered section between

brachiopod shale and beginning

of first measured section.

\section{Unit Number: 1 Quarry Measured Section1}

Unit Thickness: 9 feet

Facies Number: 4

Rock Type: non-calcareous

shale

Interbeds: none

Color Fresh: very black

Color Weathered: orange and maroon, yellow weathering on parting surfaces
Grain Size: N/A

Visible Minerals: none

Parting Thickness: papery to

platy, .5-2mm

Parting Geometry:

discontinuous, wavy

Bedding Planes: slightly

irregular, wavy

Sedimentary Structures: none

Fossil Content: none

Color When Powdered: dark

brown to black

Luster of Streak: very waxy

Other: partings may be

deformed by faulting;

unweathered sections have less

distinct parting

Unit Number: 2 Quarry

Measured Section 1

Unit Thickness: 4 feet

Facies Number: 4

Rock Type: non-calcareous

shale

Interbeds: none

Color Fresh: very black

Color Weathered: N/A

Grain Size: N/A

Visible Minerals: pyrite

associated with nodules

Parting Thickness: fissile-platy,

.5-1 $\mathrm{mm}$,

Parting Geometry:

discontinuous, nodules

Bedding Planes: irregular, nodules

Sedimentary Structures:

incipient nodules on bedding

planes

Fossil Content: none

Color When Powdered: N/A

Luster of Streak: N/A

Other: oxidizing halo around

incipient nodules, partings are

irregular and thicker due to

prevalence of nodule features

$5-10 \mathrm{~mm}$, bed sets $\sim .5-1$ inch

with internal partings, incipient

nodules are heavy and flat and

formed on bedding planes

Unit Number: 3 Quarry

Measured Section 1

\section{3}

Unit Thickness: 9 feet

Facies Number: 4

Rock Type: non-calcareous

Interbeds: none

Color Fresh: black

Color Weathered: grey, orange,

and maroon

Grain Size: N/A

Visible Minerals: none

Parting Thickness: fissile to

platy, .5-1 mm

Parting Geometry:

discontinuous, nodules

Bedding Planes: regular, some

wavy around nodules

Sedimentary Structures:

incipient nodules

Fossil Content:

Color When Powdered: medium

to dark brown

Luster of Streak: semi-waxy

Other: partings near nodules are

larger and less regular, oxidized

halos around nodules, yellow

weathering on bedding planes

Measured Section 2 Notes:

This section is significantly upsection from measured section 1

( 52 paces). Measured sections

2 and 3 hold a character unlike

that of the Marcellus Shale in

my study area. Therefore the

transition zone from the lower

Milboro (true Marcellus shale)

and the Upper Milboro

(overlying shale members) is

within this covered interval.

Unit Number: 1 Quarry

Measured Section 2 (Upper

Milboro)

Unit Thickness: 7 feet

Facies Number: 4

Rock Type: non-calcareous

shale

Interbeds: none

Color Fresh: black

Color Weathered: maroon, tan,

orange, white

Grain Size: N/A

Visible Minerals: none

Parting Thickness: platy, $1-4 \mathrm{~mm}$ 
Parting Geometry: continuous, non-parallel

Bedding Planes: wavy, ridges

Sedimentary Structures: none

Fossil Content: none

Color When Powdered: black

Luster of Streak: waxy

Other:

Unit Number: 2 Quarry

Measured Section 2

Unit Thickness: 1 foot

Facies Number: 4

Rock Type: non-calcareous

shale

Interbeds: none

Color Fresh: black

Color Weathered:

Grain Size: N/A

Visible Minerals: non

Parting Thickness: platy, $\sim 1$ -

4mm

Parting Geometry: mostly

continuous, non-parallel

Bedding Planes: irregular

Sedimentary Structures:

septarian concretions

Fossil Content: none

Color When Powdered: medium

brown

Luster of Streak: intermediate

Other: concretions are septarian

and formed along bedding

planes, range from 1-3 feet in

width, calcite and unknown

black mineral in veins.

\section{Unit Number: 3 Quarry}

Measured Section 2

Unit Thickness: 3 feet

Facies Number: 4

Rock Type: non-calcareous

shale

Interbeds: none

Color Fresh: black

Color Weathered: grey, green, orange

Grain Size: N/A

Visible Minerals: none

Parting Thickness: platy, 1-4mm

Parting Geometry: N/A

Bedding Planes: semi-irregular

Sedimentary Structures:

incipient nodules

Fossil Content: none
Color When Powdered: N/A

Luster of Streak: N/A

Other: none

Unit Number: 4 Quarry

Measured Section 2

Unit Thickness: 2 feet

Facies Number: 5

Rock Type: non-calcareous

shale

Interbeds: none

Color Fresh: medium grey

Color Weathered: grey, tan

Grain Size: silt and clay

Visible Minerals: none

Parting Thickness: platy to

flaggy, 2-10mm

Parting Geometry:

discontinuous

Bedding Planes: irregular

Sedimentary Structures:

Fossil Content: none

Color When Powdered: dark

brown

Luster of Streak: waxy

Other: this unit is more

susceptible to weathering than

surrounding units,

Unit Number: 5 Quarry

Measured Section 2

Unit Thickness: 1 foot

Facies Number: 4

Rock Type: non-calcareous

shale

Interbeds: none

Color Fresh: black

Color Weathered: yellow, maroon

Grain Size: N/A

Visible Minerals: none

Parting Thickness: N/A

Parting Geometry: N/A

Bedding Planes: irregular, ridges

Sedimentary Structures:

incipient nodules

Fossil Content: none

Color When Powdered: black

Luster of Streak: waxy

Other: partings are distorted by

deformation

Unit Number: 6 Quarry

Measured Section 2

Unit Thickness: 1 foot
Facies Number: 5

Rock Type: non-calcareous

shale

Interbeds: none

Color Fresh: dark grey

Color Weathered: green, grey,

orange

Grain Size: N/A

Visible Minerals: none

Parting Thickness: platy, 2-

$5 \mathrm{~mm}$

Parting Geometry:

discontinuous

Bedding Planes: irregular

Sedimentary Structures: none

Fossil Content: none

Color When Powdered: light

brown

Luster of Streak: waxy

Other: none

Unit Number: 7 Quarry

Measured Section 2

Unit Thickness: 7 feet

Facies Number: 4

Rock Type: non-calcareous

shale

Interbeds: none

Color Fresh: black

Color Weathered: white, yellow, maroon

Grain Size: N/A

Visible Minerals: none

Parting Thickness: platy, $\sim 1$ -

$3 \mathrm{~mm}$

Parting Geometry: continuous, non-parallel

Bedding Planes: semi-irregular, ridges

Sedimentary Structures: none

Fossil Content: none

Color When Powdered: dark

brown

Luster of Streak: intermediate

Other: shale is in bedsets $\sim 4-8$

inches each

Unit Number: 1 Quarry

Measured Section 3 (Upper

Milboro)

Unit Thickness: 4 feet

Facies Number: 4

Rock Type: non-calcareous

shale

Interbeds: none 
Color Fresh: dark grey to black

Color Weathered: buff to grey, white efflorescence $>$ sp

Grain Size: N/A

Visible Minerals: none

Parting Thickness: papery to

platy, <.5-1 mm

Parting Geometry: N/A

Bedding Planes: regular

Sedimentary Structures: large

calcareous concretions at base of

unit $\sim 3$ feet

Fossil Content: none

Color When Powdered: medium

brown

Luster of Streak: semi-waxy

Other: partings come in books

of varying in size, white

precipitate on shale surface

\section{Unit Number: 2 Quarry}

Measured Section 3

Unit Thickness: 2 feet

Facies Number: 4

Rock Type: non-calcareous

shale

Interbeds: none

Color Fresh: black

Color Weathered: N/A

Grain Size: N/A

Visible Minerals: none

Parting Thickness: platy, 1-

2mm

Parting Geometry:

discontinuous, nodules

Bedding Planes: mostly regular, ridges and wavy features

associated with nodules

Sedimentary Structures:

incipient nodules

Fossil Content: none

Color When Powdered: light to

medium brown

Luster of Streak: semi-waxy

Other: oxidized halo around

nodules

Unit Number: 3 Quarry

Measured Section 3

Unit Thickness: 3

Facies Number: 4

Rock Type: non-calcareous

shale

Interbeds: none

Color Fresh: dark grey to black
Color Weathered: N/A

Grain Size: N/A

Visible Minerals: N/A

Parting Thickness: papery to

fissile, .5-1 mm

Parting Geometry:

discontinuous

Bedding Planes: mostly regular

Sedimentary Structures: none

Fossil Content: none

Color When Powdered: brown

Luster of Streak: semi-waxy

Other: faults in section, may be repeated

Unit Number: 4 Quarry

Measured Section 3

Unit Thickness: 4 feet

Facies Number: 4

Rock Type: non-calcareous

Interbeds: none

Color Fresh: chocolate brown,

dark grey to black

Color Weathered: brown

Grain Size: N/A

Visible Minerals: none

Parting Thickness: fissile to

platy, .5-2mm

Parting Geometry: N/A

Bedding Planes: relatively

smooth

Sedimentary Structures: none

Fossil Content: none

Color When Powdered: dark

brown, peels

Luster of Streak: waxy

Other: brown shale breaks

blocky in up to $\sim 5 \mathrm{~mm}$ partings;

section has localized folds and

deformation

Unit Number: 5 Quarry

Measured Section 3

Unit Thickness: 3 feet

Facies Number: 4

Rock Type: non-calcareous

shale

Interbeds: none

Color Fresh: dark grey to brown

Color Weathered: brown

Grain Size: N/A

Visible Minerals: none

Parting Thickness: platy,

$2 \mathrm{~mm}$
Parting Geometry: some

discontinuous

Bedding Planes: semi-regular Sedimentary Structures: none

Fossil Content: none

Color When Powdered:

medium brown

Luster of Streak: semi-waxy

Other: section has multiple

small scale faults offsetting

section 


\section{MCCOOLE MD, OUTCROP}

\section{Location: 3 miles Northeast of Keyser, WV on $21^{\text {st }}$ St. Bridge \\ Road (SW) \\ Latitude/Longitude: \\ $39.451803 / 78.960822$}

Notes: The Needmore/

Marcellus contact is covered.

The Needmore shale consists of dark grey, green and blue calcareous mudstone with both vertical and horizontal burrows. Body fossils such as brachiopods, cephalopods and gastropods are found in light grey mudstone. Needmore transitions very quickly to the darker more fissile shale of the Marcellus.

\section{Unit Number: 1}

Unit Thickness: 7 feet

Facies Number: 4

Rock Type: non-calcareous

shale

Interbeds: none

Color Fresh: black

Color Weathered: red, orange, and maroon

Grain Size: N/A

Visible Minerals: none Parting Thickness: partings destroyed by deformation Parting Geometry: N/A

Bedding Planes: N/A

Sedimentary Structures: none

Fossil Content: none

Color When Powdered: brown

Luster of Streak: semi-waxy

Other: fault at 5 feet, multiple small faults and fold in unit, highly fractured, shale is coaly and shiny

Unit Number: 2

Unit Thickness: 4 feet

Facies Number: N/A

Rock Type: Covered Section

Interbeds: N/A

Color Fresh: N/A

Color Weathered: N/A

Grain Size: N/A

Visible Minerals: N/A
Parting Thickness: N/A

Parting Geometry: N/A

Bedding Planes: N/A

Sedimentary Structures: N/A

Fossil Content: N/A

Color When Powdered: N/A

Luster of Streak: N/A

Other: N/A

Unit Number: 3

Unit Thickness: 9 feet

Facies Number: 4

Rock Type: non-calcareous

shale

Interbeds: none

Color Fresh: black

Color Weathered: red, orange, and maroon

Grain Size: N/A

Visible Minerals: N/A

Parting Thickness: parting no

distinctive, destroyed by

deformation

Parting Geometry: N/A

Bedding Planes: N/A

Sedimentary Structures: N/A

Fossil Content: N/A

Color When Powdered: N/A

Luster of Streak: N/A

Other: same as unit 1 , highly

deformed, fault gauge common

Unit Number: 4

Unit Thickness: 17 feet

Facies Number: 4

Rock Type: non-calcareous

shale

Interbeds: none

Color Fresh: dark grey to black

Color Weathered: white

efflorescence, red, orange,

concretions weather yellow to

light brown

Grain Size: N/A

Visible Minerals: pyrite in

concretions

Parting Thickness: platy, 1-

2mm

Parting Geometry: N/A

Bedding Planes: N/A

Sedimentary Structures: non

calcareous and calcareous,

pyritic concretions
Fossil Content: none

Color When Powdered: medium

brown

Luster of Streak: intermediate

Other: shale breaks in to very

small shards, some incipient

nodule like features on parting

surface, small displacement

faults cut through unit

\section{Unit Number: 5}

Unit Thickness: 3 feet

Facies Number: 5

Rock Type: non-calcareous

shale

Interbeds: none

Color Fresh: medium to dark

grey

Color Weathered: maroon

Grain Size: N/A

Visible Minerals: none

Parting Thickness: N/A

Parting Geometry: N/A

Bedding Planes: N/A

Sedimentary Structures:

incipient nodules, with maroon

weathering halos

Fossil Content: brachiopod

molds, lingula

Color When Powdered: brown

Luster of Streak: dull

Other: some bedding planes

have abundant brachiopod shells

that seem to be the same species

Unit Number: 6

Unit Thickness: 16 feet

Facies Number: N/A

Rock Type: Covered Section

Interbeds: N/A

Color Fresh: N/A

Color Weathered: N/A

Grain Size: N/A

Visible Minerals: N/A

Parting Thickness: N/A

Parting Geometry: N/A

Bedding Planes: N/A

Sedimentary Structures: N/A

Fossil Content: N/A

Color When Powdered: N/A

Luster of Streak: N/A

Other: N/A 


\author{
Unit Number: 7 \\ Unit Thickness: 18 feet \\ Facies Number: 4 \\ Rock Type: non-calcareous \\ shale \\ Interbeds: none \\ Color Fresh: dark grey to black \\ Color Weathered: white, \\ maroon, orange \\ Grain Size: N/A \\ Visible Minerals: none \\ Parting Thickness: platy, $\sim 2 \mathrm{~mm}$ \\ Parting Geometry: N/A \\ Bedding Planes: irregular, \\ incipient nodules, ridges \\ Sedimentary Structures: \\ incipient nodules \\ Fossil Content: none \\ Color When Powdered: brown \\ to tan \\ Luster of Streak: waxy \\ Other: fault gauge and folded \\ beds present, books of partings \\ present
}

\section{Unit Number: 8}

Unit Thickness: 10 feet

Facies Number: N/A

Rock Type: Covered Section

Interbeds: N/A

Color Fresh: N/A

Color Weathered: N/A

Grain Size: N/A

Visible Minerals: N/A

Parting Thickness: N/A

Parting Geometry: N/A

Bedding Planes: N/A

Sedimentary Structures: N/A

Fossil Content: N/A

Color When Powdered: N/A

Luster of Streak: N/A

Other: N/A

\section{Unit Number: 9}

Unit Thickness: 5 feet

Facies Number: 5

Rock Type: non-calcareous

shale

Interbeds: none

Color Fresh: dark grey

Color Weathered: orange

Grain Size: N/A

Visible Minerals: none

Parting Thickness: platy, 1-2mm

Parting Geometry:
Bedding Planes: irregular

Sedimentary Structures: non-

calcareous nodules

Fossil Content: none

Color When Powdered: tan

Luster of Streak: dull

Other: nodules are grey, round and $\sim 1$ inch in diameter

\section{Unit Number: 10}

Unit Thickness: 7 feet

Facies Number: 5

Rock Type: non-calcareous

shale

Interbeds: none

Color Fresh: dark grey

Color Weathered: N/A

Grain Size: N/A

Visible Minerals: none

Parting Thickness: no distinct

partings, 1 -2 inch beds

Parting Geometry: N/A

Bedding Planes: N/A

Sedimentary Structures: bedded nodules

Fossil Content: unknown black and round imprints on parting

surfaces, possible ammonoids or crionoids

Color When Powdered: tan to

grey

Luster of Streak: dull

Other: nodules are dark grey,

oblong and $\sim 3$ inches in length

\section{Unit Number: 11}

Unit Thickness: not measured

Facies Number: Mahantango

Formation

Rock Type: non-calcareous

shale

Interbeds: micaceous siltstone

and fine sandstone

Color Fresh: grey to black

Color Weathered: brown, grey

Grain Size: silt to fine sand

sized grains

Visible Minerals: micas

Parting Thickness: platy, (2-

4mm)

Parting Geometry:

discontinuous, wavy

Bedding Planes: irregular

Sedimentary Structures: non-

calcareous bedded nodules, calcareous nodules, cross

bedding

Fossil Content: none

Color When Powdered: N/A

Luster of Streak: N/A

Other: interbeds of cross-

bedded sandstone $\sim 4$ inches

thick 


\section{TOMAHAWK WV, OUTCROP}

Location: 2 miles Southwest of Tomahawk, WV on Co. Rt. 74

Latitude/Longitude:

39.506425/-78.060651

Unit Number: 1

Unit Thickness: 1 foot

Facies Number: 4

Rock Type: non-calcareous

shale

Interbeds: none

Color Fresh: black

Color Weathered: N/A

Grain Size: N/A

Visible Minerals: none

Parting Thickness: some papery

to fissile $<.5-1 \mathrm{~mm}$

Parting Geometry: some

parallel

Bedding Planes: regular

Sedimentary Structures: none

Fossil Content: none

Color When Powdered: dark

brown

Luster of Streak: waxy

Other: shale is sooty and

smudges fingers, some shale has

distinct papery partings and

others are coaly and lack

distinctive partings

Unit Number: 2

Unit Thickness: 1 foot

Facies Number: 4

Rock Type: non-calcareous

shale

Interbeds: none

Color Fresh: black

Color Weathered: some red to

orange weathering

Grain Size: N/A

Visible Minerals: none

Parting Thickness: fissile, .5mm

Parting Geometry: mostly

parallel

Bedding Planes: regular to

slightly irregular, bumpy

Sedimentary Structures: none

Fossil Content: none

Color When Powdered: dark

brown

Luster of Streak: waxy, peels
Other: fissile partings come in

packages $\sim 1-5 \mathrm{~mm}$

Unit Number: 3

Unit Thickness: 2 feet

Facies Number: 4

Rock Type: non-calcareous

shale

Interbeds: none

Color Fresh: black to brown

Color Weathered: brown

Grain Size: N/A

Visible Minerals: none

Parting Thickness: papery, $<.5$

$\mathrm{mm}$

Parting Geometry: N/A

Bedding Planes: N/A

Sedimentary Structures: none

Fossil Content: none

Color When Powdered: medium

brown

Luster of Streak: waxy

Other: locally drag folded, may

have repeated beds, breaks into

very soft, papery, polygons

Unit Number: 4

Unit Thickness: 3 feet

Facies Number: 4

Rock Type: papery non-

calcareous shale

Interbeds: fissile non-calcareous

shale

Color Fresh: black, interbeds:

dark grey to black

Color Weathered: dark grey, orange

Grain Size: N/A

Visible Minerals: none

Parting Thickness: papery, <.5

$\mathrm{mm}$, interbeds: fissile $\sim 1 \mathrm{~mm}$

Parting Geometry: mostly

parallel

Bedding Planes: mostly regular

Sedimentary Structures: none

Fossil Content: none

Color When Powdered: black to

grey

Luster of Streak: waxy

Other: locally drag-folded,

deformation has destroyed

parting
Unit Number: 5

Unit Thickness: 2 feet

Facies Number: 4 and 6

Rock Type: non-calcareous

shale

Interbeds: bentonite, $\sim 4$ inches

Color Fresh: very black,

interbed: brown to tan

Color Weathered: red, interbed:

white to grey clay

Grain Size: interbed: coarse

sand to clay size

Visible Minerals: interbed: mica

Parting Thickness: platy, 2-

$5 \mathrm{~mm}$, some internal laminations

Parting Geometry: N/A

Bedding Planes: N/A

Sedimentary Structures:

hardground: bioturbation,

interbed: graded

Fossil Content: none

Color When Powdered: grey to

brown, interbeds: brown

Luster of Streak: waxy, interbed:

waxy

Other: black shale below

bentonite is very hard and has

no distinct partings, possibly a

bioturbated subjacent

hardground

Unit Number: 6

Unit Thickness: 1 foot

Facies Number: 4 and 6

Rock Type: non-calcareous

shale

Interbeds: bentonite, $\sim 3$ inches

Color Fresh: black to dark grey

Color Weathered: white to dark

grey

Grain Size: N/A

Visible Minerals: interbed: mica

Parting Thickness: papery to

platy, $<.5-2 \mathrm{~mm}$

Parting Geometry: parallel,

continuous

Bedding Planes: regular

Sedimentary Structures: internal laminations

Fossil Content: none

Color When Powdered: black

Luster of Streak: medium waxy 
Other: black shale has very flat fissile partings, shale breaks off in brittle sheets up to 1 foot in size.

\section{Unit Number: 7}

Unit Thickness: 1 foot

Facies Number: N/A

Rock Type: covered section

Interbeds: N/A

Color Fresh: N/A

Color Weathered: N/A

Grain Size: N/A

Visible Minerals: N/A

Parting Thickness: N/A

Parting Geometry: N/A

Bedding Planes: N/A

Sedimentary Structures: N/A

Fossil Content: N/A

Color When Powdered: N/A

Luster of Streak: N/A

Other: section covered by tree roots and soil

\section{Unit Number: 8}

Unit Thickness: 4 feet

Facies Number: 4 and 6

Rock Type: non-calcareous

shale

Interbeds: bentonite, $\sim .5$ feet

Color Fresh: black, interbeds:

grey

Color Weathered: interbed:

grey to tan clay

Grain Size: interbed: sand sized

Visible Minerals: interbed: mica

Parting Thickness: papery to

fissile, $<.5 \mathrm{~mm}-1 \mathrm{~mm}$

Parting Geometry: N/A

Bedding Planes: N/A

Sedimentary Structures: one

Fossil Content: none

Color When Powdered: dark

brown to black

Luster of Streak: waxy

Other: upper 2 feet of unit is

papery black shale

\section{Unit Number: 9}

Unit Thickness: 6 feet

Facies Number: 4

Rock Type: non-calcareous

shale

Interbeds: none

Color Fresh: black
Color Weathered: grey, white, orange

Grain Size: N/A

Visible Minerals: none

Parting Thickness: fissile to

platy, 1-2mm

Parting Geometry: parallel,

sheets

Bedding Planes: regular

Sedimentary Structures: none

Fossil Content: none

Color When Powdered: black

Luster of Streak: semi-waxy

Other: some papery partings,

shale is in books $\sim 1-10 \mathrm{~mm}$

with internal partings $1-2 \mathrm{~mm}$

Unit Number: 10

Unit Thickness: 3.5 feet

Facies Number: 4

Rock Type: non-calcareous

shale

Interbeds: none

Color Fresh: black

Color Weathered: white, orange

Grain Size: N/A

Visible Minerals: none

Parting Thickness: platy, 1-

$5 \mathrm{~mm}$

Parting Geometry: N/A

Bedding Planes: slightly

irregular

Sedimentary Structures: none

Fossil Content: none

Color When Powdered: N/A

Luster of Streak: N/A

Other: locally folded, some

partings come in books $1-2 \mathrm{~cm}$ 


\section{PETERSBURG WEST WV, OUTCROP}

Location: 2.2 miles West of

Petersburg, WV on Rt. 28/55

Latitude/Longitude:39.003594/

$-79.156687$

Unit Number: 1

Unit Thickness: 1.5 feet

Facies Number: 4

Rock Type: non-calcareous

shale

Interbeds: none

Color Fresh: dark grey to black

Color Weathered: orange, white

Grain Size: N/A

Visible Minerals: none

Parting Thickness: papery to

platy, $<.5-2 \mathrm{~mm}$

Parting Geometry:

discontinuous

Bedding Planes: slightly

irregular

Sedimentary Structures: none

Fossil Content: none

Color When Powdered: medium

brown

Luster of Streak: semi- waxy,

powdery

Other: shale becomes more

papery at top .5 feet of this unit

\section{Unit Number: 2}

Unit Thickness: 6.5 feet

Facies Number: 4

Rock Type: non-calcareous

shale

Interbeds: none

Color Fresh: dark grey- black

Color Weathered: white,

orange, light grey

Grain Size: N/A

Visible Minerals: N/A

Parting Thickness: fissile to

platy, .5- $2 \mathrm{~mm}$

Parting Geometry: non-parallel

Bedding Planes: irregular,

curved

Sedimentary Structures: none

Fossil Content: none

Color When Powdered: tan

Luster of Streak: dull- semi

waxy

Other: breaks into irregular

pieces
Unit Number: 3

Unit Thickness: 8 feet

Facies Number: 5 to 1

Rock Type: grey non-calcareous

to slightly calcareous shale

Interbeds: calcareous nodule

beds

Color Fresh: grey

Color Weathered: white, white

residue

Grain Size: none

Visible Minerals: none

Parting Thickness: no

distinctive partings

Parting Geometry: N/A

Bedding Planes: N/A

Sedimentary Structures: bedded nodules

Fossil Content: none

Color When Powdered: N/A

Luster of Streak: N/A

Other: nodules are dark grey, calcareous, oval, 1-2 inches in

diameter, and are found in beds roughly $.5-1$ foot apart. Shale breaks into blocks controlled by jointing not parting.

Unit Number: 4

Unit Thickness: 7.5 feet

Facies Number: 1

Rock Type: calcareous shale

Interbeds: none

Color Fresh: grey

Color Weathered: nodules:

orange, red, yellow

Grain Size: none

Visible Minerals: none

Parting Thickness: platy, 2-

$3 \mathrm{~mm}$

Parting Geometry: non-

parallel, discontinuous

Bedding Planes: none

Sedimentary Structures: bedded

nodules, siderite

Fossil Content: nodules contain

fossils

Color When Powdered: white to

grey

Luster of Streak: dull

Other: nodules are bigger than

unit 3 ( 5-6 inches in diameter), bedded nodules every .5 foot, nodules are slightly calcareous and very flattened, shale beds draped over nodules.

Unit Number: 5

Unit Thickness: 1 foot

Facies Number: 2

Rock Type: Limestone

Interbeds: none

Color Fresh: Dark grey

Color Weathered: light grey

Grain Size: N/A

Visible Minerals: calcite

Parting Thickness: N/A

Parting Geometry: N/A

Bedding Planes: N/A

Sedimentary Structures:

bioturbation, siderite no

Fossil Content: large and small brachiopods, crionoids

columnals, and cephalopods

Color When Powdered: N/A

Luster of Streak: N/A

Other: large brachiopods are flattened 